\title{
Inflation und Krise der Kapitalverwertung
}

\author{
Elmar Altvater, Jürgen Hoffmann, Rainer Künzel, Willi Semmler
}

\section{Einleitung}

1.

Noch vor einigen Jahren waren sich die bürgerlichen Ökonomen „eigentlich ganz sicher: Eine Weltwirtschaftskrise wie in den dreißiger Jahren wird es nie wieder geben. Die Kenntnis der ökonomischen Zusammenhänge ist heute so weit fortgeschritten und das wirtschaftspolitische Instrumentarium so erweitert und verfeinert, daß derartige Katastrophen verhindert werden können." Eine solche Euphorie ist offensichtlich neuerdings angesichts weltweiter Krise bei anhaltender Inflation einer pessimistischeren Betrachtungsweise der kapitalistischen Realität gewichen, seitdem jene ,ökonomischen Rezepte, auf die wir uns so lange verlassen haben (und verlassen konnten), versagen, weil es gilt, Inflation und Arbeitslosigkeit gleichzeitig zu besiegen $^{\text {" }}(1)$. Über die tieferen Ursachen dieser Entwicklung macht sich die bürgerliche Öffentlichkeit wiederum wenig Gedanken: Soziale Unruhen, rücksichtslose Verteilungskämpfe, das Ölkartell der arabischen Länder und die Paralyse des Staates „,machen eine konsequente Politik zur Stabilisierung der Beschäftigung und des Geldwerts nahezu unmöglich ..."(2). Die Gleichzeitigkeit von Inflation und Stagnation bzw. Krise (mit der sie begleitenden Arbeitslosigkeit) war in der Tat in der keynesianischen Wirtschaftstheorie, die jahrzehntelang das Dogma jedes Wirtschaftspolitikers und -journalisten war, nicht vorgesehen.

Die „Stagflation“ hat das Kalkül der Wirtschaftspolitik in den entwickelten kapitalistischen Staaten, über Fiskal- und Geldpolitik den kapitalistischen Zyklus zu regulieren (antizyklisch einzuebnen), gründlich verdorben. Die Inflation macht sich gegenüber der staatlichen Wachstums- und Beschäftigungspolitik in der Krise als eine scheinbar äußere Schranke geltend. Antizyklische Interventionen zur Beseitigung der Arbeitslosigkeit fördern zugleich inflationäre Prozesse, die Gegenmittel der staatlichen Wirtschaftspolitik gegen die Inflation erweisen sich aufgrund der möglichen Gegenaktion der Kapitale als relativ wirkungslos und verstärken zugleich jene Tendenzen, die zur Krise und Arbeitslosigkeit führen. Die Inflation verweist den Staat auf seine Schranken: die Geseczmäßigkeiten der Kapitalakkumulation und deren Widersprüche.

Zugleich gerät aber auch die herkömmliche Politik der westdeutschen Gewerkschaften im Verlauf dieser Entwicklung in ein Dilemma: Angesichts drohender Arbeitslosigkeit und angesichts des Drucks der sozialliberalen Regierung auf die Lohnpolitik der Gewerkschaften wird die Durchsetzung der Geldlohnforderungen Ebd. 
schwieriger, während zugleich zu erwarten ist, daß die Reallöhne infolge der Inflation gemindert werden. Gegenüber dem Druck der Regierung, die - nicht ohne Grund - angesichts des Scheiterns der eigenen Wirtschaftspolitik auf die Wirkungen einer verschärften Einkommenspolitik (als Instrument der Umverteilung zugunsten der Profite), setzt ist die Politik der Gewerkschaften hilflos: Theoretisch auf Basis der „Kaufkraft- ${ }^{6 \text { " }}$ und „,Monopol ${ }^{65}$-Theorie argumentierend, hat sie den von der Regierung und der bürgerlichen öffentlichkeit artikulierten Zwängen der Kapitalakkumulation wenig entgegenzusetzen. Politisch hat sie kaum noch Machtmittel ins Feld gegen das Kapital zu führen: Denn die jahrelange Disziplinierung der eigenen Basis insbesondere nach den spontanen Streiks 1969 und 1973 (mit der Folge mangelnder Entwicklung einer kampfkräftigen Organisation), ihre Bindung an die SPD, ihre Beschränkung auf den Lohnkampf, die Verniedlichung der Probleme der Arbeitslosigkeit haben zu einer Lähmung der gewerkschaftlichen Organisation geführt.

Unter diesen Bedingungen muß die Erfahrung der Grenzen reformistischer (gewerkschaftlicher) Politik innerhalb der kapitalistischen Entwicklung umschlagen in individuelle Resignation und Desorientierung, in die Erfahrung des hilflosen Ausgeliefertseins gegenüber dem kapitalistischen Zyklus. Von den Arbeitern wird das Kapitalverhältnis zwar als beherrschendes gesellschaftliches Verhältnis erfahren, aber nicht als ökonomisch vermitteltes Herrschaftsverhältnis, gegen das kollektiv der Kampf entwickelt werden muß. Umso wichtiger ist es in einer solchen Situation, die Anknüpfungspunkte sozialistischer Politik in der Entwicklung des Kapitalverhältnisses zu finden. Umso wichtiger ist es, in der theoretischen Arbeit Inflation und Krise als Produkt der Entwicklung des Kapitals zu bestimmen, um die mit dem Kapitalverhältnis produzierten falschen Vorstellungen, die zugleich Anknüpfungspunkt bürgerlicher Theorie und Propaganda sind und deren Plausibilität ausmachen, aufdecken zu können.

Der folgende Beitrag ist als ein Versuch zu werten, die Inflation und die Krise der Kapitalverwertung im Zusammenhang mit der Akkumulation des Kapitals zu untersuchen. Auf diesem Wege soll zunächst jenes oben noch als dichotomisch charakterisierte Verhältnis von Inflation und Krise aufgelöst werden, um zeigen zu können, daß die Stagflation als Erscheinungsform der aktuellen Krise des Kapitals nich Resultat äußerer Umstände der Kapitalakkumulation ist (wie sie dann als Krücken von unzulänglichen bürgerlichen Inflationstheorien dienen), sondern auf die entwickelten Widersprüche der Kapitalakkumulation zurückzuführen ist.

2.

Ohne hier auf die Widersprüche und Mängel bürgerlicher Inflationstheorien näher einzugehen (vgl. dazu den im vorliegenden Heft abgedruckten Beitrag von O. Demele) kann doch der Kern vieler alter und neuer Ansätze in der Behauptung von den übermäßigen Ansprüchen der Lohnabhängigen gesehen werden. Der Nachfrageüberhang, das Oligopol und/oder das Monopol ermöglichen wiederum die Überwälzung der Lohnkosten, wodurch die verbesserte Stellung der Lohnabhängigen wieder zurückgenommen wird. Diese im Begriff der „Lohn-Preis- oder Profit-Lohn-Spirale" popularisierte Version wird auch von linken Inflationstheorien, 
soweit sie vom Monopolbegriff ausgehen, vertreten, teils allerdings in Umkehrung der Version als „Preis-Lohn-Spirale“. Mit Hilfe der Kategorie des Monopols und des Staats (der über Defizitpolitik die Überwälzung finanziert) wird in diesen Theorien die willkürliche Preissetzung durch die großen Kapitale zum Zweck der Umverteilung des Wertprodukts behauptet und begründet; Reallohn- und Preishöhe sind hier jeder Notwendigkeit enthoben und vom bloßen Willen der Kapitalisten (der Monopole) und/oder vom Stand der unmittelbaren Machtkonfrontation zwischen Gewerkschaften und Kapital bestimmt.

Gegenüber diesen oberflächlichen Ansätzen, die ein ökonomisches Gesetz in den Preisbewegungen gar nicht mehr aufspüren können, weil diese der Willkür oder der Machtentfaltung von Personen (oder Institutionen) unterliegen, setzen sich in jüngster Zeit marxistisch orientierte Erklärungsversuche $a b$, die die inflationären Prozesse historisch aus der Entwicklung der Kapitalakkumulation in den kapitalistischen Ländern nach der Weltwirtschaftskrise und nach dem Zweiten Weltkrieg herleiten (3). Theoretisch-systematisch setzen diese Theorien i. d. R. bei der Analyse des Wert-Preisverhältnisses und der Darstellung der Überakkumulationskrise an. Diese Ansätze versuchen auch, die Entwicklung und Reproduktion des Kapitalverhältnisses als ökonomisch vermitteltes Herrschaftsverhältnis zum Ausgangspunkt der Analyse zu nehmen, um von dorther die inneren Gesetzmäßigkeiten der kapitalistischen Akkumulation, wie sie sich auch in der inflationären Entwicklung noch aufspüren lassen, in ihren historischen Ausdrucksformen zu untersuchen.

\section{3.}

Für einige dieser neueren Ansätze gilt, daß sie von den entwickelten Konflikten im Akkumulationsprozeß des Kapitals einerseits ausgehen (als Überakkumulation, Fall der Profitrate), während sie andererseits die Möglichkeit der Durchsetzung höherer Preise zum Zwecke der notwendigen Finanzierung der angestiegenen Zusatzkapitale (die Ersatz- und Neuinvestitionen steigen infolge der Inflation und der technologischen Entwicklung rapide an) auf die Monopolform des Kapitals zurückführen. Wird so ein Moment des Zwangs zur erhöhten Preissetzung aus dem Akkumulationsprozeß heraus erklärt, so geschieht die Durchsetzung höherer Preise wiederum über die Monopolform des Kapitals. Deren Grenzen bleiben allerdings unaufgedeckt, vielmehr wird das Monopol von vornherein als ein Machtkomplex verstanden, der das Notwendige auch mit „ökonomischer und außerökonomischer Gewalt" durchsetzen könne. Zumal eine generelle Preiserhöhung, die der Preisentwicklung bei allen Kapitalen geschuldet ist, kann nicht mehr über die Monopolform erklärt wer-

3 Wir beziehen uns hier auf:

A. Blechschmidt, G. Hoffmann, R. v. d. Marwitz, Das inflatorische Zusammenwirken von Kapitalkonzentration, Weltmarkt und Staatsintervention, in: Kursbuch Nr. 36 (1974); E. Dähne, Ursachen und Wesen der Inflation, in: Marxistische Blätter Nr. 4 (1974);

Chr. Deutschmann, Inflation und Weltwährungskrise, in: V. Brandes (Hrsg.), Handbuch 1 - Perspektiven des Kapitalismus, Ffm und Köln 1974;

E. Mandel, Der Spätkapitalismus, Ffm 1972 (bes. Kap. XIII);

P. Mattick, Marx und Keynes, Ffm 1971;

J. Reiche, Permanente Inflation, in: Kursbuch Nr. 36 (1974) 
den: dem Werttransfer aus dem nichtmonopolistischen Sektor in den monopolistischen Sektor der Industrie müßte ein entsprechendes Zurückhinken der Preisentwicklung im nichtmonopolisierten Sektor entsprechen, was zumindest empirisch nicht zu belegen ist (4). Staatsnachfrage und Kreditsystem werden dann äußerlich als Bedingungen der Realisierung der monopolistisch erhöhten Preise eingeführt; ihr Zusammenhang mit der realen Akkumulation wird nicht mehr entwickelt, es sei denn, sie werden als ,im Dienst" der Monopole stehend begriffen. So Dähne: „Die Inflation ist Ausdruck der allgemeinen Krise des Kapitalismus. Im Wesen ist sie ein durch den Staat vermittelter Umverteilungsprozeß zugunsten der Monopole " (5). Wenn dann Dähne im weiteren die Inflation auf die Notwendigkeit der erweiterten Akkumulation bei tendenziell fallendem Verwertungsgrad zurückführt, so landet er schließlich doch wieder beim Monopolpreis als Durchsetzungsform dieses Widerspruchs: „Zu den schon von Karl Marx beschriebenen objektiven ökonomischen Tendenzen und Manövern der Bourgeoisie, die dem Fall der Profitrate entgegenarbeiten, seine Wirkungen abschwächen und zeitweilig nicht sichtbar werden lassen, tritt im Zeitalter des Monopolkapitalismus der Monopolpreis" (6). Dähne kann daher auch nicht hinreichend eine allgemeine Preissteigerung begründen, sondern weicht auf die These aus, daß sich die „Preise aller anderen Waren ... dem durch die Konzerne verzerrten Preismaßstab anpassen (müssen)“ (7). Dennoch bleibt festzuhalten, daß er in der Inflation eine Form der Verlagerung der Widersprüche in den Geld-, Preis- und Finanzsektor sieht, die dadurch nach seiner Auffassung nicht aufgehoben, sondern lediglich aufgeschoben werden.

Dieser Bezug auf die Widersprüchlichkeit des Akkumulationsprozesses und deren temporäre Lösung in der Inflation wird von Blechschmidt, Hoffmann, v. d. Marwitz als empirisch (!) nicht nachweisbar abgelehnt. Auch sie gehen vom Monopol aus, bestimmen die Konzentration und Zentralisation aber lediglich als Resultat der zyklischen Krise. Die Monopolisierung führt erst zur relativen, dann zur absoluten Inflation, wodurch allerdings die depressiven Momente im zyklischen Abschwung nicht beseitigt, sondern eher verschärft werden. Denn ,wenn sich die ,monopolistische "Preisbewegung der Aufschwungphase in den Abschwung hineinverlängert, entstehen mehr oder minder Überkapazitäten“" (8). Verstärkt sich andererseits von Zyklus zu Zyklus die Monopolisierung, führt der dadurch bewirkte Werttransfer aus den nichtmonopolistischen Bereichen in den monopolistischen Sektor zur „Entstabilisierung der anderen Branchen“ (9). Nicht Überakkumualtion, sondern Überproduktion und Werttransfer, beides Produkt des Monopols, ist daher der Ausgangspunkt bei Blechschmidt u. a.; das Monopol verschärft die Krise und ist

4 Vgl. dazu Chr. Neusüß, Imperialismus und Weltmark tbewegung des Kapitals, Erlangen 1972, S. $223 \mathrm{ff}$ 。

5 Dähne, a. a. O., S. 43

6 A. a. O., S. 44

7 Ebd.

8 Blechschmidt u. a., a. a. O., S. 102

9 Ebd. 
zugleich Produkt derselben. Das Ende des ganzen Prozesses ist absehbar: „Während ... auf der einen Seite immer mehr transferiert werden soll, ist auf der anderen immer weniger da, was transferierbar wäre" $(10)$. Daß es dennoch nicht zu einer Verstärkung der Krisen kommt, erklären die Verfasser mit der Weltmark tbewegung, die zumindest in den 50er und 60er Jahren aufgrund der ungehemmten Expansion des Weltmarkts der Monopolisierung und der durch sie bewirkten Inflation äußere Grenzen setzte, während in einer zweiten Phase auch auf dem Weltmarkt (etwa seit Ende der 60er Jahre) die Monopolisierung durchschlug (was übrigens aus den steigenden Weltmarktpreisen gefolgert wird). Die dadurch freigesetzten depressiven Tendenzen konnten dann nur noch durch verstärkte Staatseingriffe aufgehalten werden, die durch eine (schon im Äufschwung defizitäre) Politik den Nachfragerückgang ausgleichen mußten und so als inflatorische Stütze dienten. Monopol, Krise, Inflation, Staat: Blechschmidt u. a. beschreiben diesen Zirkel, können ihn aber nicht auflösen. Dort, wo sie zum Problem der Verwertung kommen, reduziert sich dies für sie plötzlich auf die Frage der mangelnden empirischen Überprüfbarkeit; dabei hätte zumindest ihre These von der allgemeinen Überproduktion, die sie vertreten, sie zu Überlegungen hinsichtlich der Überakkumulation von Kapital veranlassen müssen.

Gehen Blechschmidt $u$. a. noch von der mangelnden effektiven Nachfrage bei fortschreitenden Konzentrationsprozessen aus, so sieht Deutschmann das Problem der effektiven Nachfrage eigentümlicherweise durch den Staatsinterventionismus als gelöst an (11), Stagnationstendenzen sind ,verdeckt" um den Preis wachsender Inflationsraten. Deutschmann knüpft in seinem Beitrag zunächst an die von Ch Levinson (12) vertretende These an, nach der die Inflation auf den wachsenden Kapitalbedarf der großen Konzeren und die Schwierigkeit diesen zu befriedigen zu erklären ist:

„Wenn Levinson von den Schwierigkeiten der Finanzierung des Kapitalbedarfes als dem Hauptproblem der kommenden Entwicklungsphase des Kapitalismus spricht, so wird damit nur der gleiche Sachverhalt empirisch umschrieben, den Marx theoretisch mit dem von ihm analysierten Grundgesetz der kapitalistischen Entwicklung faßt: dem Gesetz des tendenziellen Falls der Profitrate..."(13).

Wie Mattick (14) bestimmt allerdings auch Deutschmann den Widerspruch im Akkumulationsprozeß einseitig im Mangel an Mehrwert, der ,zentrale(n) Ursache der kapitalistischen Krisentendenzen" (15). Damit wird das Problem der Entwertung von Kapital (auch unter inflationistischen Bedingungen) ausgeblendet. Die Überakkumulation von Kapital und ihre Lösungsformen werden unzureichend entwickelt, wenngleich Deutschmann darstellt, daß die Inflation nur eine vorüber-

10 A. a. O., S. 103

11 Deutschmann, a. a. O., S. 86

12 Ch. Levinson, Wirtschaftskrise und Multinationale Konzerne, Reinbek b. Hamburg 1974

13 Deutschmann, a. a. O., S. 86

14 Mattick, a. a. O., S. 66-81; bes. S. 77

15 Deutschmann, a. a. O., S. 85 
gehende Lösungsform sein kann: „Die Inflation kann das Problem der Verwertung des Kapitals nicht lösen, die Geldexpansion kann die wirkliche Wertexpansion nicht ersetzen, sondern nur vortäuschen ${ }^{66}(16)$. Wird hier schon ein zentrales Problem - die Unterscheidung von nomineller und realer Akkumulation - benannt (wie auch schon bei Dähne und Blechschmidt u. a.), so gelingt es dem Verfasser nicht, die Bedingungen inflationärer Preisentwicklung, nämlich den Staatsinterventionismus und das Kreditsystem, immanent aus der Reproduktion des Kapitals zu entwickeln.

Dieser Einwand ist auch gegenüber dem Beitrag Jochen Reiches (17) zu erheben, der ebenfalls die Inflation als ein Versuch der Kapitale darstellt, uber die „,nominelle Akkumulation die reale" zu sichern; die „Finanzierung" der Inflation wir $^{r}$ mit der relativen Autonomie des Kreditzyklusses gegenübèr dem industriellen Zyklus erklärt. Dieser Einschätzung aber liegt - ähnlich wie bei Mandel (18), auf den sich Reiche bezieht - ein problematisches Verständnis vom Verhältnis von Kreditzyklus und industriellem Zyklus zugrunde. Wir werden weiter unten darauf noch eingehen. Darüberhinaus ist aber bei Reiche die alternative Setzung von Inflation und Krise, wie sie aus der folgenden Passage deutlich wird, anzuzweifeln:

„Der Kapitalismus muß in seiner Entwicklung an einen Scheidepunkt gelangen, wo ihm nur noch die Wahl (!) bleibt zwischen dem Weg in die offene Krise und Stagnation (um dadurch die Bedingungen für einen neuen Akkumulationszyklus zu schaffen) oder der permanenten Inflation als historischem Vehikel zur vorübergehenden Lösung der Schwierigkeiten der Akkumulation" (19).

Gerade die Wahl zwischen $5 \%$ Arbeitslosenrate oder $5 \%$ Inflationsrate besteht eben nicht mehr! - Auch wenn der Verfasser zunächst grundsätzlich richtig eine allgemeine Preiserhöhung im Abschwung begründet (, ... selbst wenn das Einzelkapital seine Profitrate nich erhöhen, sondern nur stabilisieren will, ist es gezwungen, die Preise seiner Waren zu erhöhen, da anders seine Akkumulation nicht gelingen kann" $^{\text {" }}(20)$ ), fehlt hier - wie wir später in unserer Darstellung der Bedeutung der organischen Zusammensetzung und insbesonders des Fixkapitals zeigen werden - die materielle Begründung.

4.

Wir können jetzt, nach diesen kurzen Bemerkungen zu einigen neueren Beiträgen zur Inflationsproblematik, den Kern dieser Ansätze herausstellen: Inflation wird als Versuch des Kapitals begriffen, über die nominelle Akkumulation die reale zu sichern, d. h. mittels Preisaufblähung und Geldexpansion die Durchschnittsprofitrate aufrechtzuerhalten. Hier wird der von Marx entwickelte Zusammengehang umgekehrt. Es wird von dem Festhalten an einer gegebenen Durchschnittsprofitrate

A. a. O., S. 87

Vgl. Reiche, a. a. O., S. 78

Mandel, a. a. O., S. $401 \mathrm{ff}$.

Reiche, a. a. O., S. 77

a. a. O., S, 74 
zur Sicherung der ,,nominellen Akkumulation“ ausgegangen, aus der Durchschnittsprofitrate ergeben sich mit der Bildung von Produktionspreisen der Reallohn und die Mehrwertrate quasi als Restgrößen. Diese U ıkehrung des eigentlichen $\mathrm{Zu}$ sammenhangs darf aber - wie dies in den vorliege den Beiträgen geschieht - nicht nur als allgemeines Phänomen behauptet werden, sondern muß im Reproduktionsprozeß des Kapitals nachvollzogen werden; Krecit und Staat dürfen nicht nur als äußere Stützen der inflationistischen Preisset ung dargestellt werden, sondern müssen im Zusammenhang der wirklichen Reproduktion und Akkumulation des Kapitals entwickelt werden. Wenn wir hier diese Mängel benennen, heißt dies allerdings nicht, daß wir im folgenden fähig wären, sie zu beheben, wohl aber ist damit die Richtung der zu leistenden Arbeit benannt.

\section{Der Preis als notwendige Erscheinungsform des Werts}

Die Produkte menschlicher Arbeit sind Werte, weil die Arbeit in spezifisch gesellschaftlicher Form verausgabt wird: als tauschwert-setzende Arbeit. Der Begriff des Werts bezeichnet so ein gesellschaftliches Verhältnis, das als solches ebensowenig unmittelbar erscheint wie der Wert auch. Im einfachen Austauschverhältnis zweier Waren erscheint nicht deren Wert; er stellt sich vielmehr dar in zwei Tauschwerten, die den Waren dinghaft als ihre natürliche Eigenschaft anzuhaften scheinen. Wenngleich daher abstrakte Arbeit Substanz und die Zeitdauer ihrer Verausgabung Maß des Wertes sind, kann weder die Arbeit als Substanz unmittelbar erscheinen noch die Arbeitszeit als unmittelbares Maß im Tauschverhältnis zweier Waren dienen. Die Ware ist in ihrer dinglichen Form Gebrauchswert (für andere als dem Warenbesitzer); im Austauschverhältnis zweier Waren findet ihr Wert seinen Spiegel im Gebrauchswert der einzutauschenden Ware, das Produkt abstrakt-menschlicher Arbeit findet so seinen Wertspiegel im Produkt konkret-nützlicher Arbeit, dem Gebrauchswert der Äquivalentware. Da es so viele Äquivalentwaren (Wertspiegel) wie Austauschverhältnisse gibt, kann zunächst der Gebrauchswert jeder Ware als Wertspiegel aller anderen Waren dienen. Erst die Verallgemeinerung des Warenaustausches führt zur Aussonderung einer besonderen Ware als allgemeines Äquivalent für alle anderen Waren. Im Gebrauchswert dieser Äquivalentware drückt sich nun der Wert aller anderen Waren aus; es entsteht das Geld, das somit als besondere Ware gesellschaftlich gültiges Äquivalent wird. Der gesellschaftliche Charakter der warenproduzierenden Gesellschaft scheint sich so im Geld zu manifestieren; genauer: erst im Geld erhält der Wert sein äußeres Maß; alle Warenwerte drücken sich in einer gemeinsamen Dimension aus. Die Arbeitszeit als Maß des Wertes findet ihr äußeres Maß in einem bestimmten Quantum der Geldware, dem Preis. ,Der Preis ist der Geldnahme der in der Ware vergegenständlichten Arbeit" (21). Erst in der äußeren Beziehung zum Geld findet der Gegensatz vom privat verausgabter und gesellschaftlich notwendiger Arbeit seine Bewegungsform. Darin liegt in nuce die Mög-

21 Karl Marx, Das Kapital, 1. Band (MEW 23) Berlin (DDR) 1962, S. 116 (im folgenden zitiert als Kapital 1 ) 
lichkeit quantitativer Inkongruenz von Wert und Preis (worauf wir noch näher eingehen werden).

Unterschiede in der Preisgröße können Verschiedenes ausdrücken: einmal kann die Abweichung der Preise verschiedener Waren die unterschiedlichen Arbeitsquanta widerspiegeln, die in den Warenkörpern vergegenständlicht sind; zum anderen ermöglicht es die Preisform, daß Wert und Preis so differieren können, daß die in der Ware vergegenständliche Arbeitszeit nicht mit der Arbeitszeit übereinstimmt, die in der durch den Preisausdruck bestimmten Menge der Geldware verkörpert ist. In der Möglichkeit dieser Abweichung kommt zum Ausdruck, daß die für die Bestimmung der Wertgröße durchschnittlich gesellschaftlich notwendige Arbeitszeit sich in einem beständigen Prozeß der Durchschnittsbildung aus den individuell verausgabten Arbeitsquanta herausbildet. Die Preisform ist die Bewegungsform für diesen Prozeß der Vermittlung individueller und gesellschaftlicher Produktionsbedingungen:

„Die Möglichkeit quantitativer Inkongruenz zwischen Preis und Wertgröße, oder der Abweichung des Preises von der Wertgröße, liegt also in der Preisform selbst. Es ist dies kein Mangel dieser Form, sondern macht sie umgekehrt zur adäquaten Form einer Produk tionsweise, worin sich die Regel nur als blindwirkendes Durchschnittsgesetz der Regellosigkeit durchsetzen $\mathrm{kann}^{\prime 6}(22)$.

Die Preisform als notwendige Erscheinungsform des Werts und Bewegungsform des Widerspruchs zwischen individueil verausgabter und durchschnittlich gesellschaftlich notwendiger Arbeitszeit zur Herstellung einer Ware ist jedoch auf der Ebene der einfachen Warenzirkulation erst unvollständig bestimmt.

Die nähere Bestimmung der für die Allgemeinheit der Warenform des Arbeitsprodukts notwendigen Produktionsweise als kapitalistische Produktion und damit der Wertbildung als Verwertung von Wert oder Akkumulation von Kapital hat auch Konsequenzen für den Preis. „Der Preis, der ursprünglich nur als der Wert in Geld ausgedrückt erscheint, wird weiter fortbestimmt, als selbst spezifische Größe" (23). Er muß dem Umstand Rechnung tragen, daß der kapitalistische Produktionsprozeß nicht nur widersprüchliche Einheit von Wertbildungs- und Arbeitsprozeß ist, sondern von Verwertungsprozeß und Arbeitsprozeß. Infolgedessen gehen in die Preisbestimmung der Ware nicht nur die Momente der Wertbildung, sondern auch die der Verwertung mit ein.

Damit ergibt sich die Notwendigkeit einer systematischen Abweichung des Preises von der Wertgröße durch die nähere Bestimmung der Arbeit als unter das Kapital subsumierte Lohnarbeit und folglich der Ware als Produkt des Kapitals. Die Entwicklung dieser systematischen Differenz führt uns zum Problem des Zusammenhangs der Kategorien Wert, Marktwert, Produktionspreis und Marktpreis. Bei der Behandlung dieser Kategorien geht es uns nicht um eine ausfïhrliche Ableitung ihrer Genesis, sondern um eine auf unser Problem der Inflation hin orien-

22 Kapital I, S. 117

23 Karl Marx, Grundrisse der Kritik der politischen Ökonomie, Berlin (DDR) 1953, S. 336 (im folgenden zitiert als Grundrisse) 
tierte Darstellung der in ihnen ausgedrückten ökonomischen Verhältnisse. In der möglichen Abweichung des Preises vom Wert einer Ware erschien sowohl die Übereinstimmung der produzierten Menge dieser Ware mit dem Umfang des durch ihren Gebrauchswert zu befriedigenden gesellschaftlichen Bedürfnisses als zufällig, als auch die Gleichheit der aufgrund der Produktivkraft der Arbeit des individuellen Produzenten in der Ware vergegenständlichten mit der zu ihrer Herstellung durchschnittlich gesellschaftlich notwendigen Arbeitszeit.

Die Herrschaft der gesellschaftlichen oder Durchschnittsbedingungen der Produktion macht sich dem individuellen Produzenten gegenüber geltend durch die Herausbildung eines Marktwerts für alle Waren derselben Art. Unter der Voraussetzung, daß der tatsächliche Verkaufspreis dieser Waren der Geldausdruck ihres Marktwerts ist, fällt den unter günstigeren als den Durchschnittsbedingungen produzierenden Produzenten ein Extramehrwert zu, während die überdurchschnittlich viel Arbeit enthaltenden Waren ihren Verkäufern nur einen unterdurchschnittlichen Mehrwert anzueignen erlauben. In dieser Beziehung des ,individuellen Werts“ zum Marktwert jeder Ware wird schon das Verhältnis der kapitalistischen Produzenten zueinander als Konkurrenz sichtbar, denn nur durch beständige Erhöhung der Arbeitsproduktivität können sie den individuellen Wert ihrer Waren unter den Marktwert senken und so einen Extramehrwert erzielen bzw. umgekehrt die durch die Produktivkraftsteigerungen bei den anderen Herstellern derselben Waren bewirkte Marktwertsenkung kompensieren.

Aber die vorausgesetzte Gleichheit der produzierten Waren als Gebrauchswerte und damit der sie hervorbringenden konkret - nützlichen Arbeit beschränkt die Konkurrenz auf Produktionsbereich und Markt dieser qualitativ gleichartigen Waren und ist unvereinbar mit der für die Warenzirkulation konstitutiven Bedingung der Verschiedenheit der Waren als Gebrauchswerte. Das heißt aber: der Produktionsprozeß ist noch nicht als Stadium im Kreislauf des Kapitals entwickelt, daher die Bedingungen der Produktion noch nicht als formbestimmendes Moment in die Bewegung des gesellschaftlichen Gesamtkapitals aufgenommen. Insbesondere sind die spezifischen Schranken, die sich aus den technischen Bedingungen des Arbeitsprozesses und seines Mittelcharakters für den Verwertungsprozeß ergeben in der Wertform als bloßem Geldausdruck des Werts noch nicht enthalten.

Der immanente Zweck der kapitalistischen Produktion, nämlich rastlose Vermehrung des Werts und die damit gesetzte Gleichgültigkeit des Werts gegenüber dem Gebrauchswert, stehen im Widerspruch zu den besonderen Bedingungen des Verwertungsprozesses, die sich aus den technischen Verhältnissen des Arbeitsprozesses als Mittel des Verwertungsprozesses ergeben. Verschiedene Waren erfordern zu ihrer Produktion aus technischen Gründen unterschiedliche Quanta lebendiger Arbeit im Verhältnis zur Menge der gegenständlichen Produktionsmittel. Gleiche Kapitalmassen - ausgelegt in einem unterschiedlichen Verhältnis von Produktionsmitteln und Arbeitskraft - würden beim Verkauf zu Marktwerten aus technischen Gründen in unterschiedlichen Wert- und Mehrwertmassen resultieren, da ja nur die lebendige Arbeit Wert erhält und Neuwert schafft und gleiche Kapitalmassen unterschiedlich viel Arbeiter beschäftigen würden. 
$\mathrm{Da}$ die kapitalistische Warenproduktion zugleich die unaufhebbare aus den Bedingungen der des Arbeitsprozesses resultierende Verschiedenheit der Kapitalver* wertung und ihre tendenzielle Gleichheit in allen Produktionssphären (durch das Streben jedes Einzelkapitals nach größtmöglicher Verwertung und seine Mobilität über die Sphärengrenzen hinweg) umschließt, muß der hier erneut, aber konkreter als Verhältnis von Wertbildung und Verwertung entwickelte Widerspruch zwischen Individualität und Gesellschaftlichkeit über eine entsprechende Fortbildung der Form aufgehoben werden, durch die seine Pole vermittelt sind: an die Stelle des Wertpreises tritt der Produktionspreis (24). Durch die Bestimmung der Preisgröße nach dem Bildungsgesetz des Produktionspreises stellt sich die Ware als Produkt des Kapitals und nicht der Arbeit dar, denn die Realisierung des Produktionspreises garantiert durchschnittliche Verwertung des in ihrem Produktionsprozeß gebundenen individuellen Kapitals - unabhängig von der Größe des in diesem Prozeß erzeugten Mehrwerts. An die Stelle des Mehrwerts beim Wertpreis tritt also beim Produktionspreis eines Warenkapitals der Durchschnittsprofit, dessen Größe vom Verhältnis der gesellschaftlich insgesamt erzeugten Mehrwert - oder Profitmasse zum gesellschaftlichen Gesamtkapital (Durchschnittsprofitrate) sowie von der Masse des für die Produktion der betrachteten Warenmasse ausgelegten Kapitals abhängt. Kapitalistische Warenproduktion setzt daher die beständige Bildung einer gesellschaftlichen Durchschnittsprofitrate voraus. Die Durchschnittsprofitrate resultiert jedoch nicht aus einem gemeinsamen Wertumverteilungsplan der ,im Gesamtkapital organisatorisch zusammengefaßten Einzelkapitale ${ }^{6}$ oder aus einem staatlichen System von Steuern und Subventionen, sondern sie ist das Ergebnis der kapitalistischen Konkurrenz. Sie ist daher nie oder doch nur zufällig real vorhanden; vielmehr macht sie sich als die Aktion der Einzelkapitale bestimmende und durch sie bestimmte Tendenz geltend. Der Prozeß der Durchschnittsbildung vollzieht sich natürlich nur über den Zeitraum des ganzen industriellen Zyklus' hinweg. Hier zeigt sich erneut die Bedeutung der Form des Preises (hier: des Produktionspreises) für die Durchsetzung des Wertgesetzes.

In der Preissetzung seiner Waren bringt jeder Kapitalist zum Ausdruck, daß er durch ihre Realisierung am Markt einen Anteil am Gesamtprofit im Verhältnis zur Großße seiner Kapitalauslage beansprucht. Führt der tatsächlich erzielbare Marktpreis zur Realisierung der gesellschaftlichen Durchschnittsprofitrate, so entspricht er dem Marktproduktionspreis. Abgesehen davon, daß zufällige Abweichungen des Marktpreises vom Marktproduktionspreis, die sich aus dem wechselnden Verhältnis

,"Was die Konkurrenz, zunächst in einer Sphäre, fertigbringt, ist die Herstellung eines gleichen Marktwerts und Marktpreises aus den verschiedenen individuellen Werten der Waren. Die Konkurrenz der Kapitale in den verschiedenen Sphären aber bringt erst hervor den Produktionspreis, der die Profitraten zwischen den verschieden Spären egalisiert." Zu dem letzteren ist höhere Entwicklung der kapitalistischen Produktionsweise erheischt als zu dem frühern." Karl Marx, Das Kapital, 3. Band (MEW 25), Berlin (DDR) 1964 S. 190 (im folgenden zitiert als Kapital III); Wertpreis ist det später bei Marx als Marktwert (-preis) im Verhältnis der Konkurrenz näher bestimmte Geldausdruck des Werts. VgL, dazu Kapital III S. 184 
von Angebot und Nachfrage ergeben, zu erratischen Schwankungen der Verwertungsraten aller individuellen Kapitale einer Sphäre führen, unterscheiden sich deren tatsächliche Profitraten auch aufgrund unterschiedlicher Produktionsbedingungen bei den einzelnen Kapitalen. Sie führen dazu, daß die individuellen Produktionspreise teilweise über dem Marktproduktionspreis liegen und teilweise darunter, weil die Kostpreise (Kosten) der Waren einiger Kapitale über dem durchschnittlichen Kostpreis, andere darunter liegen, so daß der Verkauf zum Marktproduktionspreis bei den kostenungünstiger produzierenden Kapitalen zu unterdurchschnittlicher Verwertung des vorgeschossenen Kapitals (Minderprofiten) und bei den anderen zu überdurchschnittlicher Verwertung (Extraprofiten) führt. Während die Konkurrenz zwischen den Kapitalen einer Sphäre die Abweichungen der individuellen Produktionspreise vom Marktproduktionspreis immer wieder verringert durch die Verallgemeinerung der kostengünstigsten Produktionstechnik und den Untergang der sich mit weit unterdurchschnittlicher Rate verwertenden Kapitale, kann der Marktproduktionspreis sich nur zum Schwankungszentrum der Marktpreise herausbilden, indem das Kapital in die Produktionssphäre strömt, in denen der Marktpreis auf längere Sicht eine überdurchschnittliche Profitrate ermöglicht. Die Mobilität des Kapitals erfordert ein entwickeltes Kreditsystem und eine entsprechende Mobilität der Arbeitskraft oder ausreichende t’berschußarbeitsbevölkerung.

Es soll hier nicht weiter auf die mit dem Ausgleich der individuellen Profitraten zur Durchschnittsprofitrate verbundenen Probleme eingegangen werden. Für unsere Zwecke reicht es aus, dargestellt zu haben, wie die Fortbestimmung der Ware - ursprünglich bloß Produkt der Arbeit, jetzt Existenzform des sich verwertenden Kapitalwerts - in der Form des Preises ,als selbst spezifischer Größe" notwendig ihren Niederschlag findet. Aber der Prozeß der Verwertung des Werts oder Reproduktion des Kapitals ist Kreislaufprozeß durch die drei Stadien oder Existenzformen des prozessierenden industriellen Kapitals als Geldkapital, produktives Kapital und Warenkapital. Und dieser Kreislauf, in dem nicht nur die Erhaltung des Kapitalwerts stattfindet, sondern auch seine quantitative Vergrößerung, braucht Zeit. So kann es kommen, daß die in seiner Preissumme vorausgesetzte Verwertung des Kapitalwerts nicht (voll) realisiert wird.

Die kapitalistische produzierten Waren stellen zunächst Warenkapital dar, in dem ein bestimmter Mehrwert enthalten ist. Aber wie in der einfachen Warenzirkulation die „Preisform die Veräußerlichkeit der Waren gegen Geld und die Notwen-

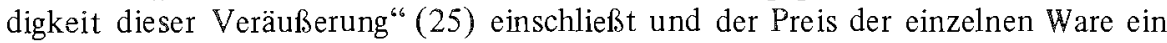
„,ideeller", weil noch nicht im Geld realisierter Wertausdruck ist, so ist „das Warenkapital an sich zugleich Geldkapital, d. h. bestimmte Wertsumme, ausgedrückt im Preis der Ware. Als Gebrauchswert ist es bestimmtes Quantum bestimmter Gebrauchsgegenstände,... Aber als Geldkapital an sich, als potentielles Geldkapital, ist es beständiger Expansion und Kontraktion unterworfen (26). Diese Expansion und Kontraktion, deren Ursachen in der Dynamik des kapitalistischen Krisenzyklus

$25 \quad$ Kapital I, S. 118

26 Kapital III, S. 507 f. 
zu sehen sind, drückt sich aus in entsprechenden Preisveränderungen der Waren, auch nachdem diese bereits produziert worden sind, nachdem also ihr Produktionspreis schon dürch die Produktionskosten und die Durchschnittsprofitrate bestimmt worden ist. Bei Kontraktion findet Minderverwertung produzierter Werte, bei Expansion Extra-Verwertung statt - beides Momente im Verlauf des industriellen Zyklus, die sich nur Geltung verschaffen können, weil die Preisgröße den Durchschnittsbedingungen der Wertbildung resp. Verwertung nicht unmittelbar zu entsprechen braucht (27). Es scheint so, als ob die Preisbewegung unabhängig von der Wertbewegung wäre. Aber wie wir gesehen haben, ist die Preisform der Waren auch die vermittelnde Form, durch die die individuelle Produktion von Gebrauchswerten an die gesellschaftlichen Bedingungen ,erinnert" wird, unter denen sie Gebrauchswerte für andere, Tauschwerte oder Waren, hervorbringt. In der Preisform tun die Waren kund, daß sie durch Verwandlung in Geld als Tauschwerte realisiert werden wollen; und wenn diese Realisierung nicht gelingt, findet Entwertung statt.

Damit erfährt das einzelne Kapital sein stetiges Dilemma, daß es nämlich als Einzelkapital privat produziert und insoweit der Kapitalist der „Meister aller Produktionsfaktoren " ist, aber in der Preissetzung der produzierten Waren bereits auf die allgemeine gesellschaftliche Ware (das Geld) Bezug genommen wird und bei der Verwirklichung dieses gesellschaftlichen Bezugs, beim Verkauf der Waren, nun Momente eine Rolle spielen, die jenseits seiner Kontrolle, Planung und Voraussicht liegen und ihm ein Schnippchen schlagen können. Zwischen dem Preis als ideellem Wertausdruck und dem realisiertem Preis liegt der Akt des Austausches oder verallgemeinert - die Zirkulation, und hier machen sich jene gesellschaftlichen Bedingungen seiner Existenz geltend, die dem Einzelkapitalisten als äußere Zwangsgewalt „des Marktes“ erscheinen. Wert und Preis bzw. Marktproduktionspreis und Marktpreis können somit auseinanderfallen, und sie werden dies regelmäßig tun. Dabei bedeutet dieses Auseinanderfallen zweierlei: Einmal nämlich ist es Ausdruck der Naturwüchsigkeit des Wirtschaftsprozesses unter kapitalistischen Bedingungen, wo das, was geplant und erwartet wird, keineswegs als wirkliches Resultat einzutreten braucht. Die gesellschaftlichen Bedingungen wirken somit für das einzelne Kapital vor allem über den realisierbaren Preis in seine Sphäre zurück.

Zum anderen hatten wir gesehen, daß der Preis als Produktionspreis notwendig vom Wertpreis abweicht. Der Produktionspreis hatte sich als die Form erwiesen, in der das Gesetz der Wertbildung (Wertgesetz) nicht nur mit dem der Verwertung des Kapitals vereinbar ist, sondern einerseits dessen Grundlage ist, andererseits sich selbst erst konstituiert durch die Verallgemeinerung der Warenform des Arbeitsprodukts im Zuge der Entwicklung der kapitalistischen Produktionsweise.

27 Dies ist - wie wir noch zeigen werden - für die Bedingung der Reproduktion des Kapitals bei Inflation von Bedeutung. Denn auch bei Kalkulation zu Wiederbeschaffungskosten bleibt die Summe der ,Abschreibungen" hinter dem Wiederbeschaffungspreis zurück. 


\section{Funktionen des Geldes und die abstrakte Möglichkeit der Inflation (28)}

Der Wert nimmt im Geld selbständige dingliche Gestalt an; seine Substanz, abstrakt allgemeine Arbeit, erhält so eine äußere Gestalt in der Geldware. Das Geld wird zum Maß der Werte. Die Wertgröße, quantitativ bestimmt durch die zur Produktion der Ware notwendige, durchschnittliche Arbeitszeit, findet eine äußere Entsprechung in dem jeweiligen Quantun der Geldware. Jedoch wird die durchschnittlich gesellschaftlich notwendige Arbeit nicht direkt in einem bestimmten Preis repräsentiert; vielmehr hängt der jeweilige Preisausdruck des Werts in quantitativer Hinsicht vom Maßstab ab, an dem die Preise gemessen werden. Das Geld mit seiner Funktion als Maßstab der Preise ermöglicht es so grundsätzlich, daß die Preisbewegung gegenüber der Wertbewegung sich dadurch ,verselbständigt ${ }^{6 *}$, daß der Maßstab sich ändert, über den Arbeitszeit in Mengeneinheiten der Geldware übersetzt wird. Die fortlaufende „Streckung“ dieses Maßstabs, die wir als eine Ausdrucksform der Inflation bezeichnen können, ergibt sich als Möglichkeit aus den Funktionen des Geldes. Darauf soll in diesem Abschnitt näher eingegangen werden.

Wir sahen bereits, daß die mit seinem Bildungsprozeß unmittelbar gesetzte Funktion des Geldes darin besteht, allgemeines Maß der Warenwerte zu sein. Weiter ergaben sich aus der Notwendigkeit der Erscheinung des Werts als Tauschwert einerseits - aufgrund der ideellen Beziehung der Ware auf das Geld im Preis - die Funktion des Geldes als Maßstab der Preise und andererseits - aufgrund der wirklichen Beziehung der Waren aufeinander im Austauschprozeß über das Geld -- dessen Funktion als Zirkulationsmittel. Aus der Funktion des Geldes als Zirkulationsmittel geht nun aber seine besondere Gestalt als Münze oder Wertzeichen hervor. Münze wird das Geld zunächst durch Prägung in Einheiten, die die Preise oder Geldnamen der Waren unmittelbar in wirklichem Geld auszudrücken gestatten. Im einfachen Zirkulationsprozeß Ware - Geld - Ware, dessen Ziel die Konsumtion ist, ist das Geld jedoch nur verschwindender Mittler zwischen den Extremen W - W. Es kommt allein auf seine Funktion als gemeinsamer Nenner an, solange die Kontinuität des Prozesses gewahrt bleibt. Daher kann das wirkliche Geld durch ein bloßes Zeichen seiner selbst ersetzt werden (29), wenn die Rückverwandlung der unterwertigen Münze oder des Zeichengeldes (Papiergeldes) in die eigentliche Geldware jederzeit

28 Die Darstellung in diesem Abschnitt ist in einigen Passagen identisch mit den Ausführungen R. Künzels zu den Funktionsbestimmungen des Geldes in seiner noch unveröffentlichten Dissertation: Die Krisentendenz der auf den Wert gegründeten Produktionsweise - Versuch einer Explikation des Marxschen Krisenbegriffs, FU Berlin 1974

29 Warum diese Möglichkeit historisch zur Wirklichkeit wurde, erklärt Marx aus der ,,naturwüchsigen Tendenz des Zirkulationsprozesses, das Goldsein der Münze in Goldschein oder die Münze in ein Symbol ihres offiziellen Metallgehalts zu verwandeln", in dem durch den Verschleiß der Goldmünze im Umlauf „Goldtitel und Goldsubstanz, Nominalgehalt und Realgehalt ... ihren Scheidungsprozes ${ }^{\text {"6 }}$ von selbst beginnen. Die daraus resultierenden Störungen des Zirkulationsprozesses führten zur staatlichen Wertgarantie (Konvertibilität in vollwertiges Geld) und nahmen der stofflichen Substanz der Münze ihre Bedeutung. Siehe Marx, Kapital I, S. 139 
garantiert ist. Diese Garantie gibt der Staat bei der Ausgabe von Staatspapiergeld mit Zwangskurs und der Prägung von metallischen Geldmarken, deren Nominalwert über ihrem Metallwert liegt. Damit jedoch die Geldsubstitute die Funktion des Geldes als Maßstab der Preise nicht beeinträchtigen, dürfen sie nur in dem Umfang anstelle der Geldware (z。B. des Goldes) umlaufen, der sich erfahrungsgemäß als Minimum der Masse des ständig fungierenden Zirkulationsmittels feststellen läßt (30). ,Nur sofern das Papiergeld Goldquanta repräsentiert, die, wie alle andren Warenquanta, auch Wertquanta, ist es Wertzeichen ${ }^{66}$ (31). D. h. mit der Verdrängung des wirklichen Geldes aus der Zirkulation durch bloße Wertzeichen, insbesondere durch Staatspapiergeld mit Zwangskurs, ,die vollendete Form des Wertzeichens, und die einzige Form des Papiergeldes, die unmittelbar aus der metallischen Zirkulation oder der einfachen Warenzirkulation herauswächst" (32), ist die Form oder abstrakte Möglichkeit für die Inflation gegeben, nicht jedoch ihre Ursache. Wird nämlich mehr Papiergeld in die Zirkulation geworfen oder weicht in entsprechender Weise sein Zwangskurs gegen Gold vom Tauschverhältnis des Goldes zur übrigen Warenwelt $a b$, so erhalten die Waren zunächst unterschiedliche, nämlich höhere Papiergeld- als Goldpreise. Die damit verbundene Ştörung der Warenzirkulation führt entweder zur Stillegung des überschüssigen Teils der Papiernoten bzw. zur Korrektur des Kurses oder zur vollständigen Verdrängung des Papiergeldes aus der Zirkulation durch wirkliches Geld: Gold (33). Die mit diesem Vorgang verbundene Störung des Warenverkehrs ist hier natürlich nur technisch begründet. Der technische Grund erscheint jedoch als ökonomische Ursache, weil der den wirklichen Zusammenhang verkehrende Eindruck, als hänge der Wert der Waren nur von der Masse des sie zirkulierenden Geldes ab, als sei also nicht auch das Geld Ware (gerade durch die mit der Inflationierung des Zirkulationsmittels verbundene Steigerung der Warenpreise bestätigt zu werden scheint (34).

30 Siehe Marx, KI, MEW 23, S. $141 \mathrm{ff}$.

31 Ders., a. a. O., S. 142

Marx, Zur Kritik der Politischen Ökonomie, in: MEW Bd. 13, Berlin (DDR), S. 95

Um dem Mißverständnis einer quantitätstheoretischen Deutung des Zusammenhangs zwischen Preisniveau und Geldmenge vorzubeugen, erscheint eine Präzisierung angebracht. Während die quantitätstheoretische Interpretation der Identität $\mathbf{M U}=\mathbf{P H}$ als Funktionalzusammenhang die Abhängigkeit des Preisniveaus $\mathrm{P}$ von der Geldmenge $\mathrm{M}$ behauptet, wenn das Handelsvolumen bzw. die zu zirkulierende Warenmasse $\mathrm{H}$ gegeben ist und die Umlaufsgeschwindigkeit des Geldes $U$ von den technischen Bedingungen des Zahlungsverkehrs und von den Zahlungssitten bestimmt wird und als konstant angesehen werden kann, hängt tatsächlich, wie wir gesehen haben, die zu realisierenden Preissumme PH von der in der Warenmasse $H$ vergegenständlichten toten und lebendigen Arbeitszeit, so daß die bei gegebener Umlaufsgeschwindigkeit des Geldes für die Zirkulation der Waren notwendige Geldmenge die abhängige Größe ist. Die Bedingungen der Wert- und Preisbildung im Verwertungsprozeß des Kapitals bestimmen also die umlaufende Geldmenge und nicht umgekehrt. Als Ausnahme kann nur der Fall der Aneignung cincs wachsenden Teils des Produktenwerts durch den Staat im Wege der defizitären Finanzierung seiner Ausgaben über die Notenpresse bei reiner Staatspapiergeldwährung (z. B. Kriegsfinanzicrung) gelten.

34 Hinzu kommt der der bloßen Form des Zirkulationsmittels als Papiergeld geschuldete Schein, als repräsentiere es den Wert der Ware unmittelbar, ,während die Goldmünze augenscheinlich nur den Wert der Waren repräsenticrt, soweit dieser selbst in Gold geschätzt oder als Preis dargestellt ist。“ Marx, Zur Kritik..., MEW 13, S. 100 f. 
„Das VerhäItnis, worin das Wertzeichen, sei es Papier oder gef́älschtes Gold oder Silber, dem Münzenpreis gemäß berechnete Gold- oder Silbergewiehte vertritt, hängt ab, nicht von seinem eignen Material, sondern von seiner in Zirkulation befindlichen Quantität. Die Schwierigkeit im Verständnis dieses Verhältnisses entspringt daher, dafs das Geld in den beiden Funktionen als Maß der Werte und als Zirkulationsmittel nicht nur umgekehrten, sondern dem Gegensatz beider Funktionen scheinbar widersprechenden Gesêtzen unterworfen ist. Für seine Funktion als Maß der Werte, wo das Geld nur s Rechengeld dient und das Gold nur als ideelles Gold, kommt alles auf das natürliche Material an. In Silber geschätzt oder als Silberpreise stellen sich die Tauschwerte natürlich ganz anders dar als in Gold geschätzt oder als Goldprejse. Umgekchrt in seiner Funktion als Zirkulationsmittel, wo das Geld nicht nur vorgestellt ist, sondern als ein wirkliches Ding neben den andern Waren vorhanden sein muß, wird sein Material gleichgültig, während alles von seiner Quantität abhängt. Für die Maßeinheit ist es entscheidend, ob sie ein Ffund Gold, Silber oder Kupfer ist, während bloße Anzahl die Münze zur entsprechenden Verwirklichung jeder dieser Maßeinheiten macht, welches immer ihr eigenes Material sei: $E s$ widerspricht aber dem gemeinen Menschenverstand, daß bei dem nur gedachten Geld alles von seiner materiellen Substanz und bei der sinnlich vorhandenen Münze alles von einem idealen Zahlenverhältinis abhängt" $135 \%$.

Die Úberfüllung der Zirkulationskanäle mit konvertiblem Staatspapiergeld und darauf folgende allgemeine Diskreditierung des Geldsurrogats (Inflation) muß aber nicht allein đarauf zurückzuführen sein, daß die umlaufende Papiergeldmenge dem Maximum der durch sie zu realisierenden Preissumme der Waren angepaßt worden ist und so bei deren Kontraktion ihr Maß, die an ihrer Stelle zirkulierbare Goldmenge, überschreitet. Da das Geld als Zirkulationsmittel immer Kaufmittel ist, wäcnst relativ zur Preissumme der auszutauschenden Waren die Zirkulationsmittelmenge auch in dem Maße, in dem es innerhalb der Zirkulation (36) von seiner Kaufmittelfunktion suspendiert wird. Nicht-Kaufmittel innerhalb der Zirkulation kann das Geld aber nur sein, wenn die Veräußerung der Ware als Gebrauchswert mit der Realisierung ihres im Preis ideell gesetzten Tauschwerts zeitlich auseinanderfällt. „,Der Verkäufer wird Gläubiger, der Käufer Schuldner. Da die Metamorphose der Ware oder die Entwicklung ihrer Wertform sich hier verändert, erhält auch das Geld eine andre Funktion. Es wird Zahlungsmittel ${ }^{6 /}$ (37). Der Tauschwert, das Geld, ist hier nur ideell gesetzt, auf Seiten des Verkäufers weiterhin im Preis der Ware - auf Seiten des Käufers vertritt dieser selbst symbolisch das Geld., ,Wie aber früher die allgemeine Symbolik des Wertzeichens die Garantie und den Zwangskurs des Staates, ruft jetzt die persönliche Symbolik des Käufers gesetzlich erzwingbare

35 Marx, Zur Kritik..., MEW 13, S. 99 f. Die infolge der Schwierigkeit der administrativen Aufrechterhalten dieses idealen Zahlenverhältnisses gegebene Möglichkeit der Zirkulationsstörung durch allgemeine Diskreditierung des Papiergeldes erscheint hier noch insoweit als technisches Problem, als die ökonomische Formbestimmung des bürgerlichen Staates und seiner besonderen Funktion als Münzer und Festsetzer des Maßstabs der Preise nicht entwickelt ist. Siehe hierzu vor allem den Ansatz von Blanke, Jürgend und Kastendiek, Zur neueren marxistischen Diskussion über die Analyse von Form und Funktion des bürgerlichen Staates. Überlegungen zum Verhältnis von Politik und Ökonomie, PROKLA 14/15, IV. Jg. 1974, Nr. 3, S. 51 ff.

36 Ist die Aufhebung der Kaufmittelfunktion des Geldes mit seiner Entfermung aus der Zirkulation verbunden, so erstarrt es zum Schatz.

37 Marx, Kapital I, S. 149, Hervorhebung durch die Verfasser. 
Privatkontrakte unter den Warenbesitzern hervor" (38). Als Zahlungsmittel fungiert das Geld daher in doppelter Weise nur ideell, als Wertmaß im Preis der Ware und dementsprechend bei der Festsetzung der Höhe der Kaufschuld, und als ideelles Kaufmittel. Érst bei Fälligkeit des Kontrakts tritt es in die Zirkulation ein und schließt den Prozeß, den es nicht selbst vermittelt hat, selbständig ab, falls nicht die Möglichkeit des rechnerischen Ausgleichs wechselseitiger Forderungen gegeben ist oder das Schuldzertifikat zur Begleichung eigener Obligationen verwendet werden kann. Im ersten Fall fungiert das Geld überhaupt nur als ideelles Rechen- oder Buchgeld; im zweiten ist seine Funktion als ideelles Zahlungsmittel Grundlage der Entwicklung des Kreditwesens. Nur im Umfang der Salden wechselseitiger Zahlungsverpflichtungen wird wirkliches Geld zur Realisierung der Warenpreise notwendig, so daß die Geldmenge relativ zur Preissumme der Waren mit der Ausdehnung der Kreditsumme wächst.

Umgekehrt ergibt sich hieraus, daß die realisierbare Preissumme der Waren wachsen kann, ohne daß die als Zirkulationsmittel fungierende Geldmenge zunehmen muß, wenn sich das Kreditvolumen entsprechend ausdehnt (39).

Für die Funktion als Zahlungsmittel hängt alles von der Eignung des Geldes als Maß der Werte ab. Dazu muß es selbst Wert sein, wie das Gold, oder sich jederzeit zu einem festen Kurs in die produzierte Geldware verwandeln lassen. Es ist dann Goldsurrogat, wie das Staatspapiergeld mit Zwangskurs, und spiegelt in seinen Kursveränderungen nur die Wertschwankungen der wirklichen Geldware im Verhältnis zu allen übrigen Waren wider (40). Gilt das Papiergeld jedoch als gesetzliches Zahlungsmittel ohne Einlösungszwang in Gold, so verliert es in einem gemischten Währungssystem sofort seine Funktion als allgemeine Ware der Kontrakte an das Gold. Denn die Preisbewegung kann nur dann Index für die Veränderung der Warenwerte sein, wenn dem Verhältnis zwischen der Menge der Geldware und der Warenmenge, deren Wert sich so als Preis darstellt, als gemeinsame Basis die für die Produktion beider Waren jeweils durchschnittliche gesellschaftlich notwendige Arbeitszeit zugrunde liegt. Eine allgemeine Erhöhung der Produk tivkraft der gesellschaftlichen Arbeit, die auch die Goldproduktion verbilligt, drückt sich allerdings nicht in einem Fall der Warenpreise aus, so daß dieselbe Geldsumme eine geringere Wertmasse repräsentiert. Da die geringere Wertmasse jedoch derselben Gebrauchswertmasse entspricht, garantieren die in Goldpreisen ausgefertigten Kontrakte die Konstanz der dem Geldverhältnis zugrundeliegenden stofflichen oder Gebrauchswertbedingungen. Bleibt aber, wie zu vermuten ist, die Produktivkraftentwicklung in der Goldproduktion weit hinter der Entwicklung der Arbeitsproduktivität in den

Marx, Zur Kritik ..., MEW 13, S. 117

39 Vgl. hierzu den Zusammenhang zwischen industriellem Zyklus und Kreditzyklus in Abschnitt 4 und 6.

Einflüsse der Spekulation bleiben hier außerhalb der Betrachtung. 
übrigen Produktionsbereichen zurück (41), so bleibt die Konstanz der Wertmaßfunktion des Geldes gewährleistet, und die Produktivitätssteigerung drückt sich in einer Kontraktion des Preismaßstabs, d. h. allgemein fallenden Preisen aus. Während also in jedem Fall beim produzierten Geld die Wertmaßfunktion auf der Basis seines eigenen Wertseins beruht, verschmilzt im Wertschein des reinen Staatspapiergelds die Wertmaß- mit der Preismaßfunktion. Die Funktionsfähigkeit des Staatspapiergelds als Wertmaß schęint von der relativen zeitlichen Konstanz der Warenpreise abzuhängen. Aber relativ in Bezug worauf? Auf die Entwicklung der Arbeitsproduktivität? Die Produktivkraft der Arbeit gehört jedoch der konkreten Arbeit an, der Wert, dessen adäquate gegenständliche Repräsentanz durch die Geldware im Preis der Ware unterstellt ist, drückt jedoch abstrakte, allgemein menschliche Arbeit aus. Konnte das allgemeine Äquivalent als Ware nur deshalb Maßstab der Preise sein, weil es wegen seiner Eigenschaft, selbst Ware, als auch Wert zu sein, als Maß der Warenwerte fungierte, so ist dieser Zusammenhang im reinen Staatspapiergeld vollständig ausgelöscht. Das Staatspapiergeld ist die praktische Verwirklichung des dem Wertzeichen überhaupt angehörenden Scheins, als repräsentiere es unmittelbar den Wert der Ware. Es stellt die unlösbare Verschmelzung der einander entgegengesetzten Funktionen des Geldes dar, Maß der Werte und Maßstab der Preise zu sein, denn es leitet seine Maßstabsfunktion nicht aus einer festen Beziehung zu einer besonderen Ware, der allgemeinen Äquivalentware ab. Konnte die durch Überschwemmen der Zirkulation mit konvertierbarem Papiergeld ausgelöste allgemeine Preissteigerung noch auf diese Unverhältnismäßigkeit der Zirkulationsmittelmenge zurückgeführt und durch entsprechende Kontraktion des Preismaßstabs (,Umwertung“, „Währungsreform“) korrigiert werden, so läßt sich beim reinen Staatspapiergeld der Einfluß der Geldmenge vom Einfluß der Entwicklung der Arbeitsproduktivität auf die Warenpreise nicht mehr trennen. Für seine Zirkulationsfunktion ist das weniger von Bedeutung - denn es selbst ist im Grunde die Erhebung dieser Funktion, die nur ideelles Geld unterstellt, zum allgemeinen Prinzip - aber als Zahlungsmittel muß es ein verläßliches und möglichst stabiles Wertmaß sein. Die Koppelung seiner Qualität als Zahlungsmittel an seine Funktionsfähigkeit als Zirkulationsmittel, bei der es nur auf seine Quantität ankommt, verkehrt die im Geld als Zirkulations- und Zahlungsmittel gegebene Form für die Inflation in eine mögliche, hier zunächst nur technisch bestimmte Inflationsursache.

Der bloß formelle Charakter der staatlichen Garantie der Wertmaßfunktion des Geldes wird deutlich, sobald es die innere Zirkulation verläßt und als Weltgeld den internationalen Warenverkehr vermittelt.

„,Mit dem Austritt aus der inneren Zirkulationssphäre streift das Geld die dort aufschießenden Lokalformen von Maßstab der Preise, Münze, Scheidemünze und Wertzeichen, wieder ab und fällt in die ursprüngliche Barrenform der edlen Metalle zurück... Erst auf dem Weltmarkt

41 Zu bedenken ist vor allem, daß der physische Verschleiß des Goldes als Geldware relativ gering ist und die Kapitalisten bemüht sind, die Geldmenge zu ökonomisieren, da ihre Erhaltung und Vermehrung zu den faux frais der kapitalistischen Produktion zählt. Die Produktivkraftsteigerung in der Goldproduktion wird daher ohnehin nicht unmittelbar in einer entsprechenden.Vergrößerung der Geldmenge resultieren. 
funktioniert das Geld in vollem Umfang als die Ware, deren Naturalform zugleich unmittelbar gesellschaftliche Verwirklichungsform der menschlichen Arbeit in abstracto ist. Seine Daseinsweise wird seinem Begriff adäquat" (42).

Das Weltgeld funktioniert als ,absolut gesellschaftliche Materiatur des Reichtums überhaupt (universal wealth)" (43) und allgemeines Kaufmittel (falls der Stoffwechsel zwischen verschiedenen Nationen plötzlich oder ständig gestört ist sowie notwendigerweise auf Seiten der Erzeugerländer der Geldware), vor allem aber als allgemeines Zahlungsmittel (44). Auf dem Weltmarkt kommt aber zu der die Zahlungsmittelfunktion des Geldes konstituierenden zeitlichen Differenz zwischen dem Verkauf der Ware und der Realisierung ihres Werts resp. Preises noch die räumliche Distanz und die damit verbundene Möglichkeit sehr unterschiedlicher Produktivkraftentwicklung der gesellschaftlichen Arbeit hinzu. Deutlicher Ausdruck dieser Tatsache ist bei freien Wechselkursen deren beständiges Schwanken. Die chronin schen Zahlungsbilanzungleichgewichte im System fester oder nur diskret variierbarer Wechselkurse sind nur negativer Ausdruck der administrativen Unterbrechung dieser quasiautomatischen Ausgleichsfunktion des Goldes als internationales absolutes Zahlungsmittel. Wird also der Versuch gemacht, nationale Formen des Geldes durch politisch-technische Vereinbarungen (Wechselkursbestimmung, Bedingungen der Konvertierbarkeit der Währungen, internationale Kreditfazilitäten, Sonderziehungsrechte etc.) unmittelbar als Weltgeld zu etablieren, so ergibt sich daraus ähnlich wie beim reinen Staatspapiergeld in der inneren Zirkulation eine enge Verquickung technischer mit ökonomischen Krisenursachen. Die ökonomischen Gesetze lassen sich nichì administrativ außer Kraft setzen, und die Konformität derartiger Manipulationen mit diesen Gesetzen muß mehr oder weniger zufällig bleiben.

\section{Produk tivkraftentwicklang, Warenwert und Verwertung}

Wir haben jetzt die Formen - Geld und Preise - entwickelt, in denen sich die Wertbewegung darstellt. Als Erscheinungsformen des Werts und seiner Bewegung sind sie deren notwendiger Ausdruck, ohne jedoch ihre Veränderungstendenz unmittelbar widerzuspiegeln. Das zu erklärende Phänomen der Inflation besteht ja gerade darin, daß die mit der Entwicklung der kapitalistischen Produktionsweise verbundene Steigerung der Produktivkraft der gesellschaftlichen Arbeit in einem beständigen Preisfall (oder wenigstens in konstanten Preisen, wenn die Produktivkraftsteigerung auch in der Erzeugung der Geldware Gold wirksam ist) resultieren müßte, während eine

42. Marx, Kapital I, S. 156

43 Derso, a. a. O., S. 157

44 „Die Funktion als Zahlungsmittel, zur Ausgleichung internationaler Bilanzen, herrscht vor。" Ebd. 
säkulare Tendenz zur Preissteigerung zu beobachten ist (45). Es gilt also, die in der Preisform gegebene Möglichkeit des numerischen Auseinanderfallens von Wertgröße und Wertausdruck als langfristige Tendenz zu begründen, indern das beständige Resultat der Produktivkraftsteigerung, die Senkung der in jeder einzelnen Ware dargestellten Gesamtarbeitszeit, mit der dieser Entwicklung widersprechenden Erscheinung steigender Preise vermittelt wird. Da jedoch die Wertbildung nur ein Moment der Verwertung des Kapitals ist, müssen wir zunächst untersuchen, wie sich die mit der Produktivitätssteigerung verändernden Bedingungen der Wertbildung für das Kapital geltend machen.

\subsection{Kapitalzusammensetzung, Mehrwertrate und Profitrate}

Die dem Kapital immanente Tendenz zur Steigerung der Arbeitsproduktivität setzt sich über die Konkurrenz der Einzelkapitale durch. Sie erscheint dort als Bestreben der Kapitalisten, durch die Senkung ihres Kostenpreises unter den Branchendurchschnitt einen Extraprofit zu erzielen. Mittel zur Kostpreissenkung sind Veränderungen im Arbeitsprozeß, die eine Einsparung an Arbeitskräften, Intensivierung der Arbeit und größere Ökonomie in der Anwendung der Produktionsmittel bewirken (46). In der Regel ist die Produktivkraftsteigerung mit einer Vermehrung der Produktionsmittel im Vergleich zur Anzahl der an ihnen beschäftigten Arbeitskräfte verbunden, d. h. mit einer Ersetzung von lebendiger durch tote Arbeit. Die organische Zusammensetzung des Kapitals als Wertausdruck des Verhältnisses von Produktionsmittelmasse zu Arbeiteranzahl (technische Zusammensetzung) muß daher wachsen. Zugleich kann die Mehrwertrate aus zwei Gründen steigen: zum einen sind die Kapitalisten bestrebt, den Arbeitstag der beschäftigten Arbeiter auszudehnen, um den Kapitalumschlag durch Verlängerung der täglichen Funktionszeit der Elemente des fixen Kapitals zu beschleunigen (durch Mehrschichtbetrieb, Überstunden usw.), zum andern sinkt der Wert der Arbeitskraft durch die Wertsenkung der zu ihrer Reproduktion notwendigen Lebensmittel. Da aber auch der Wert der Elemente des konstanten Kapitals im Zuge der Produktivkraftsteigerung sinkt, steigt die organische Zusammensetzung des Kapitals weniger als seine technische Zusammensetzung. Eine Erhöhung der organischen Zusammensetzung ist aber unvermeidbar. Denn die Vermehrung der Produktionsmittel, die Produkte vergangener, weniger produktiver Arbeit sind, wird in zunehmenden Maße Voraussetzung für die Steigerung der Arbeitsproduktivität. Daher ist die in den Produktionsmitteln vergegen-

45 W. Hofmanns Begriff der ,säkularen Inflation“, der die Beobachtung nicht fallender Preise bei steigender Arbeitsproduktivität thematisiert, beruht jedoch auf einem unzureichenden Begründungszusammenhang, als Hofmann die Ablösung der Preisbewegung von der Wertbewegung behauptet. Damit wird die Existenz des Werts vor dem Tauschwert (oder Preis) und unabhängig von ihm unterstellt und die Marxsche Wertheorie auf reine Scholastik reduziert. Siehe W. Hofmann, Die säkulare Inflation, Berlin 1962

46 Die Möglichkeit, derartige Wirkungen durch ausschließlich organisatorische Veränderungen zu erzielen, bleibt Ausnahme. 
ständlichte Arbeitsmenge größer als die zur Reproduktion der Arbeitskraft notwendige. Die im Zuge der Kapitalakkumulation forcierte Produktivitätssteigerung verschiebt die.Aufteilung des gesellschaftlichen Arbeitskräftepotentials auf die Abteilungen I (Produktionsmittel) und II (Lebensmittel) zugunsten der Abteilung I. In der Bewegung der Durchschnittsprofitrate findet die widersprüchliche Wirkung der Produktivkraftsteigerung auf Mehrwertrate und organische Kapitalzusammensetzung ihren zusammengefaßten Ausdruck, denn sie ist das Verhältnis des Zwecks, der Produktion von Mehrwert bzw. relativem Mehrwert (Erhöhung der Mehrwertrate), zum Mittel, dem vorgeschossenen Kapital bzw. dem Ausdruck der Veränderungen des Arbeitsprozesses in der Zusammensetzung des Kapitals, d. h.

$\mathrm{p}^{*}=\frac{\mathrm{m}}{\mathrm{C}+\mathrm{V}}=\frac{\mathrm{m} / \mathrm{V}}{\mathrm{S}(1+\mathrm{C} / \mathrm{V})}$

mit $\Theta=V$ Umschlagszeit des vorgeschossenen variablen Kapitals (in Jahren) (47). Unter Berücksichtigung der Verwandlung der Warenwerte in Produktionspreise tritt jedoch an die Stelle des Geldausdrucks (48) der Mehrwertmasse pro Produktionsperiode (Jahr) der Jahresprofit (P), an die Stelle der Wertpreissumme (v) der zur Reproduktion der Arbeiter während eines Jahres notwendigen Lebensmittelmasse deren Produktionspreissumme ( $\mathrm{vp}$ ) und an die Stelle der Kapitalvorschüsse zu Wertpreisen $(\mathrm{C}$ und $\mathrm{V})$ die entsprechenden Produktionspreisausdrücke $\left(\mathrm{C}_{\mathrm{p}}\right)$ und $\left(\mathrm{V}_{\mathrm{p}}\right)$ :

$p_{p}^{c}=\frac{p}{C_{p}+V_{p}}=\frac{p / V_{p}}{\rho\left(1+C_{p} / V_{p}\right)}$

Da es nicht auf die absolute Größe der Profitrate, sondern auf ihre langfristige

47 Die porgeschossenen Kapitalteile $\mathrm{C}$ und $\mathrm{V}$ werden mit großen Buchstaben bezeichnet, um sie als Bestandsgrößen (stocks) von den korrespondierenden Strömungsgrößen konstantes Kapital c (= Wertübertragung/Jahr) und Wert der Jahresarbeitszeit v (= Lohnsum$\mathrm{me} / \mathrm{Jahr}$ ) zu unterscheiden. Bestand sgrößen werden zu einem Stichtag gemessen; Strömungsgrößen beziehen sich auf einen bestimmten Zeitabschnitt. Kapital-,,stocks" und " flows" sind durch die jeweiligen Umschlagszeiten miteinander verbunden, also $\mathrm{V}=\mathrm{C}=\mathrm{c}$. Siehe auch Autorenkollektiv, Gesamtwirtschaftliche Grundbegriffe und -beziehungen, 1. Teil: Wert- und Preislehre, mehrwert 1, Westberlin und Bremen, Okt. 1972, S. $62 \mathrm{ff}$.

48 Die vorstehende Argumentation in Wertgrößen, die nur als Tauschwerte (Geldgrößen) erscheinen können, unterstellt ein konstantes „Übersetzungsverhältnis" von Werten in Wertpreise. Diese Voraussetzung ist nicht einmal durch die Konstanz von Wertsumme und Umlaufgeschwindigkeit der produzierten Geldware erfüllt, da schon die aus der Zirkulationsmittelfunktion des Geldes entstehenden Geldsurrogate, vor allem aber der in seiner Zahlungsmittelfunktion enthaltene Kredit, die realisierbare Preissumme der Waren weitgehend von der Geldmenge unabhängig macht. Siehe den 2. Abschnitt dieses Beitrages. Da wir davon ausgehen können, daß die Durchschnittsprofitrate nur die durchschnittlichen Verwertungsbedingungen des Kapitals ausdrückt - und zwar über die Akkumulationszyklen hinweg - ist es unbegründet, von einer fortschreitenden Vermehrung der als Geld fungierenden Wertzeichen und einer Vergrößerung des Kreditvolumens auszugehen, selbst wenn diese im Verlauf der Zyklen notwendig (vgl. Abschnitt 4) stattfindet. 
Bewegungsrichtung ankommt, ergeben sich aus dieser Umformulierung zunächst keine wesentlichen Unterschiede (49). Nun scheinen aus der Voraussetzung einer allgemeinen Produktivkraftsteigerung unmittelbar keinerlei Konsequenzen für die Höhe der Profitrate zu folgen. Denn blieben die Länge des Arbeitstags und der Beschäftigungsgrad über die industriellen Zyklen hinweg im Durchschnitt konstant und wäre der wertsenkende Effekt der Produktivitätserhöhung für alle Existenzformen des Kapitals und alle Einzelkapitale - unabhängig von ihrer Größe und Zusammensetzung - derselbe, so bliebe die allgemeine Profitrate im langfristigen Durchschnitt konstant, weil Zähler und Nenner des Ausdrucks für die Profitrate in Richtung und Ausmaß auf gleiche Weise modifiziert würden.

In einem bloß formallogischen Zusammenhang lassen sich daher keinerlei Konsequenzen hinsichtlich der langfristigen Tendenz der Profitrate ableiten. Die bürgerlichen Ökonomen haben also recht, wenn sie betonen, daß aus der bloßen Gegenüberstellung von Mehrwertrate und organischer Kapitalzusammensetzung ein Fall der Profitrate bei einer angenommenen Steigerung der Produktivkraft der Arbeit nicht bewiesen werden könne. Das war auch Marx klar:

,Abstrakt betrachtet, kann beim Fall des Preises der einzelnen Ware infolge vermehrter Produktivkraft und bei daher gleichzeitiger Vermehrung der Anzahl dieser wohlfeilen Waren, die Profitrate dieselbe bleiben, z. B. wenn die Vermehrung der Produktivkraft gleichmäßig und gleichzeitig auf alle Bestandteile der Waren wirkte, so daß der Gesamtpreis der Ware in demselben Verhältnis fiele, wie sich die Produktivität der Arbeit vermehrte, und andrerseits das gegenseitjge Verhältnis der verschiednen Preisbestandteile der Ware dasselbe bliebe ${ }^{6}(50)$.

Aber der Fall der Profitrate ist schließlich keine Definitionsangelegenheit, sondern Ausdruck der wirklichen Bewegung von Widersprïchen der kapitalistischen Produktionsweise. So ist immer bei der Untersuchung der Bewegung der Profitrate die Gesamtbewegung aller Widerspruchsmomente der Produktionsweise einzubeziehen; denn nur dann erhält der ,synthetische Ausdruck“, den nun einmal die gesamtgesellschaftliche Durchschnittsprofitrate darstellt, einen materiellen Gehalt: es werden also die im Verlauf der Kapitalakkumulation sich vollziehenden Prozesse der Konzentration und Zentralisation die strukturellen Veränderungen der Verteilung der gesellschaftlichen Arbeit zu berücksichtigen sein, um den Gründen für den - sogar in historischer Analyse nachweisbaren - Fall der Profitrate (51) auf die Spur zu kommen. Zugleich ist die Tatsache von Bedeutung, daß das Gesamtkapital notwen-

49 Im übrigen läßt sich sogar beweisen, daß die Durchschnittsprofitrate gegenüber Fehlern in der Erfassung der gesellschaftlichen Produktionsstruktur und der Bestimmung des Preissystems relativ unempfindlich ist, woraus ihre annähernde Gleich heit bei der alternativen Messung von Zähler und Nenner in Werten oder Produktionspreisen folgt. Siehe Brody, Proportions, Prices and Planning. A Mathematical Restatement of the Labor Theory of Value, Amsterdam/London 1970, S. 90 und Abschnitt 3.1.3, S. $123 \mathrm{f}$.

$50 \quad$ Kapital III, S. 239 f., Hervorhebung von uns

51 Vgl. W. Schoeller, W. Semmler, J. Hoffmann, E. Altvater, Entwicklungstendenzen des Kapitalismus in Westdeutschland (II), PROKLA 16, IV. Jg. 1974, Nr. 4, S. 55 ff. 
dig aus einer Vielzahl von Einzelkapitalen besteht und daher alle Tendenzen, die wir hier feststellen, immer in den vielfältigen Aktionen der Einzelkapitale „,hinter ihrem Rücken" als Tendenzen des Gesamtkapitals durchgesetzt werden. Die Durchsetzung braucht Zeit und sie erfolgt schließlich zwangsläufig als Eklat, da ja keinerlei gesellschaftliche Planung ihren kontinuierlichen Ablauf garantiert und die Widersprüche der Produktionsweise keine Harmonie ermöglichen. So ist es gerade der die kapitalistische Produktionsweise kennzeichnende periodische Krisenzyklus, in dem sich die Tendenz der auf den Wert gegründeten Produktionsweise durchsetzt und im Fall der Profitrate ihren zusammengefaßten Ausdruck findet (52).

In der zyklischen Akkumulationsbewegung des Kapitals werden die strukturellen Bedingungen der Kapitalverwertung so verändert, daß daraus eine Tendenz zum Fall der Profitrate resultiert. Denn im Krisenzyklus der kapitalistischen Produktion entfaltet sich der diese Tendenz erzeugende Widerspruch zwischen dem bornierten Zweck, der größtmöglichen Verwertung des vorgeschossenen Werts, und dem Mittel, der Produktivkraftsteigerung der gesellschaftlichen Arbeit, das von einer beständigen Vergrößerung der Produktionsmittelmassen im Vergleich zur Arbeiteranzahl begleitet ist. In der Wertbewegung macht sich damit erstens geltend, daß die gesellschaftlichen Potenzen der Arbeit den unmittelbaren Produzenten immer beherrschender in der entfremdeten Gestalt der stofflichen Elemente des konstanten Kapitals gegenübertreten. Zweitens bildet sich die über die Warenzirkulation vermittelte Gesellschaftlichkeit der individuellen Arbeiten durch die kapitalistische Konkurrenz zur Vergesellschaftung im hochzentralisierten Kapital fort. Drittens macht sich das Anwachsen der toten gegenüber der lebendigen Arbeit, die Steigerung der Masse des in Form von Produktionsmitteln existierenden konstanten Kapitals, auch für die Kapitalzirkulation geltend. Denn mit der absoluten und relativen Zunahme der in Produktionsmitteln gebundenen Kapitalmassen verlängert sich die Zirkulationszeit des vorgeschossenen Kapitals. Anders ausgedrückt: die Bedeutung des nicht in einer Umschlagsperiode mit dem ganzen Wert auf das Produkt übertragenen fixen Kapitals steigt an. - Diese Tendenzen sind nun näher zu untersuchen, um die Momente herausarbeiten zu können, die für ein Anwachsen der organischen Zusammensetzung des Kapitals verantwortlich sind, ohne zugleich eine entsprechende Steigerung der Mehrwertrate zu bewirken oder von ihr begleitet zu sein.

52 In diesem Zusammenhang sei auf eine spezifische begriffliche Struktur bei Marx verwiesen: In der begrifflichen Analyse deckt er allgemeine Gesetze der Produktionsweise auf (z. B. das allgemeine Gesetz der kapitalistischen Akkumulation), die sich aufgrund von inneren Widersprüchen nur als Tendenzen durchsetzen können. Die Durchsetzungsform aber impliziert notwendig auch Entfaltungsmöglichkeiten der dieser Tendenz zugrundeliegenden Widersprüche, so daß die zyklische Verlaufsform der Tendenz sich nat urnotwendig ergeben muß. 


\subsection{Die Tendenz zur Konzentration und Zentralisation des Kapitals und das Ver- hältnis von Profitrate und Profitmasse}

Mit dem Fortgang der kapitalistischen Akkumulation vollzieht sich die Verallgemeinerung der kapitalistischen Produktionsweise, indem allmählich für alle Bereiche der gesellschaftlichen Produktion die Voraussetzungen einer profitablen Kapitalanlage geschaffen werden. Diese Voraussetzungen sind aber nur teilweise technischer Natur und werden - soweit sie es sind - im wesentlichen auch erst unter dem Kapital hergestellt. Als entscheidende Bedingung für die direkte Subsumtion neuer Reproduktionsbereiche unter das Kapital sind vielmehr das Größenwachstum oder die Konzentration des Kapitals und die Entwicklung des Kreditsystems anzusehen. Denn mit der Größe der in einer Hand konzentrierten Kapitalmasse eröffnen sich dem Einzelkapital Anlagemöglichkeiten, die dem kleinen Kapital aus verschiedenen Gründen verschlossen bleiben müssen. So sind die von großen Einzelkapitalen in einer Periode akkumulierbaren Profitmassen nicht nur Mittel zur Selbstfinanzierling von Neuanlagen, sondern auch die Basis zur Erlangung umfangreicher Kredite. Deshalb können die erforderlichen Kapitalsummen für den Beginn weitreichender, durch einen verhältnismäßig langsamen Umschlag des vorgeschossenen Kapitals charakterisierter Unternehmungen aufgebracht werden. Wichtiger noch als dies ist jedoch der Umstand, daß große Kapitale aufgrund der von ihnen angeeigneten Profitmassen schneller akkumulieren können als kleine Kapitale, selbst wenn sie sich mit einer geringeren Rate verwerten als diese. Sie dringen daher auch in Produktionssphären ein, obwohl sie dort nur eine geringere Profitrate erzielen können, selbst wenn die durch das Kapital vorangetriebene Revolutionierung der Produktionsmethoden dort ebenfalls die Produktivkraft der Arbeit außerordentlich steigert. Aber diese „propagandistische Tendenz" des Kapitals ist nicht allein die Folge des individuellen Größenwachstums der Kapitale im Zuge ihres Akkumulationsprozesses. Denn die ,einfache, mit der Akkumulation identische Konzentration von Produktionsmitteln und Kommando über Arbeit" wird ergänzt durch die „,Konzentration bereits gebildeter Kapitale, Aufhebung ihrer individuellen Selbständigkeit, Expropriation von Kapitalist durch Kapitalist, Verwandlung vieler kleineren in weniger größere Kapitale. ... Das Kapital schwillt hier in einer Hand zu großen Massen, weil es dort in vielen Händen verlorengeht. Es ist die eigentliche Zentralisation im Unterschied zur Akkumulation und Konzentration" (53).

Jede Krise beschleunigt den Prozeß der Zentralisation und bildet den Ausgangspunkt einer großen Neuanlage von konstantem Kapital (54). Zugleich nimmt die unter dem Kommando eines einzelnen Kapitals vereinigte Arbeiterzahl außerordentlich zu, aber relativ zum Wert und noch mehr zur Masse der zu ihrer Exploita-

Kapital I, S. 654

54 Zwar ist ein wachsender Teil des neu angelegten Kapitals in der Form des fixen Kapital gebunden, aber auch das konstante zirkulierende Kapital nimmt aufgrund der mit steigender Stufenleiter der Produktion notwendig verbundenen Vergrößerung der Lagerhaltung zu. 
tion vom Kapitalisten bereitgestellten Produktionsmittel nimmt sie beständig ab. Bei immer weitgehender Arbeitsteilung wächst die Kooperation der Teilarbeiter innerhalb der ins Riesenhafte expandierenden kapitalistischen Unternehmungen. Trotz der damit verbundenen Produktivkraftsteigerung und entsprechenden Erhöhung des Exploitationsgrads der Arbeit erwächst dem Kapital jedoch in dem durch seinen anschwellenden Massenumfang nicht automatisch erfülten qualitativen Voraussetzungen seiner weiteren Expansion periodisch immer von neuem eine Verwertungsschranke, die sich in einer Tendenz zu nur mangelhafter Erhöhung der allgemeinen Profitrate nach der Krise geltend macht. Zwar ist das gewachsene Kapital auch bei niedrigerer Rate in der Lage zu expandieren, weil es auf der Grundlage der in kurzer Zeit angeeigneten Profitmassen die wachsende Hürde des jeweils notwendigen und beständig zunehmenden Kapitalminimums überwinden kann. Aber in der beim Fortgang der Akkumulation nicht ohne weiteres wieder auf ihre alte Höhe ansteigenden Profitrate drückt sich aus, daß mit der Entwertung und Vernichtung der weniger profitablen Kapitale nicht zugleich auch die höhere Profitabilität der überlebenden Kapitale gesichert ist. Insoweit, als die erzielbare Profitmasse auch dort noch der Motor der Kapitalexpansion ist, wo eine niedrigere Profitrate in Kauf genommen werden muß, kann auch die Entwertung von Kapital in der Krise die Profitrate nicht wieder auf das ursprüngliche Niveau anheben, wenn nicht außergewöhnliche Produktivkraftsteigerungen stattfinden. Die Voraussetzungen derartiger Produktivkraftsteigerungen können aber in immer geringerem Maße vom Einzelkapital selbst geschaffen werden, denn sie überschreiten entweder aufgrund der extrem langen Umschlagszeit und gewaltigen Größenordnung des notwendigen Kapitalvorschusses sowohl den Planungshorizont als auch die Finanzkraft selbst der größten Kapitale, oder sie geraten zunehmend mit den Naturbedingungen der Produktion in Konflikt. Es sind dies die mit der Entwicklung der kapitalistischen Produktion verstärkt wirksam werdenen Momente, die einen retardierenden Einfluß auf die durch bloßes Größenwachstum der Kapitale mögliche Produktivkraftsteigerung der Arbeit ausüben. So absorbieren die gewachsenen Produktenmassen in einem Ausmaß natürliche z. T. beschränkt reproduzierbare Rohstoffe, daß deren Verteuerung unausweichlich ist, weil „ein Teil des Rohmaterials, wie Wolle, Seide, Leder durch tierisch organische Prozesse, Baumwolle, Leinwand etc. durch vegetabilisch organische produziert wird, es [aber] der kapitalistischen Produktion nicht gelungen ist und nie gelingen wird, ebenso über diese Prozesse wie über rein mechanische oder unorganisch-chemische zu verfügen ... Was Kohle und Metall angeht (Holz), so sehr verwohlfeilert im Fortschritt der Produktion; indes bei Erschöpfung der Minen wird auch dies schwieriger etc." (55). Die daraus resultierende Erhöhung der organischen Zusammensetzung des Kapitals senkt die allgemeine Profitrate unmittelbar, da sie nicht mit einer Steigerung, sondern - wegen der Erhöhung des Werts der Arbeitskraft - eher mit einer Minderung der Mehrwertrate verbunden ist. Da aber die Profitmasse weiter wachsen kann und muß, setzt sich die Akkumulation 
bei niedrigerer Profitrate fort.

Die Kapitalauslage kann jedoch auch aus einem anderen Grund gesellschaftlich wachsen, ohne daß die hierdurch für das Gesamtkapital sinkende Profitabilität auf der Ebene des Einzelkapitals so unmittelbar wirksam würde, daß dieser Prozeß sofort zum Stillstand kommt. So können die in der Zirkulationssphäre gegen das industrielle Kapital verselbständigten Kapitale durch ihr Größenwachstum des Teilungsverhältnis der gesellschaftlichen Profitsumme in industriellen Profit auf der einen und Handelsprofit und Zins auf der anderen Seite zugunsten des letzteren verschieben, ohne daß die vom Zirkulationskapital exploitierten Arbeiter Mehrwert produzierten. Ein absolutes Wachstum der faux frais der kapitalistischen Produktion muß also die gesellschaftliche Profitrate drücken, soweit es nicht mit einer so starken Beschleunigung der Umschlagsgeschwindigkeit des industriellen Kapitals verbunden ist, daß dessen gestiegene Profitabilität die zusätzliche unproduktive Kapitalauslage in der Zirkulation kompensiert.

Schließlich aber macht auch die wachsende Verwertbarkeit ihrer Resultate sowie die notwendige Anpassung des Qualifikationsniveaus der Arbeiter an die Anforderungen der industriellen Großproduktion eine immer größere Kapitalauslage notwendig, ohne daß hierdurch die Mehrwertrate direkt und kurzfristig erhöht würde. Das Kapital kann dem hieraus resultierenden Druck auf die Profitrate auch nicht dadurch entgehen, daß der Staat (56) diese und weitere für das Einzelkapital nicht unmittelbar profitable Aufwendungen übernimmt. Denn zur Erfüllung seiner Funktionen entzieht er dem Kapital beständig einen entsprechenden Teil seines Akkumulationspotentials in Form von Waren, Arbeitskräften und Geld. Soweit er das Geld durch Steuern aus der Zirkulation zieht, die das verfügbare Einkommen der Arbeiter verringern, ohne zugleich die individuellen Reproduktionskosten der Arbeitskraft durch eine entsprechende Erhöhung unentgeltlicher staatlicher Leistungen zu senken, müssen die Löhne im langfristigen Durchschnitt den Wert der Arbeitskraft um den Steuerbetrag übersteigen. Die Nettomehrwertrate ist dann verringert; sie sinkt aber auch aufgrund einer direkten Verringerung der akkumulierbaren Mehrwert oder Profitmasse durch Steuern, die auf Kapitaleinkommen erhoben werden (57). Aus alledem folgt, daß die Nettoprofitrate und damit die Akkumulationsrate des Kapitals in dem Maße sinkt, in dem die Staatsausgaben nicht zugleich die Produktivkraft der Arbeit steigern. Zwar kann die Zunahme der Staatstätigkeit nicht als Ursache für den tendenziellen Fall der Profitrate genommen werden, aber

56 Wir müssen an dieser Stelle auf eine systematische Ableitung von Begriff und Funktionen des bürgerlichen Staates verzichten, wollen aber wenigstens eine minimale Begründung für das rapide Wachstum unproduktiver oder nur mittelbar produktiver Neuwert - Absorption durch den Staat liefern.

57 Eine tatsächliche Ửberwälzung bzw. Rückwälzung dieser Steuern über die Preise auf die Lohnarbeiter und den Staat kann nicht dauernd gelingen, weil sonst eine dauerhafte Senkung der Löhne unter den Wert der Arbeitskraft oder die Nichtexistenz des Staates impliziert wäre. Das schließt nicht aus, daß Steuererhöhungen in bestimmten konjunkturellen Situationen bei noch wenig eingeengtem Kreditspielraum nur das allgemeine Preisniveau erhöhen und d̦adurch vorübergehend die Reallöhne senken können. 
der mit ihr einhergehende Zuwachs des unproduktiven Teils der gesellschaftlichen Arbeit ist Ausdruck des widersprüchlichen Prozesses der Produktivkraftentwicklung unter dem Kapital, in dem sich die Kostpreissenkung und Verbesserung der Profitabilität für das Einzelkapital auf der Ebene des gesellschaftlichen Gesamtkapitals tendenziell als Verschlechterung der Verwertungsbedingungen erweist.

Daß dieser Widerspruch durch das Kapital nicht auflösbar ist, folgt aber nicht allein aus der Inkongruenz seiner individuellen und gesellschaftlichen Verwertungsrationalität. Produktivkraftentwicklung ist notwendig mit Entwertung verbunden. Nur dadurch, daß die mit der Produktivitätserhöhung bewirkte Senkung des Warenwerts nicht allgemein und augenblicklich, $d$. h. für alle Waren wirksam wird und so auch das Kapital in allen seinen Existenzformen entwertet, kann die Steigerung der Arbeitsproduktivität überhaupt zum Resultat kapitalistischen Profitstrebens werden. Denn nur unter dieser Voraussetzung kann das Einzelkapital einen Extramehrwert oder -profit erzielen. Aber auch für das Gesamtkapital kann sich eine Phase beschleunigter allgemeiner Produktivkraftsteigerung $u$. $U$. erst mit großer zeitlicher Verzögerung als massive Entwertung auswirken, denn solange produktivitätssteigernde Innovationen aufgrund günstiger Realisierungsbedingungen für das produzierte Warenkapital nicht in einem allgemeinen Fall der Warenpreise resultieren, gehen sie mit einer Beschleunigung der Kapitalakkumulation einher. Doch jede derartige Prosperitätsphase endet notwendig im Krach, in dem die aufgeschobene Entwertung umso plötzlicher nachgeholt wird. Von entscheidender Bedeutung dafür, $\mathrm{da} ß$ sich die veränderten Verwertungsbedingungen auf der Preisebene nicht unmittelbar geltend machen, ist die wachsende Rolle des fixen Kapitals im Prozeß der Produktivkraftsteigerung. Das ist im folgenden noch zu zeigen, bevor wir durch die Betrachtung des klassischen Akkumulationszyklus die Basis für die Herausarbeitung der besonderen Momente im gegenwärtigen kapitalistischen Reproduktionsprozeß legen können, die den Wechsel von Wertbildung und Entwertung auf der Ebene der Preise nur als Schwankungen der Inflationsrate, nicht aber der Höhe des absoluten Preisniveaus erscheinen lassen.

\subsection{Die wachsende Bedeutung des Fixkapitals für die Preisbewegung}

Im Verlauf der Kapitalakkumulation steigt nicht nur, wie wir gesehen haben, die organische Kapitalzusammensetzung. Vielmehr wächst innerhalb des zunehmenden Anteils des konstanten Kapitals am Gesamtkapitalvorschuß insbesondere der für Fixkapital verauslagte Teil an. Dabei handelt es sich vor allem um Produktionsmittel, die durch ihre Natur immer in die Produktionssphäre gebannt sind und diese niemals verlassen. Sie sind also im Prozeß, den der Kapitalwert notwendig durchmacht, in bestimmter Form fixiert. ,Mit der Funktion und daher der Abnutzung des Arbeitsmittels geht ein Teil seines Werts auf das Produkt über, ein andrer bleibt fixiert im Arbeitsmittel und daher im Produktionsprozeß..."(58). Mit der Ent-

58 Karl Marx, Das Kapital, Bd. 2, (MEW 24) Berlin (DDR) 1963, S. 159 
wicklung der Produktivkraft der Arbeit nehmen die Arbeitsmittel, die von einem Arbeiter angewendet werden, enorm zu. Die Herrschaft der toten über die lebendige Arbeit macht sich folglich gerade darin geltend, daß die fixen Elemente des produktiven Kapitals zunehmen. Dies ist schon grundsätzlich in der steigenden organischen Kapitalzusammensetzung angelegt. Denn mit der relativen Zunahme des konstanten Kapitals nimmt notwendig das variable zirkulierende Kapital relativ ab. Das variable Kapital zirkuliert als Wert voll und ganz, es bleibt zu keinem Deut in der Produktionssphäre fixiert. Anders beim konstanten Kapital, dessen - wachsender - Teil in dem oben beschriebenen Sinne fixes Kapital darstellt. Also ist auch die wachsende Bedeutung des fixen Kapitals ein Ausdruck der oben beschriebenen Vergesellschaftungsformen im Verlauf kapitalistischer Entwicklung, ein Moment der sich im tendenziellen Fall der Profitrate synthetisch ausdrückenden Widersprüche.

Die wachsende Bedeutung des Anteils von Fixkapital hat aber Konsequenzen für die zyklische Preisbewegung, deren sozusagen klassischen Verlauf wir im nächsten Abschnitt darstellen werden. Uns wird es hier darum gehen, die über den Zyklus vermittelten strukturellen Bedingungen für die Preisbewegung zu untersuchen. So muß jetzt danach gefragt werden, wie sich der als konstantes fixes Kapital vorgeschossene Kapitalwert auf die Kostpreiskalkulation der Einzelkapitale auswirkt. Steigende Massen von in der Produktionssphäre fixiertem Kapital setzen sich in eine steigende (in der Betriebswirtschaftslehre wohlbekannte) Fixkostenbelastung um. Fixe Kosten aber sind dadurch definiert, daß sie nicht unmittelbar mit der jeweiligen Ausbringungsmenge variieren. Wenn also die Produktion um 10 v. H. eingeschränkt wird, weil der Absatz infolge von irgendwie gearteten Markteinflüssen zurïckgeht, dann wird ein Teil der Kosten (z. B. die Kosten der verbrauchten Rohstoffe, Energiekosten usw.) ebenfalls um 10 v. H. absinken, ein anderer - und wachsender Teil - aber keineswegs fallen. Die Konsequenz in diesem Fall ist eindeutig: die Kosten pro Stück der geschrumpften Ausbringungsmenge steigen.

Welches sind solche aus dem Fixkapital resultierenden fixen Kosten? Dazu gehören Instandhaltungs-, Überwachungs- z. T. auch Reparaturkosten für in der Produktionssphäre während der Lebenszeit ihres Gebrauchswertes fixierte Produktionsmittel. Sie sind weitgehend unabhängig davon, mit welcher Auslastung der Kapazität die Anlage gefahren wird. Dazu gehören weiterhin Kosten des , ${ }_{9}$ moralischen Verschleißes". Denn ob eine Anlage ausgelastet ist oder nicht, die Entwicklung und Einführung technologisch verbesserter Maschinerie geht weiter und infolgedessen kann der Wert der Maschine sinken, den der Kapitalist ja in Höhe der Auslagen für die Anschaffung ersetzt haben will, ob diese Maschine nun ausgelastet wird oder nicht. Eine Wertsenkung aufgrund von moralischem Verschleiß verunmöglicht den vollen Ersatz des vorgeschossenen Kapitals. Über diese direkt aus dem Fixkapital ableitbaren Fixkosten können in der Krise auch bislang variable Kosten zu fixen werden. Teilweise sind Löhne und Gehälter dann fixe Kosten, wenn nämlich die Verringerung des Absatzes und der Ausbringungsmenge der Produktion nicht sogleich zu Reduktionen der Beschäftigung führt. Allerdings ist es klar, daß nur in bestimmten Grenzen diese an sich variablen Kosten fixierte sein können. In diesem Zusammenhang ist auch zu erwähnen, daß Teile des konstanten zirkulieren- 
den Kapitals in der Produktionssphäre fixiert werden können. Rohstoffe, die gekauft worden sind und nicht verarbeitet werden, produzierte Waren, die nicht absetzbar sind, stêllen für das jeweilige Einzelkapital eine Belastung als fixe Kosten dar, da ihr Wert nicht zirkuliert. Schließlich ist noch zu erwähnen, daß für den Einzelkapitalisten auch die Zinsbelastung von Teilen des vorgeschossenen Kapitals, das er als Fremdkapital auf dem Kreditmarkt aufgenommen hat, sich als Fixkostenbelastung darstellt. Denn die Zinsen müssen unabhängig von der Ausbringungsmenge, also unabhängig von der Wertzirkulation, in der sich nur der Mehrwert zu realisieren vermag, aus dem schließlich die Zinsen gezahlt werden, aufgebracht werden.

Zur Verdeutlichung des Problems, um das es uns geht, soll ein Beispiel dienen. Wir gehen von zwei Kapitalen mit unterschiedlicher organischer Zusammensetzung aus. Weiter nehmen wir an, daß der Anteil des fixen konstanten Kapitals gegenüber dem zirkulierenden konstanten Kapital unterschiedlich ist.

Kapital A: $\quad 100 \mathrm{v}+100 \mathrm{cz}+100 \mathrm{cf}=300 \mathrm{~K}$

Kapital B: $\quad 100 \mathrm{v}+200 \mathrm{cz}+300 \mathrm{cf}=600 \mathrm{~K}$

Bei Kapital A haben wir ein Verhältnis der organischen Zusammensetzung des Kapitals von $2: 1$, das Verhältnis des fixen konstanten Kapitals of zum zirkulierenden konstanten Kapital ist $1: 1$ bzw. zum gesamten zirkulierenden Kapital v + cz $1: 2$, und der Kostpreis $\mathrm{K}$ beträgt 300 . Bei Kapital B haben wir eine organische Zusammensetzung von $5: 1$, ein Verhältnis von $3: 2$ zwischen fixem und zirkulierendem konstanten Kapital bzw, bei Berechnung von $\mathrm{cf}:(\mathrm{v}+\mathrm{cz}) 1: 1$ und einen Kostpreis von 600. Wenn wir jetzt die zusätzliche Annahme machen, daß die Kosten des fixen Kapitals zu 80 v. H. anfallen, ob die Kapazitäten ausgelastet sind oder nicht, und wir eine Einschränkung der Produktion um die Hälfte annehmen, dann ergibt sich folgende Kostpreiskalkulation:

Kapital A: $\quad 50 \mathrm{v}+50 \mathrm{cz}+80 \mathrm{cf}=180 \mathrm{~K}$

Kapital B: $\quad 50 \mathrm{v}+100 \mathrm{cz}+240 \mathrm{cf}=390 \mathrm{~K}$

Der Kostpreis bei Kapital A verringert sich also bei einer Produktionseinschränkung von 50 v. H. nur um 40 v. H., bei Kapital B auf Grund des größeren Fixkostenanteils nur um 35 v. H. Nehmen wir weiter an, beide Kapitale beziehen bei Vollauslastung der Kapazitäten eine Profitrate von 10 v. H., Kapital A also 30 und Kapital B 60 Geldeinheiten Profit. Wenn A 100 Stücke produziert und B 300, dann beträgt bei Kapazitätsvollauslastung der Produktionspreis der einzelnen Ware von A 33, derjenigen von B 22. Der Kostpreis der einzelnen Ware bei A ist dementsprechend 30 , bei B folglich 20 . Wenn aber aufgrund der Produktionseinschränkung von $50 \mathrm{v}$. H. bei A nur noch 50 Stück Ware, bei B nur noch 150 Stück Ware produziert werden, dann steigt infolge des Anteils des auch bei Produktionseinschränkungen weiter Kosten verursachenden Fixkapitals der Kostpreis bei A pro Ware auf 36, bei $B$ gar auf 26. Der Kostpreis pro Ware bei Produktionseinschränkungen liegt somit bei A um $20 \mathrm{v}$. H. über dem Kostpreis bei Kapazitätsvollauslastung, bei B ist er um $30 \mathrm{v}$. H. höher. Um unter diesen Bedingungen weiterhin einen Profit zu erzielen, müßte der Preis pro Ware bei Produktionseinschränkung noch weiter angehoben werden. Unter den hier gemachten Annahmen, die eine Tendenz bezeichnen 
sollen, müßte der einzelne Warenpreis bei der Produktionseinschränkung gegenüber einer Situation vollausgelasteter Kapazitäten schon erhöht werden, allein um den Kostpreis des Warenkapitals realisieren zu können.

Warum diese Ausführungen? Sie sollen verdeutlichen, daß die Kapitalentwertung über die Bewegung der Preise mit steigender organischer Zusammensetzung des Kapitals und vor allem mit Zunahme des Anteils des fixen konstanten Kapitals bereits bei Konstanz des Preisniveaus eintreten kann, wenn in einer Absatzflaute Verkäufe und Produktion zurückgehen. Dies ist eine in der Betriebswirtschaftslehre bekannte Tendenz, die auf die „Verschiebung der Produktionskosten“ zurückgeführt wird.

„Und zwar handelt es sich darum, ... daß der Anteil der proportionalen Kosten am Produktionsprozeß kleiner und der Anteil der fixen Kosten immer größer geworden ist, und zwar so sehr, daß schließlich der Anteil der fixen Kosten für die Produktionsgestaltung bestimmend wurde... Die Eigentümlichkeit der proportionalen Kosten ist es, daß sie mit jedem erzeugten Stück, jeder geförderten Tonne tatsächlich entstehen ... Gehen die Preise unter die Selbstkosten herunter, dann schränkt man die Produktion ein und spart ein entsprechendes Stück der proportionalen Kosten... Ist aber der wesentlichste Teil der Selbstkosten fix, dann bringt eine Verringerung der Produktion die Kosten nicht entsprechend herunter. Und wenn bei dieser Sachlage die Preise fallen, dann hat es keinen Zweck, diesen Preisverfall durch Produktionsverminderung auszugleichen ..." (59).

So ergibt sich für jedes Einzelkapital der ökonomisch bedingte Zwang, gerade in der Krise bei Absatzstockungen und Unterauslastungen der Produktionskapazitäten keine Preissenkungen vorzunehmen. Vielmehr wird das jeweilige Einzelkapital eher versuchen, seine Preise heraufzusetzen infolge der gestiegenen Kostpreise. Gerade in der Krise ist hier eine materielle Basis dafür gegeben, daß Preise steigen anstatt zu sinken.

\section{Industrielle Akkumulation, Kredit und Preise im Verlauf des Krisenzyklus}

Nachdem wir die Tendenzen der Wertbewegung als Prozeß der Vergesellschaftung und im Verlauf dieses Prozesses sich zuspitzender Widersprüche, die ihren Ausdruck im tendenziellen Fall der Profitrate finden, dargestellt haben, können wir die Bewegungsform dieser Widersprüche im Verlauf des Krisenzyklus untersuchen. Dabei wird es uns darum gehen, das innere Verhältnis von industrieller Akkumulation und Kreditbewegung aufzuzeigen. Wie wir schon in der Einleitung geschrieben haben, ist das Begreifen dieses Zusammenhangs der Dreh- und Angelpunkt für eine wissenschaftliche Inflationse rklärung.

So verschiedene Autoren wie W. Hofmann oder E. Mandel (60) legen ihren Inflationserklärungen doch die gleiche Argumentationsstruktur zugrunde. Diese ent-

59 Eugen Schmalenbach in einer bei Alfred Sohn-Rethel, Ökonomie und Klassenstruktur des deutschen Faschismus, Frankfurt 1973, S. 41 fo zitierten Rede

60 E. Mandel, a. a. O.; W. Hofmann, Die säkulare Inflation, Berlin 1962 
hält drei wesentliche Elemente, nämlich erstens die Annahme von der relativen Selbständigkeit des Kreditzyklus vom industriellen Akkumulationszyklus, zweitens die Annahme von der relativ selbständigen "Machtpreissetzung" der großen Konzerne, die zu akkumulativen Zwecken sich die entsprechende Profitmasse über den Preis (,Selbstfinanzierung ") verschaffen, drittens die Annahme von der durch den Staat und den Bankenapparat vermittelten Möglichkeit der Kreditausweitung, damit die großen Kapitale auch ihre autonom gesetzten Machtpreise zu realisieren vermögen. Diese Argumentation läuft darauf hinaus, erstens den großen Einzelkapitalen (Monopolen) eine so große Macht zuzusprechen, daß sie sich den Gesetzmäßigkeiten der Wertbewegung zumindest partiell zu entziehen vermögen, zweitens davon auszugehen, daß die großen Kapitale den von der Akkumulationsbewegung relativ selbständigen Kreditüberbau für ihre Zwecke instrumentalisieren können. Dieses Erklärungsmuster ist das in der kritischen, nicht-bürgerlichen Literatur wohl gebräuchlichste. Differenzen in der Argumentation ergeben sich dann nur noch in Details: ob die Kreditausweitung zur Preisrealisierung auf der Staatsverschuldung, der Konsumentenverschuldung beruhe, ob die Macht der Monopole unbegrenzt, oder nur ",relativ" groß sei, ob die mit der Machtpreissetzung verbundenen Wertumverteilungen vorwiegend von der Arbeiterklasse oder von anderen Kapitalen stammen usw.

Der letzte Grund für diese Argumentation ist darin zu suchen, daß der Zusammenhang von Wert und Preis von diesen Autoren nicht berücksichtigt wird. Bei W. Hofmann ist dies am deutlichsten, der ja explizit die Werttheorie zur Erklärung der Preisbewegung für ungeeignet hält, daher auch die Wert- und Preisbewegung voneinander ,loskoppelt" und folglich auch nicht mehr in der Lage sein kann, die Akkumulationsbewegung des industriellen Kapitals und die Bewegung des Kredits in einen inneren Zusammenhang zu bringen. Die Preisbewegung ist aber nur zu erklären, wenn gerade dieser innere Zusammenhang entwickelt wird. Denn der Preis - darauf haben wir bereits hingewiesen - ist zunächst einmal nur gesetzter Preis, ideeller Wertausdruck. Die über den Preis vermittelte Formverwandlung des Werts aus der Warenform in die Geldform, d. h. die Realisierung des Preises, ist aber von Bedingungen abhängig, die in der Bewegung des Geldes (und des Kredits) zu suchen sind. Diese jedoch sind nur scheinbar unabhängig von der Akkumulationsbewegung des Kapitals. Ebenso wie der Preis scheinbar unabhängig vom Wert ist und ebenso wie die langfristige Wertbewegung nicht unmittelbar in der Preisbewegung ihren unvermittelten Ausdruck finden muß, ist der Kreditzyklus nur scheinbar unabhängig vom industriellen Zyklus. Dies läßt sich zeigen, indem wir die Bewegung von Kapitalakkumulation, Geld, Kredit und Preisen im Verlauf des Krisenzyklus darstellen.

Wir unterstellen entwickelte Kreditverhältnisse auf der Basis einer Staatspapiergeldwährung mit Einlösungszwang in Gold und betrachten den Akkumulationszyklus des industriellen Kapitals. Ausgangspunkt unserer Überlegungen sei die Situation der Depression unmittelbar nach der Krise. Der Produktionsprozeß ist stark eingeschränkt, die industrielle Reservearmee der Lohnarbeiter groß, die Warenlager überfuillt, die Löhne der beschäftigten Arbeiter um Zulagen und alle Arten 
von Sondervergïtungen gekürzt, aber nicht so stark gesunken wie die Preise. Das Kreditvolumen ist stark kontrahiert und Leihkapital liegt brach, der Zinsfuß ist daher auf seinem niedrigsten Stand. Mit dem Fortgang des Preisverfalls der produzierten Waren und der Entwertung und Zentralisation des produktiven und fiktiven Kapitals mag eine Wende zur Wiederbelebung der Akkumulation eintreten, weil eine gewisse Basisnachfrage nach Lebensmitteln nicht unterschritten wird und der Unternehmergewinn trotz niedriger Profitrate aufgrund der gefallenen Zinsrate gestiegen ist (61). Mit der allmählichen Ausdehnung der Stufenleiter der Produktion steigt mit zunehmendem Beschäftigungsgrad vor allem die Nachfrage nach Lebensmitteln, und mit den verbesserten Verwertungsbedingungen in der Abteilung II beschleunigt sich auch die Produktion in Abteilung I aufgrund steigender Nachfrage nach Produktionsmitteln durch die Kapitale der Abteilung II. Die Löhne stagnieren, während die Profitrate langsam zu steigen beginnt. $\mathrm{Da}$ in dieser Phase der kommerzielle Kredit relativ unabhängig vom Bankkredit ist, „beruhend auf Flüssigkeit des Ruickstroms, kurzen Kreditterminen und vorwiegendem Arbeiten mit eigenem Kapital" (62), herrscht weiterhin relativer Überfluß an leihbarem Kapital. Zwar wird es mit fortschreitender Erhöhung der industriellen Produktion, ,in steigendem Maß angewandt, aber zu sehr niedrigem Zinsfuß, weil jetzt der industrielle und kommerzielle Kapitalist dem Geldkapitalisten die Bedingungen vorschreibt" (63). Sobald ein ausreichend hoher Auslastungsgrad der Produktionskapazitäten erreicht ist, beginnt erneut die Jagd der individuellen Kapitalisten nach Extraprofit. Durch größere Auslage von konstantem Kapital relativ zur lebendigen Arbeitskraft wird der individuelle Produktionspreis unter den Marktproduktionspreis gesenkt, also Extraprofit auf Kosten der Konkurrenten angeeignet. Durch die zunehmende ,Ausdehnung des fixen Kapitals in allen Formen und die massenhafte Eröffnung neuer weitreichender Unternehmungen" (64) beschleunigt sich die Expansion der Abteilung I, weil sowohl die interne Nachfrage der Abteilung I nach Produktionsmitteln als auch die Nachfrage aus der Abteilung zwei wächst. Gleichzeitig nimmt mit steigendem Beschäftigungsgrad bei noch stagnierenden Löhnen die Konsumtionsmittelnachfrage zu. Die Preise beginnen zu steigen und mit ihnen nimmt die in Marktpreisen gemessene Mehrwertrate und die Profitrate zu. Allerdings beginnen auch die Geldlöhne zu steigen, da die Vollbeschäftigung allmählich erreicht wird und der Arbeitstag durch Überstunden vielerorts verlängert wird. Zugleich verändert sich das Teilungsverhältnis des Profits in Zins und Unternehmergewinn zuungunsten des industriellen Kapitalisten, da auch der Zinsfuß leicht ansteigende Tendenz hat. Zwar steigt der Zinsfuß zunächst nur wenig über sein Minimum, weil der kommerzielle Kredit eine sehr große Ausdehnung erreicht, ,die dann in der Tat wieder die ,gesunde“ Basis leicht eingehender Ruickflüsse und ausgedehnter Produktion hat" (65), so daß das Ange-

61 Kapital"III, S. 512

62 Ebd.

63 Ebd., S. 511 f.

64 Ebd., S. 505

65 Ebd. 
bot von Leihkapital trotz steigender Nachfrage gesichert ist. „Es ist dies in der Tat der einzige Zeitpunkt, wo gesagt werden kann, daß niedriger Zinsfuß, und daher relative Reichlichkeit des verleihbaren Kapitals, zusammenfällt mit wirklicher Ausdehnung des industriellen Kapitals" (66). Durch die enorme Ausdehnung des Kredits wirken der steigenden Tendenz des allgemeinen Preisniveaus keinerlei Restriktionen von Seiten der die Warenzirkulation vermittelnden Geldmenge entgegen (67). Es ,ist diese flotte Geschäftszeit zugleich die Periode des elastischsten und leichtesten Kredits. Die Geschwindigkeit der Zirkulation zwischen Kapitalist und Kapitalist ist direkt durch den Kredit reguliert, und die Masse des Zirkulationsmittels, die zur Saldierung der Zahlungen und selbst zu Barkäufen erheischt ist, nimmt also verhältnismäßig ab. Sie mag sich absolut ausdehnen, aber sie nimmt unter allen Umständen relativ ab, vergleichen mit der Expansion des Reproduktionsprozesses" (68). Auch der Konsumentenkredit erreicht jetzt seine größte Ausdehnung. Mit dem Übergang von der Prosperität zur Überanspannung nimmt jedoch die Nachfrage nach Leihkapital schneller zu als das Angebot. ,Andererseits kommen jetzt in merklichem Grad die Ritter herein, die ohne Reservekapital oder überhaupt ohne Kapital arbeiten und daher ganz auf den Geldkredit hin operieren... Der Zins steigt jetzt auf seine Durchschnittshöhe“ (69). Auch die Bankkredite nehmen zu, teils zur Überbrückung kurzfristiger Zahlungsschwierigkeiten aufgrund ungleichmäßiger werdender Rückflüsse aus dem Verkauf der Waren, teils zur Ablösung des kommerziellen Kredits, um noch vor Fälligkeit der Forderungen den Geschäftsumfang weiter ausdehnen zu können. Das Preisniveau erhöht sich jetzt mit beschleunigter Rate und scheinbar ganz unabhängig vom Warenwert. Die Profite steigen ebenfalls, aber für die einzelnen Kapitale und Produktionssphären mit zunehmend unterschiedlicher und für eine wachsende Anzahl sogar abnehmender Rate. Die Profitratendifferenzen zwischen den individuellen Kapitalen einer Branche und denen verschiedener Branchen nehmen also erheblich zu, während die Durchschnittsprofitrate ihr Maximum überschreitet. Denn die Reservearmee ist inzwischen weitgehend ausgetrockent und die Löhne steigen.

Der Abschluß der großen Neuanlagen von fixem Kapital im Zuge des Aufschwungs hat auch zur Folge, daß die Arbeitsproduktivität stagniert, während die Erhöhung der Geldlöhne erst verstärkt einsetzt, sobald die Expansion der Produktion sich auf gleichbleibender technischer Grundlage fortsetzt. Die aktuelle Mehrwertrate sinkt, während die erhöhte organische Zusammensetzung des Kapitals erhalten bleibt. Mit dem Wachsen des notwendigen Kapitalvorschusses bei sinkenden Möglichkeiten zur Selbstfinanzierung nimmt die Nachfrage nach Kredit stark zu, während gleichzeitig die kommerzielle Kreditgewährung schnell eingeschränkt wird, um den Rückfluß des ausgelegten Kapitals in Geldform zu beschleunigen. Die Nachfrage nach Bankkrediten und damit die Diskontrate wachsen sehr schnell. In zuneh-

66 Ebd.

67 Ebd., S. 462

68 Ebd., S. 463

69 Ebd., S. 505 
mendem Maße sind Käufe nur noch gegen Barzahlung möglich und die Verkäufe geraten dementsprechend ins Stocken. Der Produktionsprozeß stagniert, um sehr bald stark zu kontrahieren. Der Reproduktionsprozeß des Kapitals ist daher gelähmt, das bereits ausgelegte Kapital massenhaft unbeschäftigt. „Fabriken stehn still, Rohstoffe häufen sich auf, fertige Produkte überfüllen als Waren den Markt. Es ist also nichts falscher, als solchen Zustand einem Mangel an produktivem Kapital zuzuschreiben. Es ist gerade dann Überfluß von produktivem Kapital vorhanden, teils in bezug auf den normalen, aber augenblicklich kontrahierten Maßstab der Reprodukion, teils in bezug auf die gelähmte Konsumtion" (70). Besonders stark ist die Kontraktion in Abteilung I, da die Produktionsmittelnachfrage schlagartig zurückgeht. Aber auch die Konsumtionsmittel, insbesondere langlebige Konsumgüter und Luxusmittel, werden selbst zu stark fallenden Preisen in dem Maße unverkäuflich, in dem die Arbeitslosigkeit zunimmt. Das Warenkapital ist also ,am Vorabend der Krise und innerhalb derselben ... in seiner Eigenschaft als potentielles Geldka. pital kontrahiert. Es stellt für seinen Besitzer und dessen Gläubiger (wie auch als Sicherheit für Wechsel und Anleihen) weniger Geldkapital vor, als zur Zeit, wo es eingekauft und wo die auf es begründeten Diskontierungen und Pfandgeschäfte abgeschlossen wurden. Soll dies der Sinn der Behauptung sind, daß das Geldkapital eines Landes in Zeiten der Klemme vermindert ist, so ist dies identisch damit, daß die Preise der Waren gefallen sind“ (71). Denn sobald die Rückverwandlung der als produktives Kapital und Warenkapital ausgelegten Wertsumme in die Geldform stockt, der kommerzielle Kredit kontrahiert und mit steigendem Zins, also fallenden Kursen, das fiktive Geldkapital „enorm vermindert (ist), und damit die Macht seiner Eigner, Geld darauf im Markt aufzunehmen“" (72), wird der Verkauf zu jedem Preis zum einzigen, aber mit fallenden Preisen zunehmend untauglicheren, Mittel, die in der Prosperitätsphase stark expandierten Kredite abzulösen. Zusätzliches Leihkapital zum Zweck der Umschuldung ist zunächst zu Maximalzinsen, schließslich aber gar nicht mehr erhältlich. Der Wechseldiskont wird nach einer kurzen Phase starker Verteuerung ebenso unmöglich, so daß die Wechselzirkulation vollständig zusammenbricht (73). ,In einem Produktionssystem, wo der ganze Zusammenhang des Reproduktionsprozesses auf dem Kredit beruht, wenn da der Kredit plötzlich aufhört und nur noch bare Zahlung gilt, mußs augenscheinlich eine Krise eintreten, ein gewaltsamer Andrang nach Zahlungsmitteln. Auf den ersten Blick stellt sich daher die ganze Krise nuur als Kreditkrise und Geldkrise dar. Und in der Tat handelt es sich nur um die Konvertibilität der Wechsel in Geld. Aber diese Wechsel repräsentieren der Mehrzahl nach wirkliche Käufe und Verkäufe, deren das gesellschaftliche Bedürfnis weit überschreitende Ausdehnung schließlich der ganzen

70 Ebd., S. 500

71 Ebd., S. 508; „Ein solcher Zusammenbruch der Preise gleicht übrigens nur ihre frühere Aufblähung aus." Ebd.

72 Ebd., S. 510

73 Vgl. ebd., S. 556 
Krisis zugrunde liegt (74).

Aus dieser abrißhaften Darstellung des „klassischen ${ }^{6}$ industriellen Zyklus wird deutlich, daß hier bestimmte Phasen des Zyklus allgemeine Preissteigerungen infolge von Ubernachfrage (vermittelt über das sich ausweitende Kreditsystem) hervorbringen und daß sich die durchschnittliche Verwertungsrate mit den Schwankungen des Zyklus' verändert. In der Krise werden durch Preisverfall, Entwertungsprozesse bzw. Aufhebung von Disproportionalitäten neue Bedingungen eines Aufschwungs geschaffen. Wie aber bereits in Teil 3 beschrieben, sind die zyklischen Schwankungen durch die langfristige Entwicklung der Struktur der Verwertung des Kapitals vermittelt, wie umgekehrt der einzelne Zyklus die Veränderungen (in der Zusammensetzung des Kapitals etc.) mit bewirkt. Wäre der einzelne Zyklus imstande, die Widersprüche der Akkumulation zu ,lösen“", würde sich die Profitrate immer wieder auf ein gleiches Niveau einpendeln (75). Dagegen werden aber offenbar die strukturellen Probleme der Kapitalverwertung zumindest in einem Zyklus nicht gelöst, sondern entwickeln sich überzyklisch: Die organische Zusammensetzung wächst insofern als sich die Entwertung von Kapital in der zyklischen Krise nicht vollständig durchsetzt. Dies hat langfristige Tendenzen der Überakkumulation zur Folge. Im folgenden wollen wir uns daher fragen, wie diese Tendenzen zur Überakkumulation, die sich über längere Zeiträume hinweg in schweren Krisen Geltung verschaffen müssen, mit überzyklischen Preissteigerungen zusammenhängen.

\section{5. Überakkumulation, aufgeschobene Entwertungsprozesse und überzyklische Preissteigerungen}

Wir hatten bereits allgemein gezeigt, daß sich im kapitalistischen Entwicklungsprozeß Überakkumulationstendenzen herausbilden, die ihren Ausdruck in einem tendenziellen Fall der Profitrate finden. Dies ist Resultat der Akkumulation, in deren Verlauf sich ein Zuviel an Kapitalwert herausbildet, der sich - bei beschränkter Möglichkeit der Ausdehnung der Mehrwertmasse - nicht mehr in adäquaten Raten verwerten kann. Welche Formen nimmt dieser „Überfluß" an Kapital an? Wie löst sich dieser der kapitalistischen Produktionsweise immanente Widerspruch durch Entwertung von Kapital und gesteigerte Mehrwertproduktion?

\section{1 Überfluß yon Kapital}

Der Überfluß an Kapital erscheint in allen drei Formen des Kapitals, also im Geldkapital, im Warenkapital, im produktiven Kapital. Ausdrucksformen sind:

$74 \quad$ Ebd., S. 507

75 Vgl. etwa B. Schefold, der von einer solchen Erscheinung ausgeht in: Mehrwert Nr. 2 (1973), S. 139 
- Vagabundierendes, nicht mehr nach produktiver Anlage suchendes, sondern nur noch zu jeglicher Spekulation bereitgehaltenes Leihkapital, das sich auf den nationalen und internationalen Geld- und Kapitalmärkten herumtreibt;

- Nicht absetzbares Warenkapital, oberflächlich betrachtet aufgrund einer Zirkulationsstockung, aber in Wirklichkeit aufgrund der Tatsache, daß Zusatzkapital sich nicht mehr vollständig in produktives Kapital verwandeln kann, daher sich auch nicht mehr gegen Produktionsmittel und Arbeitskraft austauscht, während zugleich die mit der Freisetzung von Arbeitskraft und der Lohnbeschränkung in der Krise und in stagnativen Phasen der Akkumulation einhergehende weitere Beschränkung der Konsumtionskraft der Massen (bei antagonistischen Verteilungsverhältnissen) eine Ausdehnung des Absatzes von Konsumtionsgütern entsprechend der Steigerung der Produktivkraft nicht mehr zuläßt;

- Nicht ausgelastete Produktionskapazitäten, d. h. Kapital in der stofflichen Form von Produktionsmitteln, das nicht mehr als Aussauger von Mehrarbeit zu dienen vermag, da der möglichen und wachsenden Verwertung des Kapitals in der Produktion nicht die Realisierung dieses Werts in seinem Kreislauf als Kapital folgen kann.

Die Überakkumulation von Kapital ist zum einen eine allgemeine Tendenz der kapitalistischen Produktionsweise, wobei darauf hinzuweisen ist, daß Überakkumulation keineswegs mit Überproduktion von Waren allein identisch zu setzen ist oder gar mit Úberfluß an gesellschaftlichem Reichtum. Kapitalistische Überakkumulation führt immer auch zu individueller und gesellschaftlicher Not, da ja das überakkumulierte Kapital sich nicht nur gegen Waren, die in das konstante Kapital eingehen, sondern auch nicht gegen Arbeitskraft umsetzt, folglich regelmäßig mit Arbeitslosigkeit einhergeht. Zum anderen verschärft sich die Überakkumulation von Kapital periodisch bis zu einem Punkt, wo sie nicht nur stagnative Tendenzen produziert, sondern die Krise hervorbringt. Akkumulation erfolgt nur, wenn die Verwertung des einzusetzenden Kapitals, d. h. die Profitrate als Motor des Prozesses - auch bei Kapitalen, bei denen die Profitmasse die Profitrate aufwiegt, verliert die Profitrate nicht vollständig ihre Bedeutung! - hoch genug ist. Dabei ist davon auszugehen, daß die aktuelle Höhe der Profitrate in verschiedenen historischen Zeitabschnitten kapitalistischer Entwicklung durchaus unterschiedlich sein kann. Dies ändert aber nichts daran, daß die Profitrate als solche überhaupt eine entscheidende Rolle für den Gang der Akkumulation spielt. Sinkt die Profitrate bis auf den Punkt, an dem sie als ,Stachel der Akkumulation" unwirksam wird, dann hört auch die Kapitalakkumulation zeitweise auf. Ohne Akkumulation aber keine Produktivkraftsteigerung, und ohne Produktivkraftsteigerung keine Wertsenkung und kein tendenzieller Fall der Profitrate. So stellen die periodischen krisenhaften Unterbrechungen der kapitalistischen Akkumulation immer wieder eine zeitweise Lösung der bezeichneten Widersprüche dar. Hinzu kommt noch, daß in den Krisen durch Entwertung von Kapital, sowohl von konstantem als auch von variablem Kapital, die Profitrate zeitweise angehoben werden kann. 


\subsection{Entwertung von Kapital}

Der Prozeß der Entwertung muß als die gesellschaftlich produzierte Rückwirkung auf das einzelkapitalistische Streben nach möglichst großer Verwertung begriffen werden. Insofern wird auch der Entwertungsprozeß - in seinen Erscheinungsformen von Konkursen, Preisverfall, nicht absetzbaren Lagerbeständen, unausgelasteten Kapazitäten, brachliegendem Leihkapital - als Katastrophe begriffen, die ,irgendwie verursacht" ist, nicht jedoch auf die gesellschaftliche Form des Produktionsprozesses zurückgeführt wird.

Wir wollen jetzt die einzelnen Formen der Entwertung genauer betrachten. Wir beginnen mit der Entwertung von Kapital in seiner Warenform durch physische Vernichtung von Waren und Preisverfall des Warenkapitals.

In jeder Produktionssphäre kann, so wurde gezeigt, der Marktpreis vom Marktproduktionspreis abweichen, die Wertbewegung und die Preisbewegung auseinanderfallen. Dies ist jedoch für die Gesamtproduktion unmöglich. Wenn etwa in Phasen des Booms die Warenpreise einiger Kapitale ansteigen, entstehen Surplusprofite, die eine geringere Verwertung anderer Kapitale oder einen geringeren Reallohn der Lohnarbeiter zur Folge haben. Preise können aber nicht allgemein von den Werten abweichen und Marktpreise können auch nicht allgemein von den Martkproduktionspreisen verschieden sein. Die im ersten Teil entwickelte These, daß die Summe der Werte gleich der Summe der Preise sein muß (übersetzt durch die Funktion des Geldes als Maßstab der Preise), muß auch bei Preissteigerungen gelten. Nur werden hier die Wertpreise durch höhere Geldausdrücke repräsentiert. Auch bei allgemeinen Preissteigerungen und „Geldwertverfall“" im Laufe der Akkumulation (etwa durch Kreditausweitung und Übernachfrage) muß diese These zutreffend sein (abgesehen von Störungen in der Aggregation) kann die Nachfrage nicht unmittelbar durch ein entsprechendes Angebot an Waren befriedigt werden und steigen die Warenpreise allgemein, so löst sich nicht die Preisbewegung von der Wertbewegung, vielmehı erhält jedes Quantum gesellschaftlicher Arbeit einen höheren Geldausdruck, da der Preis einen in Geld ausgedrückten Wert darstellt.

Preisverfall von Waren in einzelnen Produktionszweigen und der Fall der Marktpreise z. B. unter den Marktproduktionspreis stellt noch keine Entwertung dar. Hier verschwindet nur ein Zusatzprofit, der über die Preise hereingeholt wurde. Durch Preisverfall verschwindet auf diese Weise nur die vorangegangene Umverteilung. Der Profit anderer Kapitale und der Reallohn der Lohnarbeiter steigt wieder. Anders ist dies aber bei vorangegangenen allgemeinen Preissteigerungen und allgemeinem Geldwertverfall. Sinken jetzt die Warenpreise allgemein herab oder werden gar Waren in ihrer physischen Form vernichtet, wird Kapital und Mehrwert, d. h. gesellschaftliche Arbeit in vergegenständlichter Form entwertet und vernichtet. Weil der Geldausdruck der Waren - auch nach allgemeinen Preissteigerungen - ein bestimmtes Quantum gesellschaftlicher Arbeit repräsentiert (Geld als Maß der Werte), bedeutet ein Preisverfall in der Krise nicht nur eine Entwertung und Vernichtung von Kapital, sondern auch eine Entwertung und Vernichtung von gesellschaftlicher 
Arbeit. Die Gesellschaftlichkeit der Produktion macht sich hier also normalerweise in der Krise, die sich für die einzelnen Kapitale als Überproduktionskrise darstellt, als Rücknahme von Preisen, als Preisverfall geltend (76).

Diese Form der Entwertung als Beseitigung von Überfluß an Kapital bezieht sich daher nur auf bereits produziertes Warenkapital. Die Nichtabsetzbarkeit von bereits produziertem Warenkapital wirkt allerdings auf das in der Produktion angelegte und in Gang gesetzte produktive Kapital zurück. Indem nämlich so die Reproduktion des produktiven Kapitals verhindert wird (oder zumindest eines Teils desselben), zeigen sich auch hier Entwertungsprozesse:

- Der Wert des insgesamt in der Produktion beschäftigten produktiven Kapitals wird durch die Stillegung von Teilen der Produktionsanlagen vermindert. Können diese nicht wieder in Funktion gesetzt werden, bildet diese Entwertung einen echten Kapitalverlust, der vom Bruttoprofit zu tragen ist: „Da die Profitrate gleich ist dem Verhältnis des Überschusses des Werts des Produkts zum Wert des vorgeschossnen Gesamtkapitals, so wäre eine Erhöhung der Profitrate, die aus einer Entwertung des vorgeschossnen Kapitals hervorginge, mit Verlust an Kapitalwert verbunden, ebenso eine Erniedrigung der Profitrate, die aus Wertsteigerung des vorgeschossenen Kapitals hervorginge, möglicherweise mit Gewinn" (77). Dies gilt gleichermaßen für die Kapitalwerte, die in Vorrats- resp. Warenlager gebunden sind und aufgrund der Produktions- und Absatzstockung nicht umschlagen können.

- Diese Verminderung des Werts des in der Produktion angelegten Kapitals drückt sich aber auch in einer Verminderung des Veräußerungspreises der Anlagen aus: Große Kapitale, die aufgrund ihrer hohen Profitmassen weiter (wenn auch beschränkt) akkumulieren, werden daher in Phasen der Krise und Stagnation kleine - vor der Pleite stehende - Kapitale aufkaufen können; die Zentralisation von Kapital ist somit gleichermaßen mit Kapitalverlusten verbunden, eine in Preisen ausged rückte Wertsumme (Kapitalsumme) verschwindet aus dem Gesamtprozeß der Kapitalzirkulation.

- Indem so jede Krise die Vernichtung und Entwertung des vorhandenen Kapitals Raum schafft für die Neuanlage von Kapital (in technologisch umgewälzter Form), macht sie sich in einem über die Konkurrenz vermittelten moralischen Verschleiß bestehender Kapitalanlagen geltend. Alte Anlagen müssen durch neuere und produktivere Anlagen ersetzt werden, ohne daß der Kapitalwert bereits umgeschlagen wäre. Allerdings: ,Der Wert der Maschinerie etc. sinkt jetzt, nicht weil sie rasch verdrängt oder in gewissem Grad entwertet wird durch neuere, produktivere Maschinerie etc., sondern weil sie jetzt wohlfeiler produziert werden kann" (78).

Existierende Werke werden so vernichtet, indem sich die gesellschaftlich notwendigen Proportionen wieder herstellen.

77 Kapital III, S. 123

78 Ebd., S. 124 
Wir haben hier die verschiednen Formen gezeigt, durch die ein Überfluß an Kapitalwert, der sich nicht mehr zur vorausgesetzten Rate der Verwertung verwerten kann, wieder abgebaut wird. Damit sind aber Konsequenzen für die organische Zusammensetzung verbunden; diese muß aufgrund der Kapitalverluste und -entwertung wieder absinken. Darüberhinaus sinken auch die Reproduktionskosten für das fixe und zirkulierende Kapital, was wiederum die organische Zusammensetzung herabsetzen kann. Nun kann aber - wie wir in Teil 3 bereits gezeigt haben - die Zusammensetzung des Kapitals nicht mehr i. d. R. auf ein Niveau gesenkt werden, das stets (uiber den Zyklus hinweg) eine durchschnittlich gleich hohe Rate der Verwertung ermöglichen würde. Wenn in vorhergegangenen Zyklen die Bereinigung des Kapitaluberflusses nicht in genügendem Maße erfolgt ist, schleppen sich Strukturprobleme der Verwertung fort aufgrund einer mangelnden Entwertung des fixen Kapitals, eines höheren Anteils beschränkt reproduzierbarer Rohstoffe und aufgrund der Aufrechterhaltung des gegebnen Werts der Ware Arbeitskraft durch die gewerkschaftliche Aktion. Erst diese historische Entwicklung wirkt sich darin aus, daß der Fall der Profitrate, ,im Verlauf langer Perioden schlagend hervortritt" (79).

\section{3 Überakkumulation, Preissetzung und Aufschieben der Entwertung}

Diesen hier entwickelten Formen des Kapitalverlusts, der Entwertung und der Wertsenkung des konstanten Kapitals, können aber unter bestimmten historischen Umständen die Kapitale entgehen: Indem sie nämlich in der zyklischen Krise die Preise nicht senken, versuchen sie die Profitrate auf ihr vorgeschossenes Kapital zu halten. Daß in diesem Prozeß nicht vorausgesetzt werden muß, daß die Preise willkürlich gesetzt werden können (etwa durch Monopole), sondern daß sich auch in der veränderten Preisbewegung die Gesetze der kapitalistischen Akkumulation geltend machen, werden wir im folgenden zunächst von der Produktionsseite, dann (im Teil 6) von der Seite der Realisierung der Waren her betrachten.

Hatten wir zuvor die (gesamtgesellschaftlich vermittelte) Entwertung von Kapital als Voraussetzung für ein erneutes Ansteigen des Verwertungsgrades bestimmt, so war darin zugleich für die Einzelkapitale die Vernichtung bzw. Brachlegung von vorgeschossenem Kapital gesetzt. Den Einzelkapitalen müssen so die in der Krise sich durchsetzenden Bedingungen eines erneuten Aufschwungs der Profitabilität notwendigerweise als Beeinträchtigung der Reproduktion ihres Kapitals erscheinen. Wenn die Kapitale daher in der Krise der Entwertung entgehen wollen, müssen sie Mittel und Wege finden, ihre vorgegebene Profitrate.zu halten. Sie werden zunächst versuchen, ihre Produktionspreise auf dem Markt durchzusetzen, denn allein dann könnten sie dieses Ziel erreichen.

Dabei muß allerdings davon ausgegangen werden, daß die Stellung der großen

Ebd., S. 249 
und die Stellung der kleinen Einzelkapitale im Reproduktionsprozeß sich unterschiedlich auswirken kann. Große Einzelkapitale können auf drei Momente ihrer Reproduktion und Verwertung begrenzt (nämlich begrenzt durch den gesamtgesellschaftlichen Reproduktionsprozeß) Einfluß nehmen: Erstens auf den Marktpreis des eigenen produzierten Warenkapitals, um seine Realisierung in Geldkapital zu verbessern. Zweitens auf die Marktpreise anderer Einzelkapitalisten. Hier (beim Kauf von Produktionsmitteln für den eigenen Produktionsprozeß) kann die Stellung großer Kapitale dazu führen, daß für die entsprechenden Einzelkapitale die Realisierung des Warenkapitals in Geldkapital nur zu gesellschaftlich unterdurchschnittlichen Bedingungen möglich ist. Damit werden für diese Einzelkapitale die Möglichkeiten der erweiterten Reproduktion beschränkt, insofern Teile des Mehrwerts zu dem großen Einzelkapital fließen und der akkumulationsfähige Mehrwert der anderen Einzelkapitale verringert wird. Zugleich wird nicht nur die akkumulationsfähige Mehrwertmasse des großen Kapitals erhöht, sondern auch - da ja der Kapitalvorschuß auch bei einfacher Reproduktion sich verringert hat - zusätzlich Kapital zum Zwecke der erweiterten Reproduktion freigesetzt (80). Drittens kann das Einzelkapital auf den Preis der Ware Arbeitskraft Einfluß zu nehmen versuchen, indem entweder der Preis der Arbeitskraft direkt gedrückt wird (Nominallohnsenkung) oder indem die in die Reproduktion der Arbeitskraft eingehenden Lebensmittel verteuert werden (Reallohnsenkung) oder indem der Nominallohn durch Intensivierung der Arbeit oder Verlängerung der Arbeitszeit indirekt gesenkt wird.

Soweit aber die kleinen Kapitale nicht ganz der Krise zum Opfer fallen (Pleiten, Konkurse, Fusionen), sind sie gezwungen (aufgrund der gesamtgesellschaftlich sich durchsetzenden Reproduktionsbedingungen, vgl. dazu unten) ein ähnliches Preisverhalten in der Krise durchzusetzen: Auf die in der Krise sich durchsetzende Einschränkung ihrer Verwertung müssen sie als Einzelkapitale (ähnlich wie die großen Kapitale) so reagieren, daß in ihrer Preissetzung die monetäre Profitrate gehalten und der Kapitalvernichtung entgangen werden kann.

Damit ist aber das Verhältnis von Preissetzung zu Akkumulationsprozeß des Kapitals als Problem benannt, das wir im folgenden zunächst aus der Sicht des Einzelkapitals untersuchen werden, um dann den bei der Ableitung des Marktproduktionspreises entwickelten Zusammenhang von Preisbildung (resp. -setzung) und gesamtgesellschaftlichem Reproduktionsprozeß des Kapitals wieder aufzunehmen.

\subsubsection{Preissetzung aus der Sicht der Einzelkapitale}

Wir werden zunächst einige bürgerliche und marxistische Ansätze zur Erklärung der langfristigen Preissteigerungen diskutieren und aufzuzeigen versuchen, welche Oberflächenzusammenhänge sich darin reflektieren und welche Voraussetzungen darin enthalten sind. In den folgenden Theorien werden zumeist in richtiger Weise Bewe- 
gungen und Kausalzusammenhänge der Oberfläche der Kapitalakkumulation aufgenommen. Sie haben daher zunächst auch den Anschein der Plausibilität für sich. Um so mehr ist es nötig, nicht nur die Voraussetzungen dieser theoretischen Ansätze und ihren begrenzten Erklärungswert für den Wert- und Preisbildungsprozeß im wirklichen Akkumulationsprozeß aufzuzeigen, sondern auch selbst die Vermittlung von Wertbildung, Verwertung und Preisbildung im Prozeß der Kapitalakkumulation zu entwickeln.

Die gemeinsame Grundlage der folgenden Erklärungsansätze ist die Produktionspreiskategorie, von der wir auch bei der Diskussion dieser Ansätze ausgehen müssen. Andererseits beziehen sich die folgenden Ansätze auf die auf der Ebene der Konkurrenz ansetzenden Reaktionen der Einzelkapitale; sie sind somit theoretischer Reflex der Aktion der Einzelkapitale. Auf der Ebene der Konkurrenz lassen sich - wenn wir die Möglichkeit der Preissetzung durch alle Kapitale mit einbeziehen - mehrere Versionen der Bildung von Produktionspreisen darstellen: (81)

1. Es wird angenommen, daß der Geldlohn für das Kapital (die variable Kapitalanlage) gegeben ist, wodurch der Mehrwert pro Ware und pro Arbeitskraft und die Mehrwertrate eindeutig bestimmt sind (durch die von Marx entwickelten Methoden der Mehrwertproduktion). Wie die Profitrate (82) durch die Mehrwertrate und durch die organische Zusammensetzung des Kapitals in ihrer Größe eindeutig begrenzt ist, so werden auch die Produktionspreise durch den Lohnsatz, die organische Zusammensetzung und die Durchschnittsprofitrate eindeutig determiniert. Dies ist auch der von Marx im Bd. III des „Kapitals“ unterstellte Prozeß der Produktionspreisbildung und dies ist auch der Prozeß der Bildung von Produktionspreisen, wie er sich über einen Zyklus hinweg darstellt.

2. Eine andere Möglichkeit ergibt sich, wenn man diesen von Marx unterstellten und von uns zuvor auch entwickelten Kausalnexus umkehrt. Eine Reihe von Theoretikern unterstellen etwa, daß die großen Kapitale eine ihrem Investitionsbedarf entsprechende Profitrate kalkulieren und diese mit entsprechenden Preissetzungen auf den Märkten auch in der Phase der Überakkumulation und der Krise durchsetzen. Spielt man diese Möglichkeit durch, so ergibt sich eine Umkehrung des obigen Zusammenhangs. Bei einer gegebenen organischen Zusammensetzung des Kapitals ergeben sich hier die Produktionspreise, der Reallohn und auch die Mehrwertrate als Restgrößen, die durch die relativ autonom festgesetzten Profitraten bestimmt sind. Die Profitraten sind nach diesen Vorstellungen so kalkuliert, daß sie für die wachsenden Kapitalinvestitionen ausreichen (83).

Hier werden also die Preise und die Ausbeutungsrate über das willkürliche Profit- und Preisverhalten der großen Kapitale bestimmt. Man spricht daher

Vgl. Joan Robinson, Collected Economic Papers, Vol. III, Oxford (Basil Blackwell)1968, S. $173 \mathrm{ff}$.

82 Die Aufteilung in Zins und Unternehmergewinn ist hier nicht entwickelt.

83 Vgl. Deutschmann, Levinson, Mattick, a. a. O. 
auch von der Ausbeutung durch die Inflation. Das zu erklärende Phänomen der säkularen Preisentwicklung wird nur auf der monetären Ebene (des Geldausdrucks des Werts) abgeleitet.

3. Eine dritte Möglichkeit ergibt sich durch die Annahme, daß Geldlohn und Profitrate (in monetären Größen) gleichzeitig bestimmt werden; etwa der Geldlohn durch die gewerkschaftlichen Lohnforderungen (in denen die Inflationsrate bereits antizipiert ist) und die nominelle Profitrate durch die Profitratenkalkulation der großen Kapitale. Die Inflation erscheint hierdurch als Resultat der Machtauseinandersetzung zwischen Kapital und Arbeit um die Verteilung des Nettoprodukts. Ein solches Verhalten von Kapital und Arbeit wird in einigen Theorien (z. B. in den Gutachten des Sachverständigenrats) auch zur Ursache der überzyklischen Inflationserklärung verkehrt. Daran knüpfen auch so gängige Infltionserklärungen wie die der „Lohn-Preis-Spirale“ (wage-push-theory)und die der „Profit-Preis-Spirale“ (profit-push-theory) an. Dabei wird das ,typische" Verhalten der Einzelkapitale in der Konkurrenz zum Ausgangspunkt der Erklärung genommen - was nichts erklärt.

Eine der bekanntesten bürgerlichen Theorien zur Erklärung der Inflation setzt bei dem Lohn-Preisverhältnis an, die steigenden Preise zu erklären. Welche Wirkungen haben nun allgemein oder im besonderen Produktionszweige steigende Geldlöhne auf die Produktionspreise? Steigende Löhne - etwa in Phasen prosperierender Kapitalakkumulation - beschränken zunächst nur die Profite und drücken sowohl die gesellschaftliche wie die von den Einzelkapitalen realisierte Durchschnittsprofitrate herab. Da in jeder Branche die höheren Löhne und die niedrigeren Durchschnittsprofitraten die Produktionspreise in unterschiedlichem Ausmaß verändern (je nach vorherrschender organischer Zusammensetzung), dürften sich zunächst nur die relativen Preise verändern (die komplizierten Rückwirkungen auf die Preise der Produktionsmittel und Konsumguter wollen wir hier vernachlässigen).

Steigen aber dennoch die Preise, so ist die eigentliche Ursache in dem Versuch der Kapitalisten zu sehen, die gleiche Profitmasse oder gar die gleiche Durchschnittsprofitrate wie zuvor zu erhalten. Wenn etwa in dem Produktionspreis einer von uns betrachteten Ware $\left.\left(\mathrm{ci}_{\mathrm{i}}+\mathrm{vi}_{\mathrm{i}}\right) 11+\mathrm{P}^{\prime}\right)=\mathrm{p}_{\mathrm{i}}$ ist, und der Lohn und damit die variable Kapitalauslage von vi auf v'i ansteigt, muß der Versuch seitens der der Kapitalisten, die gleiche Profitmasse bzw. Profitrate wie zuvor zu erhalten, Preissteigerungen von $\mathrm{p}_{\mathrm{i}}$ auf $\mathrm{p}^{\mathrm{p}} \mathrm{i}$ hervorrufen (84). Die Ursache an den steigenden Preisen bei steigenden Geldlöhnen ist daher nicht bei den Geldforderungen der Arbeiter zu suchen, sondern bei dem Versuch der Kapitalisten, eine adäquate Durchschnittsprofitrate aufrechtzuerhalten.

Wird die erste These - bekannt unter dem Begriff der Lohnpreisspirale - von Wirtschaftswissenschaftlern, von Kapitalvertretern und vom Staat vertreten, so rückt die gängige gewerkschaftliche Erklärung der Inflation das Verhältnis von Profiten zu Preisen in den Vordergrund, wenn sie überzyklische Preissteigerungen erklären wollen. Die Preis- und Investitionspolitik der Unternehmen ist nach dieser

Vorausgesetzt, $\mathrm{c}$ und $\mathrm{v}$ schlagen gleich um und ihre Umschlagszeit ist gleich 1 
Theorie weitgehend autonom - unterstellt also oligopolistische oder monopolistische Märkte, bzw, eine entsprechende Gesamtnachfrage.

Die Erklärung steigender Preise aus dem Profit-Preis-Verhältnis gilt in eingeschränktemt Sinne bereits für den ersten Ansatz. Der Ausgangspunkt für Preisveränderungen ist aber bei der Lohn-push-Theorie das Faktum der steigenden Gehlöhne (oder schneller als die Produktivität steigenden Löhne). Der Versuch der Unternehmer, die Profitrate - oder doch zumindestens eine entsprechende Profitmasse - zu halten, bestimmt die relativen Preise und die Veränderung des absoluten Preisniveaus.

Anders verläuft das „,Kausalverhältnis ${ }^{66}$, wenn angenommen wird, daß die Profit- und Preisgestaltung der Kapitale autonom erfolgen könne. Der Produktionspreisbildungsprozeß verläuft demgemäß andersherum: bei einer vor der Produktion vom Kapital bestimmte Profitrate $\mathrm{P}^{\prime}$ bei vorgegebenen Produktionspreisen der in die Produktion eingehenden Produktionsmittel und bei vorgegebenem Geldlohn sind die Produktionspreise bestimmt - und damit auch das Preisniveau der in die Arbeitskraft eingehenden Konsumgüter. Der Reallohn wird hierbei zur Residualgröße, der entsprechend gesenkt wird, wenn die Gewerkschaften nicht ihrerseits versuchen, die Geldlohnentwicklung der allgemeinen Preissteigerung anzupassen. Fordern die Arbeiter bzw. die Gewerkschaften aber wiederum eine höhere Geldlohnrate, in der die Inflationsrate und der Reallohnverlust antizipiert wird - wie dies in jedem Tarifvertrag erfolgt -- müssen sich nicht nur die relativen Preise verändern, sondern es muß auch das allgemeine Preisniveau steigen. Dadurch mißlingt der Versuch, die Explotationsrate über steigende Preise zu erhöhen. Die Schuld an steigenden Preisen kann aber wiederum nicht den Geldlohnforderungen der Arbeiter zugeschoben werden, vielmehr sind steigende Geldlöhne nötig, die Inflationsrate zu kompensieren.

Sowohl die Erklärung der Inflation aus dem Lohn-Preis-Verhältnis wie aus dem Profit-Preis-Verhältnis unterstellt, daß ein Durchschnittsprofit (oder mehr als ein gängiger Durchschnittsprofit, wie im 2. Fall) auf den Kostpreis aufgeschlagen wird und realisierbar ist. Zudem erscheint die Inflation als Resultat der Machtauseinandersetzung zwischen Kapital und Arbeit um die Verteilung des Nettoprodukts. Warum es allerdings zu säkular steigenden Preisen und zu steigenden Preisen auch in der Krise kommt, kann hier nicht hinlänglich erklärt werden, da auf strukturelle Veränderungen im Kapitalverwertungsprozeß gar nicht eingegangen wird.

In weiteren Versionen werden solche Strukturveränderungen im Verlauf der kapitalistischen Akkumulation zwar berücksichtigt, diese aber nur als veränderte Konkurrenzformen auf dem Markt behauptet:

Ausgehend von der gemeinsamen Annahme, daß mit der Konzentration und Zentralisation des Kapitals auch veränderte Markt- und Konkurrenzformen entstanden seien, sind mehrere differenziertere Versionen zum Problem der säkularen Preissteigerungen entstanden. Typisch ist für diese Positionen, daß sie ebenfalls alle - wie bereits die Profit-push-Theorie - eine Preissetzungsmacht der großen Kapitale auf den Märkten unterstellen.

Einer Version zufolge sinken die Preise langfristig deshalb nicht ab, weil insbesondere die großen Kapitale - die zumeist überdurchschnittliche Produktivitätssteigerungen aufweisen - die Produktivitätssteigerungen nicht in Preissenkungen wei- 
tergeben. Steigern etwa die großen Kapitale die Produktivität der Arbeit in überdurchschnittlicher Weise (Extramehrwertproduktion), drängen sie kleinere Kapitale aus dem Markt und werden sie durch die Konkurrenz nicht zu Preisherabsetzungen gezwungen, dann werden sich Produktivitätssteigerungen und Wertsenkungen nicht notwendigerweise als Preissenkungen auswirken. Die Preise werden gehalten und der Extramehrwert wird fixiert solange die Nachfragesituation dies zuläßt. Da diese Waren aber in die Produktion anderer Waren eingehen, können auch die anderen Kapitale die Preise nicht senken. Steigen aber andererseits noch die Geldlöhne - etwa durch eine beschleunigte Kapitalakkumulation, Verknappung der Arbeitskräfte und steigender Lohnverhandlungsmacht der Gewerkschaften - können zwar die großen Kapitale bei gleichbleibenden Produktionspreisen die Profitmargen halten. Die Kapitale oder Branchen mit geringerer Produktivitätsentwicklung sind aber gezwungen - wenn sie die branchenübliche Profitrate wie zuvor halten wollen - die Produktionspreise zu erhöhen. Jede Kostpreiserhöhung erzwingt aber (bei gleichbleibender Profitrate) wieder Produktionspreiserhöhungen. Die großen Kapitale könnten durch Preisfortwälzung ihre Extramehrwertposition halten und die kleineren Kapitale ihre Durchschnittsprofite (solange die Nachfragesituation dies zuläßt). Eine allgemeine Preissteigerung wäre die Folge. (Dieselbe Auswirkung hätten überdies Preissteigerungen von fixem Kapital, Rohstoffen usw.) Dementsprechend erscheinen nach diesem Modell die kleinen Kapitale oder Branchen mit niedrigerer Arbeitsproduktivität als Urheber dieser Preissteigerungen, wenngleich doch der Ausgangspunkt dieser Bewegung die großen Kapitale oder hochkonzentrierten Branchen sind.

Andererseits wird die säkulare Aufwärtsbewegung der Preise direkt aus der Anderung der Marktformen und dem willkürlichen Preis- und Profitverhalten der Monopole und großen Kapitale abgeleitet. W. Hofmann hat diese Version nachhaltig vertreten: „,Die säkulare Inflation ist das Ergebnis verallgemeinerter Machtpreisbildung. Sie steht in ursächlichem Zusammenhang mit einer anderen durchgängigen Erscheinung unserer Epoche: der planvollen privaten Organisierung und Durchgestaltung der Märkte" (85). Die Erklärung der säkularen Inflation aus der oligopolitischen oder monopolistischen Machtpreisbildung dominiert auch in der Theorie vom Staatsmonopolistischen Kapitalismus. Gemeinsames Merkmal dieser Theorien ist die Annahme einer kalkulierten (monetären) Profitrate (,markup“). Die Anbieter gehen im allgemeinen nach der Regel vor, „den Produktionskosten einen bestimmten ,markup' zuzuschlagen, also mit einem ganz bestimmten Gewinnzuschlag zu operie$\operatorname{ren}^{66}(86)$.

Diese Begrïndung der Inflation von dem willkürlichen Preis- und dem Gewinnaufschlag her scheint uns ebenso unzureichend zu sein wie die Erklärung mit Hilfe der Extramehrwertposition, da auch hier weder der langfristige Prozeß 3 der Veränderung der Struktur des gesellschaftlichen Gesamtkapitals in diese Erklärungen Eingang gefunden hat, noch das Problem der Nachfrage genügend berücksichtigt

85 Hofmann, a. a. O., S. $18 \mathrm{ff}$.

86 Gerd Maas, Inflation und Industriepreis, Gersthofen 1974, S. 28 
wird. Gemeinsamer Ausgangspunkt dieser Theorien ist die Annahme einer kalkulierten monetären Profitrate mit entsprechenden Konsequenzen für die Preisbildung (markup-pricing). Während noch in der Marxschen Theorie Produktionspreisbildungsprozeß durch den Kausalnexus

Mehrwertrate, Profitrate, Produktionspreis

gekennzeichnet war, kehrt sich hier die Beziehung um. Wie bereits analysiert, verläuft hier die Kausalbeziehung von der (monetären) Profịtrate zur Mehrwertrate, nimmt also folgende Gestalt an:

Profitrate Produktionspreise Mehrwertrate.

Ob diese Art des Produktionspreisbildungsprozesses mit zunehmender Konzentration und Zentralisation des Kapitals oder in Phasen prosperierender Kapitalakkumulation tatsächlich dominiert, können wir hier nicht weiter untersuchen.

Halten wir jedoch zusammenfassend fest: Die in den hier angeführten Theorien sich reflektierenden Reaktionsweisen der Einzelkapitale sind unzulängliche Erklärungsmomente,

1. weil sie den Anschein erwecken, als könnten die Einzelkapitale ihre gesellschaftlichen Durchschnittsbedingungen selbst setzen; gerade vom Prozeß der Marktproduktionspreisbildung als Resultat des widersprüchlichen Prozesses von privater Produktion und ihrer gesellschaftlichen Bestimmtheit wird abstrahiert. Denn weder Einzelkapitale überhaupt noch große Einzelkapitale (z. B. Monopole) können ihre (gesellschaftlich notwendigen) Produktionsbedingungen und das gesellschaftlich notwendige Quantum an Waren allein festsetzen. Auch hier erweist sich das gesellschaftlich Notwendige immer noch als Zwangsgesetz.

2. weil das damit als gelöst unterstellte Problem der Nachfrage und der Realisierung der Waren eben nicht unterstellt werden kann.

3. weil in diesen Theorien nicht mehr sichtbar ist, in welcher Weise sich Veränderungen in den Bedingungen der Reproduktion des gesellschaftlichen Gesamtkapitals in der Aktion der Einzelkapitale widerspiegeln.

\subsubsection{Preissetzung und gesamtgesellschaftliche Reproduktion des Kapitals}

Wenn wir dagegen im folgenden von der Produk tionsseite her inflatorische Prozesse begründen, ist für uns das zentrale Problem, daß die Einzelkapitale zwar scheinbar - indem sie ihren nominellen Durchschnittsprofit auf die Kostpreise aufschlagen ihre Durchschnittsbedingungen (in den Produktionspreisen) setzen können, daß sich aber gesamtgesellschaftich real wieder die Zwange dêr Kapitalreproduktion letztlich in der Aktion der Einzelkapitale reflektieren. Wenn auch wir hier von der Möglichkeit der Einzelkapitale, ihre Produktionspreise auf dem Markt zu setzen, ausgehen, dann deshalb, weil mit der Loslösung des Geldzeichens von der Goldware und der Entwicklung des Kreditsystems solcherlei Preissetzung in einer Geldware als begrenztes Zirkulations- und Zahlungsmittel keine Beschränkung mehr findet. Diese Veränderung in der Geld- und Kredîtsphäre (die wir bereits im Tell 2 als technische Moglichkeit der Inflation bestimmten) ist notwendige Bedingung dafür, dałs es zu 
einer Preissetzung, mit deren Hilfe der Entwertung entgangen werden soll, kommen Kann. Wie sich unter diesen Voraussetzungen und einer zunehmenden organisetrem Zusammensetzung des Kapitals, einem Ansteigen von fixierten Kapitalmassen in der Krise und einem steigendem Anteil beschränkt reproduzierbares Produktionsmittel ein überzyklischer Preisauftrieb entwickeln kann, soll wieder an einer durchschnittlichlichen Ware einer bestimmten Produktionssphäre erläutert werden.

Wenn etwa der konstante Kapitalanteil gegenüber dem variablen sowohl im Laufe des Akkumulationsprozesses als auch erst recht in der Phase der Krise (bei „Unterauslastung“ des Kapitals) zunimmt, spiegelt sich dies auch normalerweise in der Struktur des Kostpreises der Durchschnittsware einer Branche wider. Auch hier nimmt der konstante Kapitalanteil bzw. der Anteil der „Fixkosten“ in der Krise gegenüber dem variablen zu. Wird aber weiterhin von den Einzelkapitalen in jedem Produktionszweig ein monetärer Durchschnittsprofit kalkuliert, mit dessen Hilfe z. B. der Entwertung von Kapital in der Krise entgangen werden soll, dann können auch die Produktionspreise nicht mehr sinken, sondern werden sogar noch steigen. Der Produktionspreis der von uns betrachteten Ware konnte folgendermaßen zusammengefaßt werden:

$$
(\mathrm{ci}+\mathrm{vi})\left(1+\mathrm{P}^{\prime}\right)=\mathrm{pi}_{\mathrm{i}}
$$

Steigt der konstante Kapitalanteil von ci auf ci (87) und wird trotz abgesunkener Profitrate dieselbe Profitrate P' von den Einzelkapitalen kalkuliert, dann müssen die Preise trotz Produktivitätssteigerungen gleichbleiben oder steigen. Erst recht müssen die Produktionspreise steigen, wenn auch die Reallöhne mit der Produktivität sich erhöhen und dadurch die variable Kapitalauslage ansteigt. Wir erhalten dann folgende gestiegene Produktionspreise: $\left(\mathrm{ci}_{1}+\mathrm{vi}\right)\left(1+\mathrm{P}^{\prime}\right)=\mathrm{pi}$.

Diese Preissteigerungen infolge einer steigenden Kapitalzusammensetzung, wären also letztlich darauf zurückzuführen, daß nicht eine (der gestiegenen organischen Zusammensetzung entsprechende) verminderte Durchschnittsprofitrate, sondern die alte, erfahrungsgemäß bezogenen Profitrate kalkuliert wird. Diese Überlegung gilt auch, wenn sich die Umschlagszeit des Kapitals verlangsamt und mehr Kapital durch die verringerte Umschlagszeit gebunden wird (vgl. Teil 3.1); wenn in einer Stagnationsphase Warenkapital brachliegt, fixes Kapital unausgelastet bleibt und Warenlager sich häufen, erhöht sich der Kapitalvorschuß für die Produktion. Wird weiterhin dieselbe Profitrate wie zuvor kalkuliert, müssen die Preise notwendigerweise steigen.

Die wesentliche Frage, die diese Erklärung der Preissteigerung jedoch aufwirft ist aber, ob die Kapitale die entsprechende kalkulierte Profitrate (P') trotz allgemein abgesunkener Profitrate und die entsprechenden Produktionspreise $(\mathrm{Pi})$ durchsetzen und halten können. Dies betrifft nicht nur das Realisierungsproblem (vgl. Teil 6), sondern vor allem auch die Frage, wie sich die fallende Profitrate denn jetzt eigentlich geltend macht. Es ist zwar möglich, daß das einzelne Kapital zunächst keine Rücksicht auf die langfristig sich verändernde allgemeine Profitrate nimmt und es

87 Die folgenden Überlegungen gelten auch für die Fixkosten, soweit sie nicht im Fixkapital ihre Utsache haben wie,Teile des variablen Kapitals. 
scheinbar unabhängig davon eine erfahrungsgemäße monetäre Durchschnittsprofitrate kalkuliert, dennoch muß sich die Veränderung der allgemeinen Profitrate irgendwie Geltung verschaffen!

Tatsächlich hat ja die Kalkulation der erfahrungsgemäßen monetären Profitrate Rückwirkungen auf die Produktionsmittelpreise. Durch das Ansteigen der Produktionspreise von pi auf pl steigen auch die Preise für das konstante Kapital wieder an. Dieser Preisanstieg wird nicht nur das zirkulierende, sondern auch das fixe Kapital betreffen. Dadurch ist aber die Wiederbeschaffung des konstanten Kapitals in seiner alten stofflichen oder in neuer Form teurer geworden. Die geplanten und realisierten monetären Profitraten und Profitmassen erweisen sich durch den Preisanstieg des konstanten Kapitals gewissermaßen als ,entwertet ${ }^{66}$. Es können nicht mehr dieselben Kapitalmassen wie zuvor beschafft werden. Ex post, d. h. nach dem Prozeß der Produktionspreisbildung, zeigt sich auch, daß der absinkenden Tendenz der allgemeinen Profitrate nicht entgangen werden kann, denn die allgemeine Profitrate wird nach den Preissteigerungen des konstanten Kapitals wieder ein niedrigeres Niveau aufweisen müssen. Die Verteuerung des konstanten Kapitals und die Erhöhung des variablen Kapitals dem Geldausdruck nach lassen die gesamtgesellschaftliche Profitrate also dennoch - trotz der erfahṛungsgemäß kalkulierten alten Profitrate - absinken. Die Einzelkapitale können dieser Veränderung der Kapitalstruktur und der Veränderung der gesamtgesellschaftlichen Proportionen nicht entgehen. Der Versuch der Kapitale, diesen Veränderungen zu entgehen, indem sie dieselbe Profitrate wie zuvor kalkulieren, muß sich vielmehr in einem säkularen Preisanstieg ausdrücken (88).

Wir haben bisher (am Beispiel der Durchschnittsware einer Branche) den ökonomischen Zwang entwickelt, denen die Einzelkapitale durch veränderte Reproduktions- und Akkumulationsbedingungen ausgesetzt sind. Ein Aufschieben der Entwertung durch Preissetzung (Profitratenkalkulation) ist aber im zyklischen Prozeß (und hier besonders in der Krise) für große und für kleine Kapitale, ihre Reproduktion zu vollziehen, unterschiedlich: Große Kapitale können sich aufgrund hoher Kapital- und Profitmassen wahrscheinlich eher der drohenden Entwertung von Waren- und produktivem Kapital entziehen, indem sie - wir gingen bereits darauf ein - größere Möglichkeiten haben, ihre Verwertungsprobleme abzuwälzen; indem sie über Extraprofite, die einer verhältnismäßig höheren Produktivkraft geschuldet sind, ihre Verwertung noch verbessern können; indem sie durch den günstigen Aufkauf kleinerer Kapitale ihre Konkurrenzbedingungen günstiger machen können. Teils aufgrund dieser ungleichen Konkurrenzbedingungen, teils - und das ist hier der wesentliche Aspekt - aufgrund mangelnder realer Verwertung des Gesamtkapitals und damit verschlechterten Nachfrageverhältnissen für alle wird es trotzdem zu Entwertungsvorgängen kommen. Gelingen andererseits dennoch die Versuche der

Diese Ableitung der Preissteigerungen aus der gestiegenen Kapitalzusammensetzung und fallenden Profitrate würden nicht beeinträchtigt, wenn unterschiedliche Branchenprofitraten (vgl. den Branchenteil in PROKLA 16) angenommen würden. Die Ableitung wäre nur etwas komplizierter. 
großen Masse der Kapitale, ihre Preise gemäß kalkulierter Profitrate zu setzen, so müssen veränderte Nachfrage- und Kreditverhältnisse hier eine wichtige Rolle spielen. Um daher das hier schon angedeutete Problem der Inflation bei stagnierender Akkumulation (,Stagfaltion") erklären zu können, müssen wir die veranderten Nachfrage- und Kreditverhältnisse im entwickelten Kapitalismus darstellen.

\section{Kapitalreproduktion, Nach frage und Kreditsystem}

Wären die Nachfrage- und Kreditverhältnisse unabhängig von der Kapitalreproduktion und zyklischen Akkumulation, so könnte die aktuelle Inflation schnell mit einer „Übernachfrage“ (so die Neokeynesianer) oder einer übermäßigen „Geldschöpfung" (so die Monetaristen) erklärt werden. Jede auch in der Krise bewirkte Nachfrageausweitung und/oder Geldmengenausweitung würde so Entwertungsprozesse verhindern. Nachfrage- und Kreditverhältnisse sind aber - wie wir schon im Teil 4 bei Darstellung des industriellen Zyklus gesehen haben - abhängige Variablen, Produkt der spezifischen ökonomischen und sozialen Reproduktion.

Zunächst können wir festhalten, daß eine bestimmte ,Basis“-Nachfrage auch in der Krise niicht absinken kann: der Konsum der staatlichen Lohnarbeiter und der unproduktiven Arbeiter des Kapitals wird in der Regel aufrechterhalten, und ,wie ... die Dinge liegen, hängt der Ersatz der in der Produktion angelegten Kapitale großenteils ab von der Konsumtionsfähigkeit der nicht produktiven Klassen" (89). Andererseits wird die Konsumtion der Arbeiter, die ,teils durch die Gesetze des Arbeitslohns, teils dadurch beschränkt ist, daß sie nur solange angewandt werden, als sie mit Profit für die Kapitalistenklasse angewandt werden können“ (90), durch sozialstaatliche Maßnahmen im entwickelten Kapitalismus zumindest nicht in einem solchem Maße gesenkt, daß einschneidende Beschränkungen der Nachfrageverhältnisse von dieser Seite her wirksam würden (Bedeutung der Arbeitslosen- und Sozialversicherung) (91).

Auch wirkt sich der relativ große Anteil des Staats am Wertprodukt, dessen Ausweitung wir in anderem Zusammenhang schon begründet hatten, dahingehend aus, daß der Versuch der staatlichen Fiskalpolitik, antizyklische Wirtschaftspolitik durchzusetzen, die Nachfrageverhältnisse beeinflußt: Der staatliche Konsum und die staatlichen Investitionen werden in der Krise aufrechterhalten (auf Kosten einer wachsenden staatlichen Verschuldung) und stützen die Nachfrageverhältnisse.

Eine solche Stützung der Nachfrage wird allerdings nicht imstande sein, den Nachfrageausfall, der durch die stockende Kapitalakkumulation bewirkt ist (Sinken der Nachfrage in der Abteilung I und zwischen den Abteilungen aufgrund mangelnder Profitabilität der Produktion und sinkenden Löhnen) auszugleichen. Zumal

Kapital III, S. 501

90 Ebd.

91 Die Finanzierung dieser Sozialmaßnahmen ist natürlich selbst abhängig von der Entwicklung des Profits des Kapitals und der Einkommen der beschäftigten Arbeiter im Zyklus. 
langfristig die zusätzliche Nachfrage des Staates in der Krise aus dem Wertprodukt bezahlt werden muß und dies die Produktion bzw. Profitabilität des produktiven Kapitals weiter einschränkt. Wenn dies nicht sogleich der Fall ist, so deshalb, weil zunächst überhaupt zwischen die Kapitale und zwischen das industrielle Kapital und den Staat oder die Lohnarbeiter die Kreditsphäre als eine Vermittlungsinstanz tritt, die es Kapitalen, Staat, Kapitalisten und Arbeitern ermöglicht, zu kaufen, ohne zugleich zu bezahlen. Das Geld in seiner Funktion als Zahlungsmittel ermöglicht das Auseinanderfallen von Kauf und Realisierung des Preises.

\subsection{Geldzirkulation und Kredit}

Die Geldzirkulation in entwickelten kapitalistischen Ländern resultiert (wie schon in Teil 2 entwickelt) nicht ausschließlich aus der Funktion des Geldes als Zirkulationsmittel, sondern auch aus seiner Funktion als Zahlungsmittel. Als einfache Zirkulationsmittel fungieren Scheidemünzen und Zentralbanknoten oder Staatspapiergeld mit Zwangskurs. Sie sind nur noch Wertzeichen (bei realer Konvertibilität in Gold) und vollziehen als solche die Funktion der Geld-und Warenzirkulation, ohne wirklicher Wert zu sein, ja, sie brauchen ihn noch nicht einmal unbedingt zu repräsentieren. Sie können somit zu bloßen Symbolen für Geld (Gold) werden, obgleich diese Symbole je nach der „Härte“ der Währung von den Teilnehmern am Geschäftsverkehr mehr oder weniger ernst und gern genommen werden. „Nur bedarf das Zeichen des Geldes seiner eigenen objektiv gesellschaftlichen Gültigkeit und diese erhält das Papiersymbol durch den Zwangskurs“" (92).

Zahlungsmittelfunktion erfüllt das Geld dann, wenn Warenaustausch gegen Zahlungsversprechen erfolgt, also nicht der Warenübereignung unmittelbar die entsprechende Übereignung des Geldbetrags folgt, sondern ein Kreditverhältnis zwischen Käufer und Verkäufer entsteht, die sich demzufolge auch in Schuldner und Gläubiger verwandeln. Technisch erfolgt dies dadurch, daß der Gläubiger auf den Schuldner einen Wechsel zieht, der für den Gläubiger sich in Geld verwandelt: die erste Möglichkeit besteht darin, daß er den Wechsel selbst als Zahlungsmittel benutzt, indem er durch seine Unterschrift unter den Wechsel und dessen Weitergabe an einen nächsten Gläubiger, der ihm Waren geliefert haben mag, ein Zahlungsversprechen zu einem bestimmten Termin leistet. Dieser Prozeß kann bis zum Verfallstag des Wechsels weitergehen und es können auf diese Weise eine Vielzahl von Warenübereignungen vorgenommen werden, ohne daß außer dem Wechsel irgendein anderes Zirkulationsmittel eine Rolle hätte spielen müssen. Die zweite Möglichkeit besteht darin, den Wechsel bei einer Bank zu repräsentieren und ihn diskontieren zu lassen, also den Betrag dem eigenen Guthaben gutschreiben zu lassen. Er kann dann darüber verfügen, indem er beispielsweise per Scheck bei Käufen von Waren seinerseits auf seine Bank, ,zieht". Die Bank wiederum kann den Wechsel „rediskontieren", indem sie ihn bei einer Zentralbank (Bundesbank oder Landeszentralbanken

Kapital I, S. 123 
in Westdeutschland) präsentiert und so in Geld umwandelt.

Neben diesen kommerziellen Kreditverhätlnissen, die sich aus dem Geschäftsverkehr mit Waren ergeben, tritt der Bankkredit immer dann, wenn eine Bank einem Kunden ein Konto einräumt (Kontokorrentkredit) oder ihm ein Darlehen gewährt oder eine Anleihe zuerst übernimmt, um sie erst anschließend beim „Publikum $^{66}$ unterzubringen etc. In allen diesen Fällen werden Geschäftsleute mit Geld ausgestattet, das sie zum Kauf von Waren verwenden können. Sofern die Waren ins Produktivkapital eingehen (Produktionsmittel und Arbeitskräfte), fungiert das Geld gleichzeitig als Geldkapital, vorausgesetzt der Kreditnehmer muß nicht ,Sicherheit t" $^{\text {" }}$ leisten. „Bewilligt die Bank dem Geschäftskunden eine Anleihe einfach auf seinen persönlichen Kredit, ohne Sicherheitsstellung seinerseits, so ist die Sache klar. Er erhält unbedingt einen Vorschuß von bestimmter Wertgröße als Zusatz zu seinem bisher verwandten Kapital. Er erhält ihn in Geldform; also nicht nur Geld, sondern auch Geldkapital" (93). Wenn allerdings das von Bankier vorgeschossene Geld dazu benutzt wird, Waren zur individuellen Konsumtion zu kaufen, so kann es nicht als Geldkapital fungieren, sondern nur als Kaufmittel, das durch das Kreditverhältnis entstanden ist.

So zeigt es sich, daß die Geldzirkulation zwei verschiedene, ineinander verschränkte Kreisläufe umfaßt. Als Zirkulationsmittel d. h. als Kaufmittel, fungiert es in der Regel zum Umsatz der Revenue der Lohnarbeiter und auch der Kapitalisten ,wegen der Zersplitterung dieser Käufe und Verkäufe, und weil die Mehrzahl der Revenue-Ausgebenden, die Arbeiter, relativ wenig auf Kredit kaufen können" (94). Im „Verkehr der Handelswelt hingegen fungiert das Geld wesentlich als Zahlungsmittel; Wechsel und andere Kreditformen beherrschen hier den Zahlungsverkehr und besorgen so die Metamorphosen des Kapitals in seinem Kreislauf. Anders ausgedrückt: Ist das Geld eher Geldform der Revenue der Arbeiter und Kapitalisten, dann fungiert es hauptsächlich als Zirkulationsmittel, ist das Geld eher Geldform des umlaufenden Kapitals, dann fungiert es hauptsächlich als Zahlungsmittel. Insbesondere durch bargeldlose Lohn- und Gehaltszahlungen fungiert in zunehmendem Umfang auch in der sogenannten ,kleinen Zirkulation" (Revenuezirkulation) das Geld als Zahlungsmittel (95).

\section{Kapital III, S. 444}

94 Ebd., S. 461

95 So kommt es auch, daß die Sichteinlagen (täglich abhebbare Konten) gegenüber dem Bargeldumlauf (Zentralbanknoten und Scheidemünzen) in der BRD stark zugenommen haben. Kamen im Jahre 1955 auf 100 DM Bargeld 124 DM Sichteinlagen, so waren es 1960 bereits 145 DM, 1965 schon 164 DM und 1973204 DM. Eine ebenso große Bedeutung für die Geldzirkulation spielen mittlerweile Termingelder mit einer Laufzeit bis unter 4 Jahren (sogenanntes Quaisgeld), die - auf 100 DM Bargeld gerechnet - 1955 erst 80 DM ausmachten, 1960 den Wert von 104 DM und 1965 von 95 DM erreichten, um 1972 nach einer gewaltigen Steigerung insbesondere seit 1967 auf den Wert von 203 DM anzusteigen. Während im Zeitraum von 1955 bis 1972 der Bargeldumlauf von 326 v. H. expandierte, nahmen die Kreidte der Banken an Unternehmen und Privatpersonen um 900 v. H. zu (Berechnungen nach Sachverständigenrat JG 1973 S. 234) Wenn auch ein Teil dieser Kredite nicht als Geldkapital verwendet worden sein dürfte, so ergibt sich doch aus diesen`Daten die gegenüber der Zirkulation von Staatspapiergeld mit Zwangskurs wachsende Bedeutung des Geldes als Zahlungsmittel, also des Kredits für den Geld- und Kapitalumlauf. 
Neben dem Bargeldumlauf, den kommerziellen und den Bankkrediten, spielt aber auch die Staatsverschuldung eine wichtige Rolle für die Geldzirkulation. Denn die vom Staat - oder von staatlichen Institutionen wie Bahn, Post usw. - gegebenen Anleihen verdoppeln sozusagen die Umlaufmittel: Für seine Anleihe erhält der Staat Geld, das er als solches verausgabt - für welche Zwecke auch immer; dies wird interessant zu untersuchen, wenn man die Konsequenzen der Staatsverschuldung für die Reproduktion des Gesamtkapitals untersucht. In der Regel wird es nicht als Kapital vorgeschossen, da ja der Staat nicht als Kapitalist fungiert. Derjenige, der die Anleihe zeichnet und die Papiere erhält - Schuldscheine, Obligationen - , besitzt damit Waren (fiktives Kapital), die er auf der Börse verkaufen und so in Kapital rückverwandeln kann (96). Sobald diese Scheine, indem sie als Aktiva bei Banken erscheinen, und darauf dann per Geldschöpfung des Bankensystems eine Kreditpyramide aufgebaut werden kann, zur Grundlage für erneute Bankkredite dienen, wird auch die Geld- und Kreditzirkulation ausgeweitet. Erst recht geschieht dies, wenn die Zentralbank diese „Papierchen“ als aktiven Gegenposten benutzt um ihrerseits Noten in Umlauf zu setzen. Diese Tatsache macht sich die Zentralbank zunutze mit ihrer "Offenmarktpolitik". Durch Kauf von solchen Papieren wird Geld (Noten und kurzfristige Anlagen) in die Zirkulation gegeben, durch Verkauf dieser Zirkulation dieses Geld entzogen.

Wie verhält sich nun die umlaufende Geldmenge zum Prozeß der Kapitalbewegung? Eine Antwort auf diese Frage, wie sie die Neoquantitätstheorie, aber auch keynesianische Varianten der Theorie des Staatsinterventionismus geben, muß von vornherein ausgeschlossen werden: Daß mit Hilfe staatlicher Regulierung der Geldmenge die Kapitalbewegung gesteuert werden könnte. Bei Marx heißt es dazu:

„Es gibt wohl keinen Punkt in der politischen ökonomie, über den ein so weitverbreitetes Mißverständnis besteht, wie über den, daß man vermittel Expansion oder Kontraktion der Zirkulationsmittel Einfluß auf das gesamte Preisniveau habe, einen Einfluß, den nach allgemeiner Ansicht die Notenbanken ausüben. Die Meinung, daß die Banken den Geldumlauf unmäßig ausgedehnt und so ein inflationistisches Absteigen der Preise erzeugt hätte, das schließlich durch einen Krach gewaltsam rückgängig gemacht werde, ist eine nur zu billige Methode, jede Krise zu erklären, als daß man nicht begierig nach ihr griffe. Wohlgemerkt, die Frage ist nicht, ob Banken zur Entwicklung eines fiktiven Kreditsystems beitragen können, sondern ob es in ihrer Macht steht, den Betrag an Zirkulationsmitteln zu bestimmen, der in den Händen der Bevölkerung umläuft" (97).

Bei der Zirkulation des Kredits und der auf den Kreditverhältnissen beruhenden „Papierchen“ ist dies ziemlich leicht zu klären. Denn kommerzielle Kredite entstehen erstens nur, wenn auch Warentransaktionen vorgenommen werden, wenn also gekauft und verkauft wird. Sie werden infolgedessen auch im Verlauf des ökonomischen Aufschwungs ausgeweitet. Die Nachfrage nach Kreditgeld steigt aber zweitens auch dann, wenn die Zirkulation der Waren stockt, also in der Phase

Kapital III, S. $493 \mathrm{f}$.

97 Karl Marx, Handelskrisen und Geldumlauf in England, in: MEW, Bd. 12, S. 544, ähnlich auch MEW, Bd. 25, S. 531 und 538 
rückgängiger und stockender Konjunktur. Denn die auf Kredit gekauften Waren müssen nun bezahlt werden, ohne daß die Waren auch in Geld, mit dem hätte bezahlt werden können, umgesetzt worden wären. So zeigt es sich, daß die Entstehung kommerzieller Kredite an den Gang der Akkumulation gebunden ist und diese keineswegs so etwas wie einen selbständigen Kreditzyklus konstituieren könnten. Ähnliches läßt sich von Expansion und Kontraktion der Bankkredite sagen. Es ist zwar das Geschäft der Bankiers, teurer auszuleihen als sie Einlagen aufnehmen, aber ob es zu entsprechenden Zinssätzen der von ihnen gewährten Kredite auch Kreditnehmer gibt, hängt letztlich vom Verhältnis von Zins und industriellem Profit also ebenfalls vom „,Gang der Geschäfte" in Industrie und Handel ab. Eine von den „Bedürfnissen des Verkehrs" (98) unabhängige Potenz der Banken, Geld- und Kreditschöpfung zu betreiben, gibt es nicht (99). Dies zeigte sich schon bei unserer Darstellung des klassischen industriellen Zyklus (vgl. Teil 4).

Indem die Geldzirkulation und der Kredit von dem Gang der Geschäfte abhängig sind, sind sie auch der Naturwüchsigkeit des Gangs der Kapitalakkumulation unterworfen. Daher kann auch die zeitweise Verselbständigung des Kreditzyklus gegenüber dem Industriezyklus (100) niemals mehr sein als die aufgrund der Verdoppelung der Ware in Ware und Geld im Geld der kapitalistischen Produktionsweise notwendigerweise gesetzte Verselbständigung des Werts, die aber immer nur eine scheinbare ist. In der Krise werden die verselbständigten Momente auch immer wieder gewaltsam zusammengebracht. Verselbständigung bedeutet aber auch, daß Warenkapital als ruhendes Kapital für den Kapitalisten ,,keinen Wert hat". Es muß in sein anderes Dasein mit allgemeiner gesellschaftlicher Gültigkeit, nämlich in Geld und in diesem Fall in Geldkapital verwandelt werden. Anders ausgedrückt: der Preis des Warenkapitals muß realisiert werden.

\subsection{Preissetzung und Realisierung (101)}

Der gesetzte Preis, wie wir ihn als Resultat der ökonomischen Zwänge der Kapitalreproduktion abgeleitet haben, ist aber zunächst nur vorgestelltes Geld.

Damit aber dieses vorgestelle Geld realisiert, das Warenkapital also in Geldkapital einer bestimmten Größe verwandelt werden kann, muß bei entsprechend hohen Preisen die Geldnachfrage vorhanden sein. Neben der aus dem realen Reporduktionsprozeß sich ergebenden Nachfrage (die in der Krise beschränkt ist) müssen wir daher hier die zusätzliche, kredifinanzierte Nachfrage betrachten. Für das Kapital ist es also nicht damit getan, einen Preis zu ,setzen“. Es braucht gesellschaftliche Umstände, die es ihm ermöglichen, den ,gesetzten“" Preis in Geld zu realisieren.

Kapital III, S. 540 und 556

99 Vgl dazu von Ulrich Jürgens und Gudrun Lindner, zur Funktion und Macht der Banken, in: Kursbuch 36, Juni 1974, S. $121 \mathrm{ff}$.

100 Vgl. Mandel, a. a. O., S. $416 \mathrm{f}$.

101 Die folgende Argumentation gilt gleichermaßen für Monopole. 


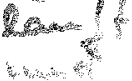

Daraus ergibt es sich aber, daß eine Preissetzung notwendigerweise Konsequenzen für die Geldzirkulation hat.

- Die Einzelkapitale können den Kauf der von ihnen produzierten Waren teilweise kreditieren, indem sie auf die Käufer entsprechende Wechsel ziehen und somit den kommerziellen Kredit ausweiten. Damit entgehen sie allerdings nicht dem Di-

lemma, daß die Kredite zu bestimmten Terminen zurückgezahlt werden müssen und in dem Augenblick der Rückzahlung - von der auf den Handelswechseln aufbauenden multiplikativen Geldschöpfung einmal abgesehen - auch das mit der Kreditierung entstandene zusätzliche Geld als Zahlungsmittel verschwindet. Es kann natürlich der Kredit immer wieder verlängert werden, an denselben Kreditnehmer oder auch an andere Warenkäufer, z. B. auch an Konsumenten, d. h. an die Lohnarbeiterklasse. Auf diese Weise kann der Rückflußtermin der vergebenen Handelskredite hinausgeschoben werden, im technischen Sinne sogar bis zum Sankt-Nimmerleinstag. Das kreditierende Einzelkapital vergibt sich dabei gar nichts. Denn nicht nur wird es dadurch möglich, höhere Preise zu erzielen als es anders der Fall wäre. Solange die Handelswechsel und die Darlehensforderungen an Konsumenten vom Einzelkapital als Zahlungsmittel verwendet werden können oder wieder zu Geld gemacht werden können, indem sie bei einer Bank diskontiert werden, fungieren die Wechsel so gut wie bares Geld. Denn durch die Diskontierung bei einer Bank erhält das Einzelkapital Geld, das wieder im Kreislauf des Kapitals in Produktionsmittel und Arbeitskraft umgesetzt werden kann. Die Bank wiederum wird so lang die entsprechenden Wechsel diskontieren und Darlehensforderungen honorieren wie sie selbst die Wechsel rediskontieren kann. Mit anderen Worten: Wenn die rediskontierende Zentralbank diese ausgeweitete Kreditschöpfung mitmacht, ist von der technischen Seite her keine Begrenzung gesetzt.

So können also technisch Preiserhöhungen von den Kapitalen selbst finanziert werden, so lange die Zentralbank diesen Prozeß trägt. Keine Ware kommt ohne Preis auf den Markt; aber damit der ihr anhaftende vorgestellte Preis realisiert werden kann, muß der Vorstellung auch hartes (oder besser: gutes konvertibles) Geld entsprechen, das durch den Mechanismus der Kreditgeldschöpfung besorgt werden kann.

Vom Käufer aus betrachtet sieht die Angelegenheit allerdings anders aus. Am einfachsten läßt sich dies noch erklären anhand der Konsumentkredite, da bei ihnen das Verhältnis von Kreditgeber und Kreditnehmer einseitig ist. Bei den Kreditbeziehungen in der ,Wirtschaft" dagegen kann davon ausgegangen werden, daß bei entwickelten Kreditverhältnissen wechselseitige Verschuldung vorliegt. Der Käufer erhält den Gebrauchswert einer Ware, deren Preis er nicht aus dem laufenden Einkommen zu bezahlen braucht, sondern aus dem künftigen Einkommen (zuzüglich Zinsen). Solange die auf der Lohnarbeiterklasse insgesamt lastende Kreditsumme nicht dazu führt, daß Ratenzahlung plus Zinszahlung aus dem laufenden Einkommen in Frage gestellt werden, und solange das laufende Einkommen groß genug ist, um neben der "Normalreproduktion“ der Arbeitskraft auch Raten und Zinsbeträge leisten zu können, kann dieses System funktionieren. Wenn jedoch die Masse an Konsumentkrediten das laufende Einkommen, das zur Reproduktion der Arbeits-
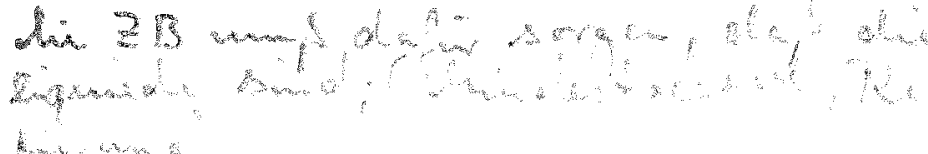
kraft benötigt wird, angreift, oder wenn infolge einer ökonomischen Krise die Beschäftigung sinkt, die Einkommen abnehmen, dann besteht immer die Gefahr, daß dieses künstliche System der Kreditausweitung zusammenbricht (102).

Ähnliche Probleme wie bei der Konsumentkreditierung ergeben sich, wenn Banken per Bankkredit Einzelkapitalen die Zahlungsmittel zur Verfügung stellen, um die Preise bezahlen zu können. Aber auch wenn die Käufe durch die Kapitale selbst oder durch die Banken kreditiert werden, stellt sich die Frage, die sich jedes einzelne Kapital vorzulegen hat, ob (a) die hohen Preise eine entsprechende Verwertung seines Kapitals zulassen, da ja die gekauften Waren in den Kapitalvorschuß eingehen, ob (b) überhaupt noch der erzielte Profit bezogen auf das vorgeschossene Kapital eine ausreichende Profitrate bringt und schließlich, ob (c) die infolge der Kreditierung zu zahlenden Zinsen genügend industriellen Profit übriglassen, um das Geschäft auszudehnen oder auch nur fortzusetzen. Dies soll besagen, daß mit der Kreditierung der Käufe von Waren diese Käufe keineswegs rentabel werden, und daß letztlich die Grenzen der Preissetzung nicht einfach durch Kreditausweitung hinausgeschoben werden können. Die Kreditschöpfung ist ein notwendiges Mittel zur Realisierung der gesetzten Preise in der Krise. Aber damit ist nicht durch die Möglichkeit der Preissetzung unter Aufrechterhaltung einer kalkulierten Profitrate überhaupt besiegelt. Hier zeigt sich ein Unterschied zu der Ausweitung der Konsumentenkredite; bei diesen ist die Einkommenslage der Lohnarbeiter die Grenze ihrer Ausdehnbarkeit und daher letztlich das Verhältnis von Lohnarbeit und Kapita1. Bei jenen ist die Verwertung des Kapitals verschiedener industrieller Einzelkapitalisten und das Verhältnis von Bankzinsen und industriellem Profit ausschlaggebend; daher - letztlich - das Teilungsverhältnis des von den Lohnarbeitern insgesamt produzierten Mehrwerts zwischen den vielen Einzelkapitalen.

Der dritte Weg der Kreditausweitung ist derjenige über die Staatsverschuldung. Der Staat kann sich das Geld selbst verschaffen, mit dem er als Käufer auf den Markt tritt, um dort Preise zu bezahlen, die Einzelkapitalen die Realisierung von kalkulierten Profiten ermöglichen. Aber in diesem Fall verschafft sich der Staat das Geld nur, um mit ihrer Hilfe entweder Profite zu den Kapitalen zu transferieren oder aber Teile des Lohns umzuverteilen. So würde der Staat also doch für die Realisierung von gesetzten Preisen und daher kalkulierten Profiten eine wichtige Rolle spielen. Aber auch der Staat ist in dieser Frage nicht allmächtig. Er ist ökono-

102 Dann ist es auch fraglich, ob es noch - wie in einigen Fälien von Betriebsstillegungen in Westdeutschland praktiziert - Zahlungsmoratorien geben kann, da ja die Teilzahlungsbanken ihrerseits mit den Darlehen, die sie gewähren, ,arbeiten " und nicht lange Zeit und in größerem Umfang auf die Zinszahlungen und Ratenzahlungen verzichten können, da sie selbst ebenfalls Zahlungen zu leisten haben. Auch Pfändungen führen in einer solchen Situation nicht weiter, da ja nicht die auf Kredit gekauften Waren benötigt werden, sondern das Geld, mit dem ihr Preis realisiert werden soll. Bei Pfändungen aber zeigt es sich ganz offen, daß für den Warenproduzenten der Warenpreis erst "halb" realisiert ist, solange der Kredit nicht voll abgezahlt worden ist. In der juristischen Figur, daß das Eigentum an der Ware beim Verkäufer bis zur Abzahlung der letzten Rate bleibt (Eigentumsvorbehalt), drückt sich dieses Verhältnis auch für den Käufer aus. 
mischen Beschränkungen unterworfen, die darin liegen, daß ja die Staatsschuld erstens verzinst und zweitens zurückgezahlt werden muß. Die Zinsen aber können nur aus den laufenden Einnahmen des Staates bezahlt werden und dies bedeutet, daß die laufenden Einnahmen, also die Steuerlast umso höher sein muß, je höher die Staatsverschuldung bei einem gegebenen Zinsniveau ist. Außerdem hat die Staatsverschuldung auf das Zinsniveau Auswirkungen. Wenn durch Staatsanleihen der Kapitalmarkt zu sehr in Anspruch genommen wird, dann kann dies zu Zinssteigerungen führen, d. h. einem Kursverfall an den Börsen, einer Verschlechterung des Teilungsverhältnisses zwischen industriellem und zinstragendem Kapital. So ist die Staatsverschuldung für das Kapital nicht problemlos, ganz abgesehen davon, daß sie die Lohnarbeiterklasse doppelt belastet: durch entsprechende Steuern und durch die mit Hilfe der Staatsschuld ermöglichten hohen Preise von Waren, die teilweise in die Konsumtion der Arbeiterklasse eingehen.

So gibt es zwar Wege, die erhöhten Preise zu realisieren. Die Realisierung ist aber keineswegs, wie dargestellt worden ist, der ökonomischen und außerökonomischen Macht der Kapitale (bes. Monopole) geschuldet, sondern ist durchaus Grenzen unterworfen. Es zeigt sich, daß - in Grenzen - durch Geldschöpfung und überhaupt durch die Bedingungen der Geldzirkulation die Realisierung der Preise ermöglicht werden kann. Keineswegs aber darf daraus die Annahme abgeleitet werden, als ob durch bloße Geldschöpfung inflationistische Tendenzen entstünden. Die Waren kommen bereits ausgepreist auf den Markt. Die Bedingungen der Geldzirkulation sind insofern wichtig, als sie mit dafür verantwortlich sind, ob es den einzelnen Kapitalisten - große Kapitale, Monopole oder nicht - gelingt, die ausgepreisten Waren zu verkaufen, die Preise also zu realisieren. Die Bedingungen der Geldzirkulation aber sind nicht einfach manipulierbar, sie sind selbst wieder an den „Gang der Geschäfte" rückgekoppelt, also abhängig vom zyklischen Gang der Kapitalakkumulation. Dies ändert sich auch nicht grundlegend unter der Annahme z. B. monopolistischer Einflußnahme auf die Geldzirkulation. Dann ist aber eine These nicht stichhaltig, die besagt, daß die Inflation die Folge von monopolistischer Machtpreissetzung wäre.

Hatten wir im Teil 5.3.1 die Möglichkeiten des Einzelkapitals beschrieben, einer Entwertung durch die Aufrechterhaltung einer monetären Profitrate zu entgehen, dann gesamtgesellschaftlich - bei Betrachtung des Reproduktionsprozesses des gesellschaftlichen Kapitals - den Zusammenhang von Überakkumulation und Preissetzung im Teil 5.3.2 dargestellt, so können wir nunmehr nach Betrachtung der Nachfrage- und Kreditverhältnisse vorläufige Schluß folgerungen auf den Gesamtprozeß ziehen: Für das Einzelkapital scheint die Preissetzung und damit die Aufrechterhaltung eines monetären Durchschnittsprofits ein Ausweg aus der Überakkumulation (bzw. - und so stellt die Überakkumulation sich dem einzelnen Kapital dar - der Überproduktion) zu sein. Schon bei gesamtgesellschaftlicher Betrachtung gilt aber diese Möglichkeit nicht mehr, weil die einzelnen Kapitel (besonders die kleinen) dem Fall des Verwertungsgrades und der Entwertung ihres Kapitals auf die Dauer 
nicht entgehen können, auch wenn sie dies fortgesetzt über die Preissetzung (und damit Preissteigerung) versuchen. Diese Preissteigerungen stoßen aber auf das Problem der Realisierung. Denn die reale Nachfrage zwischen den Kapitalen muß aufgrund der sinkenden Verwertung der Kapitale selbst stocken, während eine zyklusunabhängige Basisnachfrage zwar vorhanden, aber äußerst begrenzt ist. Dieses Realisierungsproblem verschiebt sich angesichts der Preissetzung der Einzelkapitale auf eine zusätzliche kreditfinanzierte Nachfrage in der Krișe. Die Voraussetzung hierfür ist jedoch, daß die Kreditaufnahmen tatsächlich in die Zirkulation gelangen, sich also letztlich als reale Nachfrage geltend machen können. Neben einer möglichen Ausweitung der Konsumentennachfrage durch den Konsumentenkredit und der Staatsnachfrage durch den öffentlichen Kredit kann die Nachfrage nur gehalten und gesteigert werden durch die Nachfrage der Kapitale untereinander. Diese sinkt aber gerade in der Krise stark ab. Der stockende Rückfluß des Kapitals aus der Zirkulation und die Fixierung von Kapitalwerten in der Produktion machen eine Konsolidierung durch Kreditaufnahme nötig, um der Kapitalvernichtung und dem Konkurs $z u$ entgehen. Die Konsolidierung von vorher aufgenommenen Geld- und Geldkapitalkrediten, erzwingt die Aufnahme neuer Kredite, soll das vorgeschossene Kapital nicht verloren sein und soll der Kapitalumschlag - wenn auch auf einem minimalen Niveau - flüssig gehalten werden. Darüberhinaus haben aber gerade der öffentliche Kredit, d. h. die Staatsverschuldung für staatliche Infrastrukturaufgaben, die Defizitausgaben in der Krise und die staatlichen Subventionen die Funktion, plötzliche Zusammenbrüche und Kapitalvernichtungen von großem Ausmaß (insbesondere, wenn damit eine Massenarbeitslosigkeit verbunden ist) zu vermeiden.

Dies sind auch die wesentlichen Kanäle, durch die das Geld und der private und öffentliche Kredit in die Zirkulation gelangen und zur Aufrechterhaltung einer entsprechenden Nachfrage in Krisen- und Stagnationsphasen beitragen, wodurch wiederum massive Kapitalverluste aufgeschoben werden können. Diese Nachfrageund Kreditverhältnisse ermöglichen daher auch Preissetzungen in der Krise und überzyklische Preissteigerungen. Andererseits sind die Kreditausweitungen aber - wie gezeigt wurde - begrenzt. Während daher das Aufschieben der Entwertung um den Preis einer überzyklischen Inflation und einer tendenziellen Verschlechterung der Verwertung des Gesamtkapitals erfolgt, verstärken zugleich umgekehrt begrenzte Realisierungsmöglichkeiten den Druck des konstanten und insbesondere des im Produktionsprozeß fixierten Kapitals auf die Verwertung. Diesem Widerspruch kann das Kapital nicht entgehen, er findet seinen Ausdruck in der Gleichzeitigkeit von Inflation und Stagnation.

Wir werden versuchen, den bisher entwickelten Zusammenhang in einer historischen Skizze im abschließenden Abschnitt zu illustrieren. 


\section{Der Weltmarktzyklus nach dem zweiten Weltkrieg und die inflationäre Ent- wicklung}

Die Voraussetzung dafür, daß sich die inflationären Prozesse auf der Basis der spezifischen Veränderungen der Struktur der Kapitalverwertung herausbilden konnten, war der nachhaltige und in der Geschichte des Kapitalismus einmalige dynamische Weltmarktaufschwung nach dem zweiten Weltkrieg. Es soll an dieser Stelle nicht eine ausführliche Erklärung des Weltmarktzyklus vorgestellt werden (103). Es läßt sich aber zeigen, daß die dynamische Geldmarktentwicklung vor allem getragen wurde

1. von dem Vorsprung der US-Wirtschaft gegenüber allen anderen Wirtschaften. Dadurch war es den USA möglich, Extraprofite auf dem Weltmarkt durch starke Exportsteigerungen zu erzielen. Da die Erlöse aus den Exportüberschüssen der USA konterkariert wurden durch noch größere Geldkapitalexporte, wurde die übrige kapitalistische Welt in den Aufschwung mit einbezogen.

2. von den im zweiten Weltkrieg massenhaft erfolgten Entwertungs- und Vernichtungsprozessen von Kapital, die nicht nur einen enormen Nachfrageschub produzierten, sondern zuerst einmal die Verwertung des Kapitals, sobald die Produktion wieder aufgenommen werden konnte, zu einer hohen Rate ermöglichten.

3. von der hohen Ausbeutungsrate der Arbeiterklasse und daher hohen Profitrate insbesondere in den Ländern, in denen der Faschismus an der Macht war und die den Krieg verloren hatten, nämlich Japan und der BRD. Obwohl in der Produktivitätsentwicklung hinter den USA bis in die Mitte der 60er Jahre nachhinkend, konnten sie durch vergleichsweise niedrige Löhne, lange Arbeitszeiten, ausgezeichnete Arbeitsdisziplin das Manko des Produktivitätsrückstands kompensieren.

4. von der auf dieser soliden Grundlage eines allgemeinen Booms sich entwickelnden Internationalisierung des Kapitals, insbesondere auch der Produktion des Kapitals in Form internationaler Konzerne.

Die USA konnten in dieser Phase also einen Aufschwung auf der Grundlage einer relativ hohen Profitrate erzielen trotz einer hohen organischen Kapitalzusammensetzung, weil ihnen der „technologische Vorsprung6 in den wichtigsten Weltmarktbranchen Extraprofite einbrachte. Die westeuropäischen Länder und Japan konnten mithalten, obwohl sie das ,,technologische Niveau" der USA erst sehr spät in den 60er Jahren erreichten, weil die Ausbeutungsrate durch Krieg, Faschismus und Nachkriegsnot so sehr angehoben worden war, daß dadurch das Kapital eine hohe, sehr hohe Profitrate zu beziehen verstand. Diejenigen Länder, die weder außergewöhnliche Produktivkraftsteigerungen aufwiesen, noch eine außergewöhnlich hohe Ausbeutungsrate durchzusetzen verstanden, bleiben denn auch auf der Grundlage des allgemeinen Weltmarktbooms zurück. Dies trifft vor allem auf Län-

103 Vgl. dazu Christel Neusüß, Imperialismus und Weltmarktbewegung des Kapitals, a. a. O. Neusüß, Blanke, Altvater, Kapitalistischer Weltmarkt und Weltwährungskrise, in: Probleme des Klassenkampfs, Nr. 1/1971, Ernest Mandel, a. a. O., Jochen Reiche, a. a. O. 
der wie England zu. Natürlich sind in jedem Land noch besendere historische Verhältnisse zu berücksichtigen, die in der einen oder anderen Richtung das allgemeine Bild modifizieren können, allerdings ohne die Grundstruktur des Weltmarktzyklus in Frage stellen zu können.

\subsection{Bedingungen des Weltmarktzyklus nach dem zweiten Weltkrieg}

Solange der „technologische Vorsprung" der USA wirksam war und solange die Ausbeutungsrate in den anderen Ländern hoch genug war, um den Vorsprung zu kompensieren, also die Kapitale aller entwickelten Länder - allerdings aus verschiedenen Gründen - eine hohe Profitrate zu erzielen vermochten, konnten die zyklischen Krisen noch ein sehr abgeschwächtes Aussehen haben. Positiv hinzu kam die zu Beginn des Weltmarktaufschwungs am Ende des zweiten Weltkriegs beinahe vollständige weltwirtschaftliche Desintegration. Aufgrund unterschiedlicher organischer Zusammnesetzungen und daher auch unterschiedlichen Gewichts des Fixkapitals (als materieller Basis des Zyklus), sowie aufgrund zeitlicher Verschiebungen beim „Eintritt“ in den allgemeinen Weltmarktzyklus, die den jeweiligen historischen Besonderheiten geschuldet sind, kann man zwar von einem allgemeinen Weltmarktaufschwung sprechen, nicht jedoch von einer Auflösung nationaler Konjunkturschwankungen in eine einheitliche Weltkonjunktur. Vielmehr mußten notwendigerweise die nationalen Akkumulationszyklen asynchron verlaufen; außer den schon genannten Gründen kommt noch hinzu, daß ja auch der Staat wesentlich als Nationalstaat fungiert, und daher auch die Staatseingriffe wesentlich nationalstaatlich begrenzt sind. Daraus ergab sich in den 25 Jahren nach dem zweiten Weltkrieg aber die für das Kapital ausgesprochen günstige Situation, daß es nur ein einziges Mal in dieser ganzen Phase, nämlich 1958, zu einer allgemeinen weltweiten konjunkturellen Abschwächung kam, während alle anderen Krisen in einzelnen Ländern durch konjunkturelle Aufschwünge in anderen Ländern kompensiert werden konnten. Dies zeigte sich in aller Deutlichkeit gerade in der Krise des westdeutschen Kapitals 1966/67. Das krisenverschärfende Moment des Wegfalls des äußeren Realisierungsfeldes für im Innern nicht absetzbare Waren und brachliegendes Geldkapital entfiel.

Diese so bezeichneten Bedingungen für den langen Weltmarktaufschwung aber mußten allesamt notwendigerweise im Verlauf der kapitalistischen Entwicklung schwinden: Der technologische Vorsprung der USA veranlaßte die Weltmarktkonkurrenten ebenfalls zu Anstrengungen bei der Entwicklung der Produktivkraft und so schloß sich die technologische Lücke zwischen den USA und den anderen kapitalistischen Ländern schnell. Damit aber war dem Bezug von Extraprofiten auf dem Weltmarkt durch das US-Kapital die Grundlage entzogen. Die Tatsache, daß nach permanenten Exportüberschüssen des US-Kapitals ab 1971 Handelsbilanzdefizite folgen, legt Zeugnis von der - oberflächlich formuliert - gesunkenen Konkurrenzfähigkeit der vom US-Kapital auf den Weltmarkt geworfenen Waren ab.

Auch die sehr hohe Ausbeutungsrate aufgrund der vom Faschismus und vom 
Krieg geerbten Bedingungen mußte erodieren und daher das Kapital zwingen, die Steigerung der Ausbeutungsrate mit den ihm genuinen Mitteln der Steigerung der Produktivkraft und somit der relativen Mehrwertproduktion zu versuchen. Per saldo aber hatte dies einen langfristig negativen Effekt auf die Profitrate infolge der nun stark steigenden Kapitalzusammensetzung, so daß auch in den Ländern, die nicht die Möglichkeit des Bezugs von Extraprofiten hatten, die Voraussetzungen für die außergewöhnlich hohe Profitrate als „Stachel" des außergewöhnlichen Weltmarktbooms tendenziell entfielen. Bei diesen Prozessen der Angleichung des Produktivitätsniveaus, der Verallgemeinerung der Reproduktionsniveaus der nationalen Arbeiterklassen (natürlich gibt es immer noch $z$. T. sehr starke regionale Differenzen; aber diese sind geringer als z. B. noch vor zehn Jahren), der Angleichung des Niveaus der Kapitalzusammensetzungen und $d . h$. auch der Mehrwertraten in den einzelnen Ländern haben insbesonders internationale Konzerne eine wichtige Rolle gespielt. Sie haben sich gegenüber den modifizierenden Bedingungen der Nationalstaatlichkeit, wie sie in nationalen Währungen, Wechselkursen, nationalstaatlichen Eingriffen in den Reproduktionsprozeß des Kapitals sich manifestierten, als wirksame „Exekutivorgane des Wertgesetzes" entwickelt und mit dafür gesorgt, daß im Ausgleichsprozeß der Produktions- und Zirkulationsbedingungen die Profitratenniveaus der einzelnen nationalen Kapitale ausgeglichen wurden und in diesem Angleichungs. prozeß gleichzeitig nach einer ersten Phase des rapiden Anstiegs der Profitrate sich der tendenzielle Fall der Profitrate zur Geltung brachte.

Die ,lange Welle“ nach dem zweiten Weltkrieg, von der Mandel spricht, hat also nichts mit irgendwelchen außerhalb des Kapitals liegenden technologischen Errungenschaften und Neuerungen, die en masse jetzt angelegt werden und so einen Boom induzieren, zu tun. In diesem Sinne ist der Weltmarktaufschwung nach dem zweiten Weltkrieg keine ;,lange Welle mit expansivem Grundton“, sondern das Resultat spezifischer histor ischer Prozesse, die dem Kapital zeitweise eine hohe Profitrate verschafften, wobei es aber die gleichen Prozesse sind, die dann dafür verantwortlich sind, daß der Weltmarktaufschwung sich abschwächt und mit dem Ende der 60er Jahre, Anfang der 70er Jahre allgemeine Krisentendenzen auf dem Weltmarkt sich andeuten.

Dieser langandauernde Weltmarktaufschwung war die Basis dafür, daß sich die inflationistischen Tendenzen herauszubilden vermochten. Da auch ohne weitreichende Kapitalentwertung immer wieder ein neuer Aufschwung einsetzte, wenn die Produktion nachließ, waren auch die im Verlauf der Produktivkraftentwicklung sich verwirklichenden Wertsenkungen der einzelnen Ware kein Grund, um in der Krise, die ja niemals mehr als ein kurzfristiger und nicht sehr tief gehender Produktionsrückgang war, die Warenpreise zu senken. So wird von Boom zu Boom ein ,,inflationistischer Rest" mitgeschleppt, der seinen Ausdruck als ,säkulare Inflation" findet.

Wie wir gesehen haben, ist mit der Preissetzung noch nicht die Frage entschieden, ob diese gesetzten Preise auch wirklich realisiert werden können. Dazu ist die entsprechende Geldnachfrage vonnöten, deren Entwicklung im Verlauf dieses Weltprozeß des Produktionsmarktbooms wir uns jetzt zuwenden. Im Boom schaffen 
die Einzelkapitale durch die entsprechende Ausweitung des kommerziellen und des Bankkredits die Zahlungsmittel, die dazu dienen, die Waren zu zirkulieren. Das Kreditvolumen wird entsprechend aufgebläht, wie es während der ganzen Phase nach dem zweiten Weltkrieg geschehen ist. Weiter hat die Staatsverschuldung in beinahe allen Weltmarktländern enorm zugenommen, und zwar sowohl als innere als auch als äußere Verschuldung. Gerade die letztere Methode, spielt in dieser Phase der zunehmenden Weltmarktintegration eine zunehmende Rolle, wobei neue Formen entwickelt werden - z. B. allgemeine Kreditvereinbarungen im Rahmen des Internationalen Währungsfonds, gegenseitige Kreditvereinbarungen einzelner Staaten (Swap-Abkommen), vor allem aber die Schaffung der ,Sonderziehungsrechte die bei der Saldierung der Zahlungsbilanzen Verwendung finden. Anders als in einem ,Clearing House", wo Zahlungen und Einnahmen sich über eine bestimmte Periode weitgehend ausgleichen, sind die Sonderziehungsrechte als Kreditgeld mit staatlicher und internationaler Dignität einseitig, da die Zahlungsbilanzen der beteiligten Länder sich nicht über eine einigermaßen adäquate Periode ausgleichen. Strukturelle Überschüsse und Defizite der Zahlungsbilanzen führen dazu, daß die Kredite nicht zurückgezahlt werden, vielmehr immer von neuem in Anspruch genommen werden müssen und zwar in der Regel immer von den gleichen Ländern. Diese Ausweitung des Kreditgeldes ist zwar für die Aufrechterhaltung der Geldnachfrage sehr wichtig; aber kann nicht Bestand haben, wenn einige Länder wesentlich kaufen (Handelsbilanzdefizite) und andere Länder hauptsächlich verkaufen (Handelsbilanzüberschüsse).

Auch die staatliche Finanzierung durch eigene Verschuldung von kriegerischen Aktionen, wobei der Indochinakrieg der USA die wichtigste Rolle in dieser Phase spielt, stellt ein Moment in der Entwicklung der entsprechenden Geldnachfrage dar, die es den Kapitalen ermöglicht, die gesetzten Preise auch zu realisieren. Jedenfalls scheint es so möglich, als ob das auf diese Weise staatlich erzeugte Geld nicht „verselbständigter Wert", sondern ganz und gar unselbständiges, weil vom Staat manipuliertes Geld darstelle, das zwar die Inflation anheize, aber dafür doch die kapitalistische Produktion stabilisiere. So kann auch die Auffassung vom gegenüber dem Gang der Akkumulation verselbständigten Kreditzyklus entstehen.

Auf der Grundlage der Internationalisierung des Kreditsystems haben sich in der Nachkriegszeit neue Systeme von Leihkapitalmärkten, vor allem der Euro-Geldmarkt herausgebildet, der die notwendige Konsequenz von internationalistierter Kapitalzirkulation und -produktion ist. Aber der Euromarkt ist nicht nur eine besondere Institution, sondern stellt auch sozusagen eine ,neue Etage“ auf dem komplizierten Kreditgebäude dar. Hier werden Kapitale und Geld als Ware gehandelt, deren fiktiver Charakter schon in die zweite und dritte Potenz geht: auf staatliche Schuldscheine als Sicherheit aufbauende weitere Kredite, Gelder - z. B. bei Devisentermingeschäften -, die gar nicht vorhanden sind, Schuldverschreibungen von Staaten, die, wenn es sich bei ihnen um Einzelkapitale handeln würde, längst den Bankrott hätten anmelden müssen.

So wird deutlich, daß und wie der inflationistische Preisauftrieb ,finanziert" worden ist. Wohlgemerkt, die Geld- und Kreditgeldzirkulation ist nicht die Ursache 
für die Inflation, jedoch eine notwendige Bedingung dafür, daß die ständig erhöhten Preise auch realisiert werden können. Es bestanden keine Schwierigkeiten, das Warenkapital zu. tendenziell steigenden Preisen in Geldkapital zu verwandeln. Selbst in der Abschwungsphase des Akkumulationszyklus ergaben sich hier kaum Schwierigkeiten, einmal wegen der Asynchronität der nationalen Krisenzyklen, zum andern wegen staatlich forcierter Ausweitung des Kredits gerade in der Krise. So ergab sich bisher von der Geldseite her kein unmittelbarer Zwang zur Senkung der Warenpreise in der ökonimischen Krise.

\subsection{Permanente Inflation und Verwertungskrise}

Hier haben wir bereits alle Momente ausgebildet, die dann dazu führen, daß gerade in der Phase, in der sich einmal der Fall der Profitrate weltweit bemerkbar macht und die nationalen Zyklen sich weitgehend angleichen, nicht etwa ein entsprechender Preisverfall einsetzt, sondern die bislang schleichende Inflation sich in eine beschleunigte Inflation zu verwandeln tendiert. Denn wie wir gesehen haben, wirkt die Krise zunächst jetzt nicht zur Bereinigung der im Akkumulationsprozeß des Kapitals angehäuften Widersprüche, sondern die Zwänge zur Entwertung, die in der Krise offensichtlich sind, werden dadurch wirkungslos $\mathrm{zu}$ machen versucht, daß gerade in der Krise noch der Kredit (durch staatliche Aktion) ausgeweitet wird. Dies muß bei dem gegenwärtigen Stand der Weltmarktverflechtung gar nicht in jedem einzelnen Land geschehen, um für die Geld- und Kreditzirkulation in allen Ländern Konsequenzen zu haben.

So wird die Überakkumulation von Kapital, die am Ende des langen Weltmarktzyklus nach dem zweiten Weltkrieg auch als solche erscheint, da sie sich noch aufgrund des Gleichlaufs der industriellen Zyklen in den wichtigsten Weltmarktländern verschärft, nicht durch Entwertungsprozesse vom Kapital bereinigt, sondern verlängert. Die Entwertung des Kapitals bezog sich immer, wie wir gesehen haben, auf alle Formen des Kapitals: das produktive Kapital, das Warenkapital und das Geldkapital. Die Aufblähung des Kreditsystems in der Überakkumulationsphase aber ist nur die Kehrseite von überproduzierten Waren. Denn mit Krediten wird noch der Schein reibungslos funktionierender Käufe und Verkäufe aufrechterhalten, wobei doch „deren das gesellschaftliche Bedürfnis weit überschreitende Ausdehnung schließlich der ganzen Krisis zugrundeliegt" ${ }^{6}(104)$. Zudem werden die Kredite des Banksystems und des Staates verwendet, um bereits vor dem Ruin stehende Geschäfte zu erhalten. Dies wird insbesondere dann relevant, wenn es sich bei den unrentablen Geschäften um große Unternehmen handelt, deren Ruin das labile Gleichgewicht der bürgerlichen Gesellschaft tangieren würde. Permanente Subventionen und Stützungskredite, um die Unternehmen mit Zahlungsmitteln zu versorgen, sind dann die Mittel, um dieses Gleichgewicht wieder vorübergehend zu stabili- 
sieren. Diese Art und Weise der Erhaltung von Kapital, das in der Krise entwertet würde, führt zur maßlosen Kreditausweitung, die die tatsächliche Überakkumulation von Kapital verhüllt.

Auch hier hat die hinausgeschobene Kapitalentwertung ihren Preis. Denn sowohl Subventionen, die unrentablen Einzelkapitalen noch die übliche Profitrate sichern, als auch Kredite zur Ausstattung von fallierenden Unternehmen mit Zahlungs- und Kaufmitteln bedingen eine Umverteilung von Werten innerhalb der Kapitalistenklasse und daher eine für alle niedrigere Profitrate als sie es wäre, wenn notleidende Kapitale und Branchen von der Bildfläche verschwinden würden. Der krisenhafte Einschnitt würde dann ehèr zur ,Gesundung" des kranken Kapitalismus führen. Aber eine Entwertung findet in diesem Prozeß dennoch statt. Dadurch daß auf diese Weise auch die Entwertung des Warenkapitals verhindert wird, werden die inflationistischen Reste nicht nur nicht beseitigt, sondern zudem die Möglichkeiten für Preiserhöhungen eröffnet. Diese erscheinen als unbedingt notwendig, um die auf Grund der Überakkumulation von Kapital und dem ungünstigen Teilungsverhältnis von Profit und Zins verlorengegangene Profitabilität wieder hereinzuholen. Die so weiter angeheizte Inflation in der beginnenden Krise reduziert aber die Reallöhne der Arbeiterklasse und verringert so auch das variable Kapital, erhöht also auch die Mehrwertrate. So stellt sich die Inflation auch als eine ,Solidaraktion" der Kapitalistenklasse insgesamt gegen die Arbeiterklasse insgesamt dar, die verschechterte Verwertung des Kapitals durch Reallohnsenkung wieder zu verbessern. Instrumentalistisch gesprochen ist die Inflation somit ein Mittel des Klassenkampfs von oben. Es ist so aber auch eine Frage des Verhaltens der Arbeiterklasse und ihrer Organisationen, inwieweit es dem Kapital möglich ist, die Wertsenkung des vorzuschießenden variablen Kapitals durch Beschneidung des Reproduktionsniveaus der Arbeiterklasse durchzuführen. Die Arbeiterklasse muß sich dagegen zur Wehr setzen, daß eine partielle und doch nur zeitweise und scheinbare Krisenbeseitigung auf ihre Kosten durchgeführt wird. Und die Krisenverschiebung durch permanente Ausdehnung des Geld- und Kreditvolumens kann tatsächlich nicht gelingen. Der entscheidende Grund ist darin zu sehen, daß mit der so ermöglichten, aber auch notwendigen galoppierenden Inflationierung der Warenpreise (nämlich um die Verwertung des Kapitals dadurch sicherzustellen, daß die Preise permanent erhöht werden) für alle Schuldner die Kreditaufnahme im Grad der Inflationsrate billiger wird, wohingegen die Gläubiger entsprechende Realverluste hinnehmen müssen, für die sie sich nur schadlos halten können, indem sie entsprechend hohe Zinsen einfordern. Da der Großteil der Gläubiger die Banken sind, ist deren Interesse am ehesten auf Anhalten der inflationistischen Tendenzen gerichtet. Dieses Interesse kann nur dadurch noch modifiziert werden, daß Bank- und industrielles Kapital in den großen Konzernkomplexen so eng verschmolzen sind, daß unter dem ,Obergesichtspunkt" die Profitabilität des produzierenden Kapitals zu erhalten, so mancher Verlust der Banken hingenommen wird - sofern nicht das ganze Kreditsystem dadurch zusammenbricht (vgl. die Bankpleiten in Westdeutschland). Denn „eine Entwertung des Kreditgeldes (gar nicht zu reden von einer übrigens nur imaginären Entgeldung dessel- 
ben) würde alle bestehenden Verhältnisse erschüttern ..." (105). So scheint die Ausweitung des Kredits nur ein Instrument der Krisenregulierung zu sein; doch ist sie es nicht. Die Banken leben zwar von dem Aktivgeschäft, d. h. der Kreditvergabe; aber die Basis dieses Geschäfts ist ein ökonomisch gesunder Kreditnehmer, der Zinsen zahlen und den Kredit am Fälligkeitstermin zurückzahlen kann. Ist dies nicht der Fall, dann wird das Aktivgeschäft zu einem Va-banque-Spiel, und gute Außenstände verwandeln sich in dubiose. Auch wenn infolge des Risikos, das die Bank eingeht, die Zinsen noch besonders hoch, also ihre Gewinnne besonders lukrativ sind, kann dann, wenn der Kreditnehmer bankrott geht, nicht nur der lukrative Gewinn sich in einen herben Verlust verwandeln, sondern auch das Eigenkapital der Bank verlustig gehen. Das Geld als verselbständigter Wert, das Kreditsystem, das auf seiner Funktion als Zahlungsmittel aufbaut, kann sich nicht von den Bedürfnissen, Notwendigkeiten und Begrenztheiten des „Verkehrs" emanzipieren. In einer schlechten allgemeinen Geschäftslage, sprich einer Phase des industriellen Zyklus, in der Überakkumulation herrscht, kann zwar durch Ausweitung der Kredite für alle dubiosen Unternehmen die Entwertung hinausgeschoben, aber keinesfalls aufgehoben werden.

Wenn aber infolge der Kreditausweitung das Banksystem zu wanken beginnt und evtl. teilweise zusammenbricht, dann wird sich auch die Überakkumulation als solche darstellen müssen und nur noch - da per Kreditausweitung nicht mehr zu verhüllen - durch stärkere Entwertung des Kapitals zeitweise zu beseitigen sein. Wenn in dieser Situation staatliche Interventionen versuchen, die Prozesse der Entwertung von Kapital (und der Entwicklung von Massenarbeitslosigkeit) aufzuhalten, so wird dies jetzt schwerlich gelingen aufgrund der zugespitzten Widersprüche, wie sie in der Krise sichtbar werden. Allenfalls werden zusätzlich Preissteigerungen abgestiitzt. 


\section{Prokla-Aufsatz Inflation und Verwertungskrise}

\section{Zusammenfassung}

Der Ausgangspunkt unserer Überlegungen war das Verhältnis von Wert und Tauschwert oder Preis, denn schon die vordergründige Bestimmung der Inflation als permanentes Ansteigen aller Warenpreise machte es notwendig, den Begriff des Preises, also auch den des Geldes, zu entwickeln und verwies auf die diesen Formen zugrundeliegenden gesellschaftlichen Beziehungen. Das auf der Ebene des Tauschwerts oder Preises nur als Tauschzusammenhang der Warenbesitzer darstellbare gesellschaftliche Verhältnis konnte im Nachvollzug der Marxschen Analyse näher als ein historisch spezifisches Produktionsverhältnis ausgewiesen werden, indem der Tauschwert als notwendige Erscheinungsform des Werts und dessen Substanz als abstrakte oder gesellschaftliche Durchschnittsarbeit bestimmt wurde. Die Wertabstraktion selbst erwies sich in der Folge als historisches Resultat der Verallgemeinerung der Warenform des Arbeitsprodukts durch die Entwicklung der kapitalistischen Produktionsweise. Denn der sich durch seine beständige Reproduktion verewigende Wert ist das Kapital, und die den Wert als Kapital erzeugende Tätigkeit ist die unter das Kapital subsumierte Lohnarbeit.

Die Selbstverwertung des (Kapital-) Werts in der Produktion mit der Erzeugung eines Produktenwerts, der neben dem wertmäßigen und stofflichen Ersatz des Verzehrs an Produktionsmitteln und neben der zum erneuten Ankauf von Arbeitskräften erforderlichen Wertsumme und Produktenmasse einen Überschuß (Mehrwert) enthält, der von den Kapitalisten konsumiert oder zur Erweiterung der Produktion verwendet werden kann, ist jedoch erst abgeschlossen mit der Realisierung des Produktenwerts auf dem Warenmarkt. Realisierung aber heißt Verwirklichung der in seinem Preisausdruck bloß ideellen Beziehung des Warenwerts auf seine gesellschaftlich gültige Gestalt, das Geld, durch tatsächlichen Verkauf der Waren gegen Geld. Die Bewegung der Warenpreise als der Geldausdrücke bestimmter Quanta vergegenständlichter Arbeitszeit ist daher an die Bedingungen der Reproduktion des Kapitals gebunden. Diese waren folglich sowohl in langfristiger als auch in kurz und mittelfristiger Perspektive zu analysieren. Sie sind durch den Prozeß der Kapitalverwertung selbst erzeugte stofflich-technische und soziale Bedingungen. Deren Qualität ist für das Kapital nur insofern von Belang, als sie auf die Quantität der Vermehrung des schon existierenden Werts oder des Verhältnisses von zusätzlichem zu vorausgesetztem Wert (Profitrate) Einfluß hat.

Sowohl der Kapitalwert als auch die Bestimmungsgrößen der Verwertungsrate sind Preisausdrücke; deren Bewegung ist daher an den Verwertungsprozeß des Kapitals gekoppelt und wirkt auf ihn zurück. Soll also die Bewegung der Warenpreise erklärt werden, so ist sie mit der Akkumulationsbewegung des Kapitals zu vermitteln. Inflation bezeichnet dann insofern ein widersprüchliches Verhältnis von Wertund Tauschwertbewegung, als die mit der Kapitalakkumulation verbundene Produktivkraftsteigerung der gesellschaftlichen Arbeit, die mit einer Verminderung der in jeder Ware vergegenständlichten Arbeitszeit verbunden ist, nicht als Preisfall der 
Waren, sondern als permanente Preissteigerung erscheint. Dieser Sachverhalt ist nicht damit erklärbar, daß - wie die Entwicklung vom Wertpreis zum Produktionspreis deutlich gemacht hat - der Preis jeder einzelnen Ware ohnehin nur in Ausnahmefällen der Geldausdruck ihres Werts ist, selbst wenn die Bewegung der Wertsumme der gesellschaftlich insgesamt produzierten Warenmasse von der Bewegung ihrer Preissumme unmittelbar widerspiegelt würde. Vielmehr mußte die im Zuge der Entwicklung der kapitalistischen Produktionsweise ständig stattfindende Modifikation der Verwertungsbedingungen des Kapitals, die ihren zusammengefaßten Ausdruck im tendenziellen Fall der Profitrate erhält, als die eigentliche Ursache der spezifischen Verkehrung in der Erscheinungsform der Wertbewegung gelten, die wir als Inflation bezeichnen. Es galt also zunächst herauszuarbeiten, in welchen Veränderungen der strukturellen Verwertungsbedingungen der Akkumulationsprozeß des Kapitals resultiert, so daß eine beständige Tendenz zum Fall der Profitrate besteht.

Da die mit steigender Arbeitsproduktivität einhergehende Erhöhung der organischen Zusammensetzung des Kapitals nur dann zu einer tendenziell fallenden Profitrate führt, wenn die Bedingungen der Produktivkraftsteigerung nicht zugleich eine entsprechende Steigerung der Mehrwertrate implizieren, waren diejenigen Momente herauszuarbeiten, die bei steigender organischer Zusammensetzung des Kapitals die Entwicklung der Mehrwertrate nach oben beschränken.

In diesem Zusammenhang wurden diskutiert:

a) die Rohstoffverteuerung

b) die Zunahme der unproduktiven Arbeit

c) die Zunahme der faux frais (insbesondere in der Zirkulationssphäre)

d) die zunehmende Bedeutung des Fixkapitals

Die veränderten Bedingungen der Kapitalverwertung setzen der Expansion des Kapitals jedoch nur periodisch eine Schranke in den beständig wiederkehrenden ökonomischen Krisen. Zugleich verdanken sie sich selbst weitgehend der Krisenhaftigkeit und Zyklizität der Akkumulationsbewegung des Kapitals.

Daher war es notwendig, den Krisenzyklus der Kapitalakkumulation zu skizzieren. Er stellt sich doppelt dar: als zyklische Bewegung der allgemeinen Profitrate und als Preisbewegung. Während aber der „,klassische Krisenzyklus“ eine weitgehende Parallelität der Entwicklung von Profitrate und Warenpreisen aufweist, so daß beschleunigte Verwertung (steigende Profitrate) in der Prosperitätsphase als Preiserhöhung erscheint und Entwertung (sinkende Profitrate) in der Stagnation und Krise als Preisverfall, ist in der gegenwärtigen Phase der kapitalistischen Entwicklung selbst die Stagnation noch mit ei.er Steigerung des allgemeinen Preisniveaus verbunden. Die Ursachen hierfür mußten in den veränderten Bedingungen der Kapitalakkumulation gesucht werden.

Da die Bewegung des Kapitals Kreislauf durch die Stadien der Produktion und Zirkulation ist und sich dementsprechend auf der Ebene der Preise als Preisbildung und -realisierung darstellt, waren nicht nur die sich in der Preissetzung niederschlagenden Veränderungen der Reproduktionsbedingungen des Kapitals zu betrachten, sondern auch die Wandlungen der Realisierungsbedingungen durch die Ablösung des Geldzeichens von der Goldbasis, die Entwicklung des Kreditsystems, die Zentral- 
bankpolitik, die defizitäre Vollbeschäftigungspolitik des Staates und die Organisation des Weltwährungssystems. Wenn auch unsere Überlegungen hier noch weniger erschöpfend waren, als bei der Begründung des tendenziellen Falls der Profitrate, so ergaben sie doch die Unhaltbarkeit aller Inflationserklärungen, die von einer Verselbständigung des Geld- und Kreditzyklus gegenüber der Akkumulationsbewegung des Kapitals ausgehen. Weil die Beschleunigung der Kapitalakkumulation in der Aufschwungphase selbst bei eher restriktiver Geldmengenpolitik der Zentralbank zu starken nachfragebedingten Preissteigerungen führt, die durch günstige Realisierungsbedingungen infolge der steigenden Staatsnachfrage und der Expansion der Massenkaufkraft alimentiert werden, kommt es in der Stagnation und Krise in dem Maße zu einem inflationären Überhang, in dem die Entwertung hinausgeschoben bzw. zeitlich gedehnt wird oder sich ausschließlich in einer niedrigen Profit- und Akkumulationsrate ausdrückt.

Wie wir gesehen haben, ist hierzu zweierlei erforderlich. Die Setzung steigender Preise muß in dieser Phase des Akkumulationszyklus aus steigenden Kosten pro Wareneinheit und dem Bestreben der Kapitalisten erklärt werden, die Profitrate aufrecht zu erhalten; die Möglichkeit der weitgehenden Realisierung steigender Preise auch in der Stagnation kann nur auf die große Dehnbarkeit der Verschuldungsgrenzen der Einzelkapitale aufgrund ihrer starken finanziellen und kapitalmäßigen Verflechtung sowie ihrer umfangreichen und langfristigen wechselseitigen Kreditierung, auf die defizitäre Ausgabenpolitik des Staates mit dem Ziel der Erhaltung eines hohen Beschäftigungsgrades und auf die gewachsene Lohnverhandlungsmacht der Gewerkschaften und daher nur langsam fallende Konsumgüternachfrage zurückgeführt werden. Auf der Seite der Preissetzung wurden vor allem die Rolle des Fixkapitals und die mit der Verlangsamung des Kapitalumschlags einhergehende Fixierung eines Großteils auch des zirkulierenden konstanten Kapitals, sowie die außerordentliche Verteuerung der Rohstoffe hervorgehoben, weil hieraus direkt eine Kostpreissteigerung folgt. Auch die gewerkschaftliche Verteidigung der Reallöhne im Wege der Durchsetzung von Geldlohnsteigerungen selbst bei wachsender Arbeitslosigkeit läßt dem Kapital nur den Weg, die Profitrate über Preissteigerungen aufrecht zu erhalten. Die kapitalistische Konkurrenz kann Preissenkungen nicht mehr erzwingen, weil die Kapitale durch Verkauf ihrer Waren zu sinkenden Preisen nur dann aus der Finanzklemme herauskommen können, wenn es ihnen gleichzeitig gelingt, durch Produktionseinschränkung erhebliche Kostensenkungen zu erzielen. Mit gewachsenen Fixkosten und auch in der Stagnation nicht drastisch verschlechterten Realisierungsbedingungen ist dieser Weg nicht mehr gangbar und zugleich unnötig.

Allerdings ist die Inflation kein Mittel, um die Entwertung des überakkumulierten Kapitals zu vermeiden; sie kann sie nur aufschieben bzw. in der Zeit strecken. Schon die unvermeidbare Verlangsamung des Kapitalumschlags und die daraus resultierende Profitratensenkung ist Entwertung; nur nimmt sie nicht die dramatische Form der akuten Krise und des weitgehenden Zusammenbruchs der gesellschaftlichen Reproduktion an. Auch die nur langsam wachsende Arbeitslosigkeit verhindert einen plötzlichen Rückgang der Mehrwertproduktion und der Kon- 
sumgüternachfrage zugleich, während die auch über Geldlohnsteigerung nicht vermeidbare inflationäre Reallohnsenkung zugleich die Profitabilität des Kapitals allmählich konsolidiert. Ist der mit beschleunigter Zentralisation verbundene Entwertungsprozeß weit genug fortgeschritten, so kann eine neue Aufschwungphase beginnen, ohne daß es zur akuten Krise gekommen wäre. Auf diese Weise ist es möglich, daß sehr lange Akkumulationsphasen entstehen, in denen beschleunigte Expansion mit relativer Stagnation abwechseln, ohne daß die wachsenden Verwertungsbedingungen des Kapitals unmittelbar als Wechsel von Preisaufblähung und -kontraktion erscheinen.

In der Untersuchung der historischen Entwicklungsprozesse nach dem zweiten Weltkrieg ist von uns das Hauptaugenmerk gelegt worden auf die Bedingungen, unter denen der langandauernde Weltmarktaufschwung sich nach dem zweiten Weltkrieg halten konnte. In der kapitalistischen Entwicklung hat es immer schon Phasen gegeben, in denen die zyklischen Krisen des Akkumulationsprozesses nicht unbedingt zu schweren Entwertungskrisen geführt haben, sondern sich eher in Abschwächungen des Wachstums darstellten. Nach dem zweiten Weltkrieg kann dies vor allem begründet werden mit der besonderen Rolle, die die USA auf dem Weltmarkt und in der Weltpolitik gespielt haben. Thr Vorsprung in der Entwicklung der Produkivkraft der Arbeit sicherte über lange Zeit hinweg Extraprofite für das US-Kapital, während die höheren Ausbeutungsraten aufgrund längerer Arbeitszeiten und niedrigerer Löhne in den westeuropäischen Ländern und Japan auch hier für außerordentlich günstige Bedingungen der Kapitalverwertung sorgten. Niedrige Rohstoffpreise und sich verbessernde Austauschverhältnisse für die kapitalistischen Metropolen waren ein weiterer Grund für die lange Phase expandierender Kapitalakkumulation. Aber die Bedingungen, die dies ermöglichten, veränderten sich und es wurde deutlich, daß der langanhaltende Weltmarktaufschwung in eine Phase der krisenhaften Entwicklung überging, in der sich auch die Inflationsraten beschleunigten.

Trotz unübersehbarer analytischer Mängel, die unserer Untersuchung insbesondere bei der Vermittlung von Akkumulations- und Kreditzyklus und bei der Bestimmung der Möglichkeiten und Grenzen der staatlichen Geld- und Fiskalpolitik, vor allem aber auch im Hinblick auf die Frage nach den politischen Konsequenzen der permanenten Inflation und ihrer Rückwirkungen auf den Akkumulationsprozeß des Kapitals anhaften, sollte deutlich geworden sein, daß alle Versuche einer Erklärung der Inflation aus der „Machtpreisbildung" der großen Kapitale oder Monopole bei gleichzeitiger Funktionalisierung des Staates für die Aufrechterhaltung günstiger Realisierungsbedingungen der bloßen Erscheinungsform des kapitalistischen Reproduktionsprozesses nach dem zweiten Weltkrieg aufsitzt. Sie teilen darüber hinaus mit den entsprechenden bürgerlichen Inflationserhklärungen den Mangel einer wesentlich subjektivistischen, bestenfalls verschwörungstheoretischen Betrachtungsweise, da sie die Bedingungen der Reproduktion der ,Macht zum Preisdiktat" nicht angeben können. 